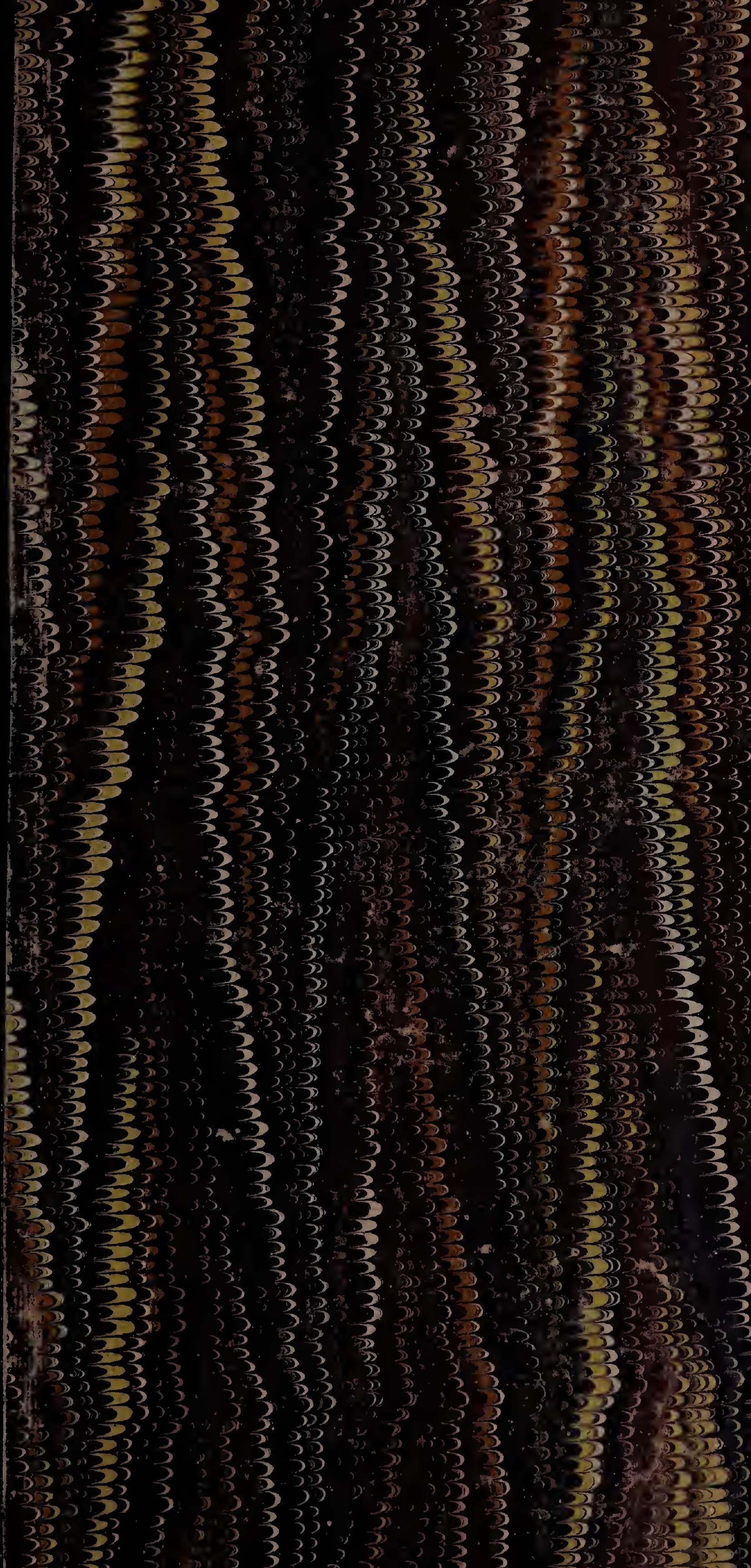




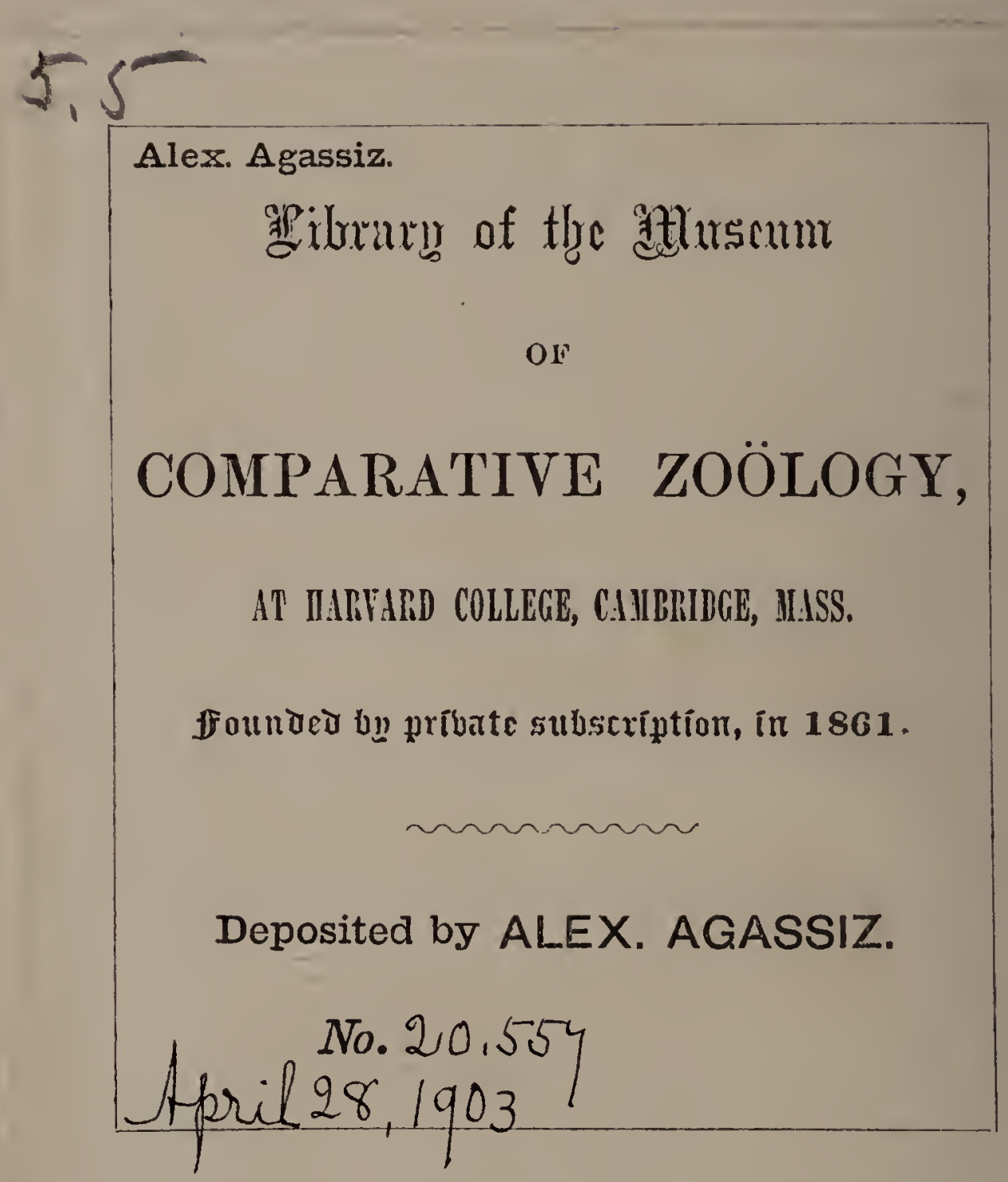


Aholaraxú 



\title{
Untersuchungen
}

\author{
äber
}

\section{PETROMYZON PLANERI}

von

\section{Dr. PAUL LANGERHANS,}

Prosector und Privatdocent in Freiburg i Br.

$\rightarrow \rightarrow$ EEE

Mit 10 lithographirten Tafeln.

\section{Freiburg i/mr.}

Universitätsbuchhandlung von CARL TROEMER.

$$
\text { sin } 1873 \text {. }
$$




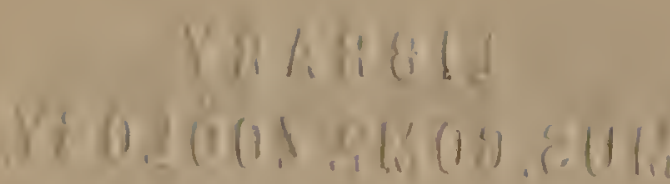

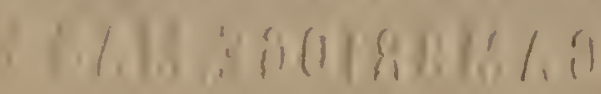

Besonders abgedruckt aus den Berichten über die Verhandlungen der naturforschenden Gesellschaft zu Freiburg i/Br. Band VI. 
Den Herren

\section{Professor R. Virchow}

und

\section{Geheim. Hofrath A. Ecker}

in Verehrung und Dank

gewidmet. 



\section{I h a I t.}

1. Von der Haut

Seite 1.

von den Seitcnorganen

vom Epithel der Haut

von der Lederhaut

2. von den Muskeln

n 1.

" 13.

$n 23$.

3. rom Skelet

n 25.

4. vom Verdauungsapparat

, 32.

$n 37$.

5 . von der Leber

$" 48$.

6. vom Geruchsorgan

$\sqcap 50$.

7. vom Auge von der retina

8. vom Centralnervensystem vom Rüickenmark vom Gehirn

" 56.

$\because 63$.

" 76 .

" 76.

$" 81$.

9. von dem peripheren Nervensystem

$" 98$.

10. vom I،ymphgefässsystem

, 101.

11. Schluss

$\eta 103$.

12. Tafelerklärung

" 105. 



\section{Von der Haut. \\ (Tafel I, II, III Fig. 1 und 2.)}

Seit langem sind in der Haut der Neunaugen eigenthümliche Grübchen bekannt. He in $\mathrm{r}$ i $\mathrm{h}$ R $\mathrm{R}$ thk e bemerkt in seiner Arbeit über die Pricke ${ }^{1}$ ), dass „eigentliche Schleimöffnungen (in der Haul) deutlich immer am Kopfe erscheinen, und zwar unter der Gestalt kleiner Warzen, die theils zerstreut stehen, theils auch kurze Reihen bilden. Eine Reihe solcher Oeffnungen aber, die sich, wie bei den Gräthenfischen, an jeder Seite des Körpers fortzöge, lässt sich mit völliger Deutlichkeit nicht wohl bemerken. Indess habe ich zuweilen gesehen, dass hier und da am Rumpfe der Schleim in kleinen Strömen hervorquoll, und die nur unter solchen Umständen bemerkbaren Grübchen schienen, obwohl in weiten Entfernungen von einander abstehend, dennoch allerdings eine seitliche Reihe zu bilden."

2) Pricke, pag. 27, $\$ 10$. Yon den Arbeiten Rathke's werde ich der Kürze halber die „Bemerkungen über den innern Bau der Pricke“, Danzig 1826, kurz als „Pricke“ citiren. Die „Bemerkungen über den' innern Bau des Querders (Ammocoetes branchialis) und des kleinen Neunauges (Petromyzon planeri) enthalten in den Beiträgen zur Geschichte der Thierwelt von Heinrich Rathke, vierte Abtheilung der Schriften der Naturforsch. Gesellschaft zu Danzig, II. Band, II. Heft, als Querder.

Berichte der naturf. Gesellsch, z. Freiburg i. B., Bd. VI, Heft III. 
Diese Angabe Rathke's ist die erste und weitaus vollständigste Notiz über die Verbreitung der Epithel-Gruben in der Haut des Neunauges. Denn alle folgenden Beobachter haben nur die am Kopfe befindlichen Gruben gesehen. Stannius ${ }^{1}$ ) bemerkt darüber: Bei Petromyzon ist nur der vordere Theil (des Seitenkanalsystems) entwickelt. Ein Bogen von Poren zieht hinter der untern Hälfte des Maules sich hin; von jedem seiner Enden aus erstreckt sich ein Arm über, der andere unter der Augenhöhle nach hinten; letzterer setzt unterhalb der pori branchiales bis zu deren hintern Ende sich fort.

Leydig und Max Schultze erwähnen ebenfalls nur die Epithelgruben am Kopfe.

Bei der Betrachtung des lebenden oder eben gestorbenen aber nicht mit Agentien behandelten kleinen Neunauges treten nun allerdings nur die am Kopfe befindlichen Epithelgruben deutlich hervor. Legt man die Thiere indessen auf 24. Stunden in Alcohol, oder in $20 \%$ ige Salpetersäure, so bemerkt man, dass diese Gruben auch beim Neunauge eine viel weitere Verbreitung haben, und ein regelmässiges System darstellen, das in vielen Beziehungen dem Seitenkanalsystem des Teleostier sich anreiht, ja sogar zum Theil reichlicher entwickelt ist als dieses. Am Kopfe beginnen die Grübchen jederzeit mit einer einfachen Reihe auf der Oberlippe (Taf. I, Fig. 1 u. 2 a). Nach kurzer Unterbrechung zu den Seiten der Nase cntwickeln sich aus der einfachen Reihe zwei, von denen die eine (Taf. I. Fig. 1 und 2 bei b) nach oben gegen das Auge hinzieht und vor demselben dann in einem nach vorn convexen Bogen bis zum untern Rand der cornea entlang geht, um dann, unterbrochen durch das Auge, von der hintern Peripherie der Hornhaut aus weiter zu ziehen.

1) Zootomie der Fische, I854, pag. 103. $10 \%$. 
(Taf. I. Fig. 2 bei $b^{1}$ ). Die andere (Taf. I. Fig. 2 und 3 bei c) Reihe umkreist, wie Stannius angegeben, das Maul, indem sie an der Wurzel der Unterlippe entlang zieht und an der Bauchseite einen fast vollkommen geschlossenen Halbkreis bildet. Von diesem geht dann (Taf. I. Fig. 3 bei $\left.c^{1}\right)$ nahe der centralen Mittellinie je eine Reihe von Grübchen aus, die in zierlicher Anordnung bis zum Ende des Kiemenkorbes sich erstreckt. An der Bauchseite finden sich keine andern Gruben; an der Seitenfläche aber setzt sich die oben besprochene vom Auge ausgehende Reihe (Taf. I Fig. 2 bei $\mathrm{b}^{2}$ ) fort, zieht in einiger Entfernung über den Kiemenlöchern weiter, bildet eine unregelmässige Seitenlinie und hört erst am Anfang der zweiten Rückenflosse auf. Zu dieser Seitenlinie kommen noch zwei andere: eine untere Seitenlinie und eine Rückenlinie. Die erstere (Taf. l. Fig. 2 bei e) ist unansehnlich und besteht aus wenigen (6-8) Grübchen, die unmittelbar über den Kiemenlöchern liegen und weder nach vorn noch nach hinten sich über sie hinauserstrecken. Um so ansehnlicher ist die Rückenlinie, ja sie ist eigentlich der Hauptabschnitt des ganzen Systems. Sie beginnt mit einer kleinen Querlinie von Grübchen ungefähr 0,75 Centimeter hinter der Nase (Taf. 1 Fig. 1 bci d); auf diese Querlinie folgt eine zweite kleinere (Taf, I Fig. 1 bei $d^{1}$ ) nach kurzem Abstand und von ihren Enden aus setzt sich eine Reihe von Grübchen (Taf. I Fig. 1 und 2 bei $d^{2}$ ) jederseits nahe der dorsalen Mittellinie fort, die sich bis zum Schwanz hin erstreckt und kurz vor der Schwanzspitze aufhört. (Taf. l, Fig. 2 bei $d^{3}$ ). Diese Reihen sind allerdings insofern unregelmässig, als die Entfernung eines Grübchens vom andern sehr bedeutend schwankt; in den meisten Fällen aber gleicht sie der doppelten Länge eines Abschnittes der Seitenrumpfmuskulatur; die Seitenlinie ist ferner noch darin besonders unregelmässig, dass sie keine gerade, sondern wie aus den Abbildungen folgt, eine vielfach geschlängelte ist. Aber 
abgesehen davon finden sich alle diese Reihen ausnahmslos an allen untersuchten Thieren.

Genau die gleiche Verbreitung besitzen die Epithelgrübchen des Ammocoetes. Ich fand bei ihm die Anwendung der Salpetersäure geeigneter, sie hervortreten zu lassen, als den Alcohol. Nur am Kopfe zeigt sich insofern eine Abweichung, als das Auge bei diesem Thiere tiefer liegt ; dafür hebt sich der vorderste, sehrlange Abschnitt der Seitenrumpfmuskeln sehr deutlich ab und ungefähr in der Mitte vom obern Rande dieses Muskels (Taf. 1 Fig. 4 bei 0) tritt nach der Metamorphose das Auge an die Oberfläche. Dieser Muskel nun wird vorn und oben von einer continuirlichen Reihe von Grübchen umzogen, die sich nach unten in den Halbkreis an der Unterlippe, nach vorn in die Linie der Oberlippe (Taf. l, Fig. 4 bei a) nach hinten in die Seitenlinie fortsetzt (Taf. l, Fig. 4 bei $d^{2}$ ). Dadurch, dass das Auge mehr und mehr an die Oberfläche rückt, wird also diese Linie erst unterbrochen und bekommt zugleich den geschlängelten Verlauf, den ich beim Neunauge beschrieben habe.-

Aus dieser Verbreitung und Anordnung der Epithelgruben des kleinen Neunauges ist zunächst ersichtlich, dass der ziemlich unbestimmten Angabe Rathke's in der That eine vollkommen zutreffende Beobachtung zu Grunde liegt, nur dass Rathke natürlich diese Gruben ebenso wie das Seitenkanalsystem vor den Leydig'schen Arbeiten für einen sekretorischen Apparat halten musste. Andererseits aber folgt daraus dass zu einer Trennung der Neunaugen von den Plagiostomen und Teleostiern, die Leydig ohne die Kenntniss von der ganzen Ausdehnung des Apparates vornehmen musste, keine Veranlassung vorliegt. Um indess mit voller Sicherheit die gesammten Epithelgruben den Seitenorganen anzureihen, war vor Allem eine erneute Unter- 
suchung des N. lateralis erforderlich. Schlemm und D'Alton ${ }^{1}$ ) haben diesen Nerven beim Neunauge entdeckt; sic geben an, dass der Seitennerv sich hier aus einem Aste des facialis, des Vagus und des ersten Cervikalnerven zusammensetzt und diclıt am Bogentheile der Wirbelsäule nach rückwärts geht, um in seinem fernern Verlauf den obern Aesten aller übrigen Cervikalnerven anzuliegen, ohne indess mit ihnen zusammenzuhängen. Ueber die Länge des Nerven und sein Aufhören fehlt jede Angabe, und Johannes Müller sagt dem entsprechend in seiner vergleichenden Neurologie der Myxinoiden ${ }^{2}$ ), dass der Seitennerv bei Petromyzon zwar vorkomme, aber nicht über den Kiementheil des Rumpfes hinausgehe. Stannius ${ }^{3}$ ) citirt in seiner Monographie über periphere Nervensysteme der Fische ebenfalls nur die Angaben von Schlemm und d'Alton und spricht also nur von dem "abortiven Seitennerven" der Neunaugen.

Bei einem so kleinen Thiere, wie Petromyzon Planeri ist, war wenig Hoffnung vorhanden, mil dem Präparir-Messer weiteres über den Seitennerven zu ermitteln. Es stellte sich dagegen heraus, dass wir in der Reichert'schen $20 \%$ igen Salpetersäure ein Reagens besitzen, welches das feinste Messer in seinen Leistungen für die Verfolgung der Nerven bei weitem übertrifft. Lässt man ein Neunauge drei Tage in dieser Flüssigkeit liegen, und wässert dasselbe dann einen Tag lang aus, so ist fast sämmtliches Bindegewebe bis auf seine zelligen Elemente aufgelöst. Man kann die Epitheldecke der Haut bequem in grossen Fetzen abheben die Pigmentschicht des Unterhautgewebes in kleinen Stücken lösen und die einzelnen Abschnitte der Muskulatur des

1) Müllers Archiv, 1838, pag. 269 und 270 .

$\left.{ }^{2}\right)$ pag. 42 und 50.

3) pag. 94 und 98. 
Rumpfes mit feinen Pincetten von der Wirbelsäule entfernen. Alle Nerven bleiben in Zusammenhang, und wir werden unten noch Gelegenheit haben, die vorzüglichen Macerationspräparate, welche diese Methode herstellt, zu besprechen. Hebt man nun sorgfältig die Seitenrumpfsmuskeln ab, so findet man im Bereiche des Kiemenkorbes leicht den von Schlemm und d'Alton beschriebenen Nervuslateralis unter den Muskeln unmittelbar dem skeletogenen Gewebe aulliegen. Aber man kann ihn ebenso leicht bei der nöthigen Vorsicht weiter verfolgen und als einfachen Längsstamm darstellen, der ungetheilt, aber reichliche Aeste abgebend, in gleicher Richtung weiter zieht. Er liegt immer unter der Muskulatur, unmittelbar dem skeletogenen Gewebe auf und verläuft so rein dorsal bis zum Schwanze. Auf Querschnitten durch den Rumpf des Thieres erscheint er als runder Strang, welcher dem Dache des Rückenmarkes unmittelbar anliegt. Die mikroskopische Untersuchung ergiebt, dass im eigentlichen Nervenstamm nirgends Ganglienzellen eingestreut sind. Des Nerven mittlere Breite beträgt $0,1 \mathrm{Mm}$. Seinen Ursprung nimmt der N. Jateralis aus einem kleinen Ganglion, das unmittelbar hinter der Gehörkapsel liegt. Zu diesem Ganglion kann man ebenso leicht den hintern Ast des facialis, welcher aussen um die Gehörkapsel herumläuft, als einen Theil des Vagus verfolgen.

Der Nervus lateralis des kleinen Neunauges ist also ein wohl ausgebildeter Nerv, der sich vom Kopf bis zum Schwanz hin verfolgen lässt, und der nur in seiner Lage von den Seitennerven der meisten andern Fische abweicht. Denn gewöhnlich stellt derselbe einen oberflächlichen Stamm dar, der genau in der Seitenlinie verläuft, und somit in dem Verhältniss zur Muskulatur und in der lateralen Lage sich anders verhält, als bei Petromyzon Planeri. Aber von diesen $\Lambda$ bweichungen findet sich die tiefe Lage nach Stannius ${ }^{1}$ ) 1) I. c. pag. 100 . 
auch noch bei den Aalen unter den Knochenfischen, ferner bei Chimaera und den Haien. Der dorsale Verlauf jedoch stimmt nicht nur zu der durch Regelmässigkeit und Ausbildung hervorragenden Rückenlinie der Epithelgruben, sondern findet sich ebenfalls bei den Haien, mit denen somit das Neunauge in allen Punkten vollkommen übereinstimmt.

Die ersten Angaben über den feinern Bau der Epithelgruben am Kopfe von Petromyzon fuviatilis rühren von Max Schultze her in seiner Arbeit „über die kolbenförmigen Gebilde in der Haut von Petromyzon elc. ${ }^{1}$ ) Er fand im Grund der Gruben ein von der Umgebung abweichendes Epithel aus langen schmalen und schwer isolirbaren Zellen, konnte zu diesem Epithel hin Fasern verfolgen, "welche aller Wahrscheinlichkeit nach Nervenfasern sind" und stellte durch diese Befunde die Fpithelgruben der Neunaugen zu den Sinnesorganen. In der Einleitung zu seinen Untersuchungen über den Bau der Nasenschleimhaut ${ }^{2}$ ) führt Schultze unter andern auch diese Epithelgruben als wahrscheinlich nervöse Epithelien auf. Leydig hatte schon vorher die Gruben mit den Schleimsäcken des Störes und der Myxine zusammengestellt ${ }^{3}$ ) und hält diese Gruppirung nach den Untersuchungen von Schultze in seiner Monographie "über Organe eines sechsten Sinnes" ${ }^{4}$ ) fest.

Schon der Umstand, dass die Epithelgruben am Kopfe des Neunauges so viel leichter zu sehen sind als am Körper deutet daraufhin, dass im gröbern Baue nicht unerhebliche Differenzen sich finden, und der ganz bedeutende Unterschied der in gleicher Richtung zwischen Ammocoetes

) Müllers Archiv, 1861, pag. 284 ff.

2) Halle 1862, pag. 11 .

$\left.{ }^{3}\right)$ Histologie, pag. 198.

$\left.{ }^{4}\right)$ Verhandlungen der Leopoldino-Carolina, Band 34, pag. 15 der Arbeit. 
und dem ausgebildeten Thiere obwaltet, lässt Gleiches erwarten. Dem ist in der That so: Ein Frontalschnitt durch die Kopfgruben des Ammococtus giebt uns das Bild der Fig. 5 (auf Tafel I.) Eine schmale Spalte theilt das Epithel der Haut von der Oberfläche bis ungefähr zur halben Höhe weicht hier in zwei Schenkel auseinander, welche einen Kegel von Epithelzellen unvollständig trennen von den Elementen der Umgebung. Unter dem Epithel zieht die obere, pigmentlose Schicht der Lederhaut gleichmässig fort, ohne irgend welche Veränderung an der Stelle der Epithelgruben und auf sie folgt nach unten die Pigmentschicht, welche unmittelbar in die Muskellage des Kopfes übergeht. Yon diesen Gruben unterscheiden sich die am Rumpfe des Ammocoetes nur durch geringere Länge; ihr Durchschnitt stimmt also fast vollkommen mit dem der Fig. 5 überein. Beim Neunauge sehen wir fast allgemein zunächst eine wesentliche Abweichung darin, dass die schmale Spalte der Haut, welche beim Ammocoetes zu dem Kegel der abweichenden Epithelien führt, auseinandergerückt ist, dass sie klafft. Am wenigsten ist das der Fall an den kleinen Gruben, mit denen die Seitenlinie hinter dem Auge beginnt (Taf. I. Fig. 1 und 2 bei $b^{1}$ ). Weit ausgesprochener gilt es für die Gruben am Rumpfe, und bei diesen ragen oben und unten je ein Epithelwulst über das Niveau der benachbarten Haut hervor (Taf. I, Fig. 6). Alle Gruben des Rumpfes und die meisten des Kopfes stimmen darin mit dem Ammocoetes überein, dass keinerlei Differenzen die liefern Schichten der Haut vor der Umgebung auszeichnen. Ganz anders verhalten sich darin die vordern Gruben des Kopfes: Ihnen fehlen einmal (Taf. ll, Fig. 1) die deckenden Epithelwulste; die tiefe Spalte, welche bei den gleichen Gruben des Querders zu dem Sinneskegel führte, ist in eine ganz flache :Einbiegung übergegangen und dann zeigen d ie tiefern Lagen der Haut bemerkenswerthe Metamorphosen: 
die feinfibrilläre pigmentlose feste Lederhaut (Fig. 1l, 1b) ist ein wenig verdickt, die pigmentreiche untere Abtheilung der Haut aber schwillt unter den Epithelgruben zu einem rundlichen Knoten an, dessen Inneres vollkommen frei von Pigmentzellen ist. Dieselben umgeben den hellen Knoten wie eine dicke Pigmentschaale, während der Knoten selbst aus platten der Hautoberfläche wesentlich parallel gelagerten Bindegewebskörpern mit reichlicher heller $\mathbf{Z}$ wischensubstanz und feinen, senkrecht aufsteigenden oder wellig verlaufenden Fibrillen bestcht. Unten wird der rundliche Knoten ebenso wie an den Seiten von einer festen Pigmentzellenreichen Bindegewebslage umgeben. Zwischen dieser und den Muskeln des Kopfes befindet sich beim Neunauge ein grosser subkutaner Lymphraum (Taf. Il, Fig. 1 bei b) von dem bei der Larve keine Andeutung existirt, und den wir unten genauer besprechen wollen. Die Entstehung dieses hellen Knotens unter den vordern Epithelgruben des Kopfes ist es, welche diese Gruben so viel deutlicher hervortreten lässt als alle andern, und welche zugleich gestattet, den zutretenden Nerven (Taf. Il, $1 \mathrm{n}$ ) mit Leichtigkeit durch die verschiedenen Schichten der Haut bis zu dem Sinneskegel hin zu verfolgen.

Während wir so in dem gröbern Bau der Epithelgruben eine Reihe von Differenzen vorfanden, welche für die Schwierigkeit des Auffindens derselben eine geeignete Erklärung darbieten, sehen wir in allen übereinstimmend im Grunde der Grube einen kleinen Kegel abweichender Epithelzellen sich erheben. Vollkommen ähnlich liegen die Verhältnisse in den.Kopfgruben von Petrom. fluviatilis ${ }^{1}$ ) und es liegt somit auf der Hand, dass dieser constante Bestandtheil aller Epithelgruben auch der wesentliche sein wird.

^) Max Schultze, Müllers Archiv, 1861, Taf. V, Fig. 5. 
Zu diescm Kegel tritt nun, wie Max Schultze mit Wahrscheinlichkeil angiebt und die vervollkommneten Methoden es jetzt mit Sicherheit aussprechen lassen, ein Bündel von Nervenfasern; dieselben sind, wie alle Nerven der Cyclostomen, marklos, und lassen sich am leichtesten an den vordern Kopfgruben des Neunauges erkennen. In Taf. Il, Fig. 1 ist der durchtretende Nerv zum Theil angeschnitten; man kann bei $(n)$ einen Theil desselben im untern Abschnitt des hellen Knotens wahrnehmen, bei $\left(\mathrm{n}^{1}\right)$ aber ihn durch den obern Abschnitt ziehen, und die Lederhaut durchsetzen sehen. Ein wesentlich übereinstimmendes Verhalten lässt sich an den Gruben des Rumpfes nachweisen, nur ist der Nachweis aus den schon von Max Schultze ${ }^{1}$ ) angegebenen Gründen etwas schwieriger.

Isolirt man nun einen Epithelkegel von frischer Haut in $1 / 10 \%$ iger Osmiumsäure oder nach zwölfstündigem Verweilen in dieser Flüssigkeit oder in Müller'scher Lösung, so erkennt man bei der Untersuchung von oben oder unten, dass er wesentlich aus drei über einander liegenden Schichten von Epithelzellen besteht: die unterste Schicht bietet beim Betrachten von unten eine sehr zierliche und regelmässige Epithelzeichnung, zu deren Analyse starke Vergrösserungen nothwendig sind (Taf. l, Fig. 7). Das gleiche gilt von der obersten Schicht, von der man bei Betrachtung von unten nur die Zellgrenzen deutlich sieht, während die Ansicht von der freien Fläche her die Mosaik der Elemente mit ihren kleinen und hellen Kernen hervortreten lässt (Fig. 8). Zwischen diesen beiden Lagen findet sich eine dritte, welche durch grössere Kerne ausgezeichnet, schon bei schwächern Vergrösserungen hervortritt, und zwischen den Kernen eine Menge von Körnchen aufweist, die nach kürzerem Verweilen

1) 1. c. pag. 284. 
in Osmiumsäure schon eine dunklere Färbung annehmen und nach eintägiger Einwirkung des Reagens dunkelbraun erscheinen. (Fig. 9, Taf. 1). Ausserdem erreicht diese mittlere Lage an keiner Stelle die Peripherie des ganzen Organs.

Die einzelnen Elemente der verschiedenen Schichten sind schwer zu isoliren, wie dies schon Max Schultze hervorgehoben. Indess mit einiger Beharrlichkeit und mit Hülfe der oben angegebenen Methoden kommt man dennoch zum Ziele, und erkennt, dass dieselben sehr verschieden von einander sind. Die Zellen der obersten Schicht sind sehr niedrig; ihre Höhe übertrifft nur selten die Breite (Taf. I, Fig. 10a) und diese Elemente sind somit ziemlich die kleinsten Zellen, welche in der Haut der Neunaugen verkommen. In vielen Fällen konnte ich mit vollkommener Sicherheit feststellen, dass dieselben mit einer deutlichen Porentragenden Cuticula versehen sind, und wenn auch die Kleinheit der Elemente wie die Schwierigkeit der Isolirung das nicht immer zu beobachten gestattete, so ist es mir dennoch sehr wahrscheinlich, dass allen Elementen dieser obersten Schicht eine cuticula zukömmt. Dieselben bilden nach der Oberfläche zu eine Decke über den Epithelkegel, welche genau soweit reicht, wie dieser frei in das umgebende Medium sieht. Während diese Decke also bei den flachen Kopfgruben des Neunauges nur die obere Fläche und einen sehr geringen Theil der Seitenfläche des Kegels überzieht, schützt sie bei den Gruben des Ammocoetes (cf. Fig. 5) fast die Hälfte der Oberfläche des Organes.

Die Zellen der untersten Schicht sind die von Max Schultze erwähnten hellen und schmalen Epithelzellen. Sie sitzen mit etwas breiterem Körper (Taf. I. Fig. 10 c) der Lederhaut auf, verschmächtigen sich schnell nach oben zu und gehen in einen langen und dünnen Fortsatz aus, welcher bis zu den dcckenden Cuticularzellen des Kegels nach oben reicht. 
Durch die Volumsabnahme dieser unteren Zellen entsteht inmitten des Epithelkegels ein Raum, welcher ausgefüllt wird von den Elementen der mittleren Schicht. Dieselben sind kürzer als die hellen der untern, länger als die der obern Lage, besitzen eine lang gestreckte Birnform und zeichnen sich durch grössern Kern vor jenen aus. Dazu kommt, dass sie (Taf. l, Fig. $10 \mathrm{~b}$ ) eine grössere Anzahl von Körnchen besitzen, welche, wie oben angegeben, zur Osmiumsäure eine grössere Hinneigung zeigen und endlich, dass auf dem abgestutzten Ende ihres peripheren Fortsatzes ein feines Haar aufsitzt. Von dem untern, Kernführenden Abschnitt ihres Zellleibes geht ein selten erhaltener Fortsatz aus welcher nach der Lederhaut zu gerichtet ist.

Gestalt, Färbung und vor allem der Besitz eines Haares lassen diese Elemente der mittleren Schicht als die eigentlichen Sinneszellen erscheinen, und wenn mir auch eine Beobachtung ihres Zusammenhanges mit Nervenfasern nicht gelungen ist, so ist derselbe doch namentlich nach den Arbeiten von F. E. Schulze ${ }^{1}$ ) im hohen Maasse wahrscheinlich.

Ziemlich schwer ist es, zu erkennen, ob das Haar dieser Sinneszellen den ganzen Epithelkegel überragt; denn diese Haare sind einmal sehr fein, und sodann sind sie auch verhältnissmässig kurz. Doch glaube ich in einigen malt glänzenden Punkten zwischen der Zellenmosaik der obern Schicht (Taf. I, Fig. 8) dic optischen Querschnilte der frei emporragenden Haare zu sehen.

Vergleichen wir mit diesen Angaben über den Bau der Epithelgruben des kleinen Neunauges die Resultate der früheren Untersuchungen über die Seitenorgane, so bestätigt die fast vollkommene Uebereinstimmung des feineren Baues

1) Schultze's Archiv, Band VI. pag. 62 . 
durchaus den schon aus der ganzen Anordnung der Gruben gezogenen Schluss. Die Gestalt und Anordnung der Sinneszellen wie der hellen Epithelien der tiefsten Schicht stimmt vollkommen mit dem überein, was F.E. Schulze an Teleostiern ${ }^{1}$ ) und ich selbst ${ }^{2}$ ) bei der Larve des Landsalamanders beobachtet habe, und nur in zwei Punkten weichen die Seitenorgane der Neunaugen von jenen ab. Einmal darin, dass bei ihrer Larvenform diese Organe im ganzen tiefer in der Haut, geschützter liegen, als beim ausgebildeten Thier, während bei den Fischen umgekehrt die Organe des jungen Thieres oberflächliche Knöpfchen vorstellen, die des alten aber tief im Grunde der Seitenkanäle liegen. Diese $A b-$ weichung möchte sich als Anpassung an die Lebensweise auffassen lassen: denn gerade der Ammocoetes lebt ausschliesslich im Schlamm, während das Neunauge im fliessenden Wasser frei umherschwimmt oder an Steinen sich ansaugt. Eine oberflächliche Lagerung würde die Organe des Ammocoetes also sehr bald vernichten. Die andere $A b-$ weichung, welche Larve und Geschlechtsthier gemeinsam den andern Fischen und Amphibien gegenüber darbieten besteht in der Existenz der obern, cuticulartragenden Epithelschicht auf dem Sinneskegel, welche sonst nirgends beobachtet worden ist. Dieselbe könnte sich aus der immerhin relativ oberflächlichen Lage der ganzen Organe erklären lassen, weIche in dieser Epithelschicht einen Schutz des Sinnesorganes sich entwickeln liess, der die tiefen Seitenkanäle ersetzen kann.

Ausser diesen Seitenorganen ist der epitheliale Theil der Neunaugenhaut zu wiederholten Malen Gegenstand ein-

1) 1. c.

2) Schultze's Archiv, Band IX., 745. 
gehender Untersuchung gewesen und unter den hierher gehörigen Arbeiten sind vor allem die schon citirte von Max Schultze und die Untersuchung über Epithel- und Drüsenzellen von F. E. Schulze ${ }^{1}$ ) zu erwähnen.

Die Epidermis der Neunaugen besteht bekanntlich aus einem mehrschichtigen Epithel, dessen obere Zelllage durch einen sehr dicken, Porentragenden Cuticularsaum ausgezeichnet ist. Alle Zellen sind reichlich mit Stacheln und Riffen versehen, wie dies zuerst von F. E. Schulze ${ }^{1}$ ) hervorgehoben ist, und die unterste Zellreihe sitzt ebenfalls nach den Angaben dieses Forschers mit leicht gezahnter Basis der Lederhaut auf. Alle diese Verhältnisse sind bei Anwendung frischer Objecte und schonender Agentien leicht zu bestätigen und namentlich die Isolirung in $1 / 10$ procentiger Osmiumsäure verdient den Vorzug vor den meisten andern Methoden. Man kann mit ihrer Hülfe leicht feststellen, dass die einzelnen Elemente nicht nur durch die Stacheln und Riffe in enger Verbindung mit einander stehen, sondern dass sie auch vielfach ausgebuchtet einander zum Theil umgreifen, wie ich das im Anschluss an die bekannten Verhältnisse des Epithels der Harnwege der Säuger für alle mehrschichtigen Epithelien der Vertebraten beschrieben habe. ${ }^{2}$ ) Namentlich von der zweiten Zellreihe von unten an gerechnet, gehen mit grosser Regelmässigkeit feinere Fortsätze aus, welche die niedern Cylinderzellen der untern Reihe umgreifend, bis zur Grenze der Lederhaut hinabreichen. (Taf. I, Fig. 11 a, b und c).

Ausserdem kommen in der Lederhaut die beiden eigenthümlichen Zellformen vor, welche zuerst Köllicker ${ }^{3}$ ) als Schleimzellen und Körnerzellen bezeichnet hat. Die ersteren

1) Schultze's Archiv, Band III, pag. 140.

$\left.{ }^{2}\right)$ Virchow.s Archiv, Band 58.

$\left.{ }^{3}\right)$ Würzburger naturw. Zeitschrift, Band I. 
hat dann Max Schultze in der schon oben angeführten Arbeit zum Gegenstande einer eingehenden Untersuchung gemacht und sie als wahrscheinlich nervöse Elemente hingestellt, denen er den Namen der Kolben gab. F. E. Schulze ${ }^{1}$ ) kam dann, wesentlich gestützt auf vergleichende Untersuchung der Physostomen zu der Ansicht, dass diese Elemente vielleicht mit den Zellen unserer Talgdrüsen zu vergleichen seien. Ich kann diesen positiven Angaben nur das hinzufügen, dass ich niemals beim kleinen Neunauge einen Kolben die Oberfläche habe erreichen sehen und somit die Möglichkeit einer sekretorischen Function dieser räthselhaften Elemente nicht verstehe. Ihr Kern ist beim kleinen Neunauge wie bei Petr. fluviatilis häufig doppelt und ihre Substanz nimmt nach Behandlung mit Salpetersäure dieselbe Schichtung an, wie sie Max Schultze von der Alkoholeinwirkung ${ }^{2}$ ) beschreibt, während die Kolben des Aales diese Erscheinung nicht zeigen.

Die Körnerzellen sind namentlich zon F. E. Schulze eingehend berücksichtigt worden; ich vermag seinen Angaben nichts hinzuzufügen.

In all' diesen Beziehungen verhält sich das kleine Neunauge ganz wie Petromyzon fluviatilis; aber in zwei Punkten weicht es von diesem ab. F. E. Schulze giebt einmal an, dass an der Bauchkante des Neunauges an Stelle des Cuticularsaums eine wahre Verhornung der obersten Epithellage vorkomme, und sodann beschreibt er aus der ganzen Haut ächte Becherzellen, während im Darmkanale des Neunauges dieselben fehlen. Beide Angaben beziehen sich nur auf Pelromyzon fluviatilis. Ich habe dieses Thier nicht frisch bekommen können und darum nicht untersucht. Beim kleinen

') Schultze's Archiv III, pag. 15' ff.

2) l. c. pag. 230 . 
Neunauge aber verhält sich das anders. Die Bauchkante des kleinen Neunauges besitzt ganz in der gleichen Weise, wie die übrige Haut, einen Cuticularsaum, und Becherzellen mit offener Mündung habe ich nie in der Haut des Neunauges gesehen. F. E. Schulze ist in der Angabe derselben zwar sehr vorsichtig, ich möchte sagen, misstrauisch, und betont, dass gerade beim Neunauge Uebergänge zwischen den offenen Becherzellen und den Cuticularzellen sich finden; indess er stellt doch die Existenz der Becherzellen sicher hin. Ich vermag, wie bemerkt, über Petromyzon fluviatilis nichts auszusagen und habe sonst, z. B. beim Schlammpeitzger, Gelegenheit gefunden, die Angabe Schulze's vollkommen zu bestätigen. Das kleine Neunauge aber ebenso wie der Querder zeigen ein abweichendes Verhalten: Ich habe nie bei Untersuchung des frischen Thieres in dünner Osmiumsäure, Müller'scher Flüssigkeit oder halbprocentigem Kochsalz eine Unterbrechung des Cuticularsaumes durch Becherzellen gefunden, sondern denselben stets vollständig und intact die Haut überziehen sehen. Nach längerer Einwirkung der Müller'schen Flüssigkeit entstanden allerdings auch hier Zellen, wie sie F. E. Schulze I.c. Taf. VIll. Fig. $2 \mathrm{~b}$ abbildet; aber bei frischer Untersuchung ist der Cuticularsaum intact, wie man das namentlich mit siarken Vergrösserungen von der Fläche aus sicher fesstellen kann. Eine Schleimsekretion kann somit nicht durch besondere, drüsige Zellen hier stattinden; es ist mir wahrscheinlich, dass sie durch die Poren der Cuticula hindurch geschieht und die Fähigkeit zu einer solchen Sekretion allen Cuticulartragenden Zellen gleichmässig zukommt.

Ausser diesen Zellformen kommen im Epithel der Neunaugenhaut noch kleine Rundzellen vor, die in allen Schichten desselben sich finden können. Sie sind (Tal. I, Fig. 11 bei $c$ und d) sehr klein und liegen stets zwischen zwei Zellen, in deren Substanz sie. ganz helle, wie mil 
einem Locheisen eingeschlagene und scharfrandige Löcher ausfüllen. Die Bedeutung dieser Elemente scheint mir ziemlich einfach. Sie gleichen nämlich vollkommen den zusammengezogenen Cromatophoren, wie sie Leydig ${ }^{1}$ ) von der Salamanderlarve abbildet und ich sie bei demselben Thiere in Lage und Form vollkommen übereinstimmend gefunden habe. Nur ist der Inhalt der Zellen hier pigmentirt, während beim Neunauge eine Pigmententwickelung nicht zu Stande kommt. Ich glaube also, diese kleinen Rundzellen als Homologa jener Cromatophoren ansprechen zu können.

Die Cuticularzellen der Epidermis sind durch die Dicke ihrer Cuticula ausgezeichnet; aber sie sind noch dadurch merkwürdig, dass sich beim Neunauge nicht selten Flimmerhaare auf ihnen finden. Ein Besatz mit Flimmerhaaren ist im Allgemeinen nicht einmal weit verbreitet; sondern er kommt, auch individuell verschieden, nur stellenweise vor. Bald trägt eine vereinzelte Zelle ein Büschel von Flimmerhaaren, bald schliessen sich an sie noch einige andere an, welche ebenfalls ganze Büschel oder wenigstens einzelne Haare besitzen. Solche Inseln von Flimmerhaaren sind aber immer durch viele flimmerlose Zellen von andern bewimperten getrennt, (Taf. Il, Fig. 2). Dieser Flimmerbesatz ist meines Wissens der einzige, der bis jetzt an Zellen mit so dicker Cuticula beobachtet worden ist, wenn auch ein Aufsitzen des Wimperhaars auf einem homogenen Grenzsaum sonst öfter statuirt wurde, z. B. von Max Schultze im Geruchsorgane.

Die Dicke der Cuticula hat nun den grossen Vorzug, dass sie den Ursprung der Haare deutlich zu erkennen geslattet. Derselbe erfolgt nämlich (Taf. Il, Fig. 3) mit leicht verdickter Wurzel in der Cuticula selbst. Diese Thatsache

') Ueber Organe des sechsten Sinnes, I. c. 'Tal. II, Fig. 13 hei e. 
ist einerseits sehr geeignet, der alten Auffassung von der cuticularen Natur der Wimperhaare einen sehr sichern Beweis zu geben - andererseits aber ist das Vorkommen dieser Wimperhaare doch wohl mehr als ein von den wirbellosen ererbter und schlecht entwickelter Rest eines allgemeinen Wimperkleides anzusehen. Denn diese Wimperhaare zeigen keine Bewegung, sie sind todt.

Ausser diesen mannigfachen Gebilden kommt nun in der Haut des kleinen Neunauges und des Querders in weiter Verbreitung noch eine bisher unbekannte Art von Zellen vor, welche namentlich an denjenigen Stellen sich findet, welche schon von Heinrich Rathke als hervorragendes Organ des Tastsinnes angesehen wurden: nämlich an den Papillen des Mundrandes. Diese Papillen sind kleine breite zollenartige Hauterhebungen, welche mit ihrer Längsaxe radial gestellt einen Kreis um die Mundöffnung des Neunauges bilden, dem Querder aber bekanntlich fehlen. Untersucht man eine solche Mundpapille ganz frisch in halbprocentiger Kochsalzlösung mil starken Vergrösserungen, so sieht man namentlich an und nahe der Spitze von Strecke zu Strecke ein feines Büschel kurzer starrer Haare den Cuticularsaum überragen. (Taf. Il. Fig. 4). Nach einiger Zeit tritt an jedem Büschel deutlich eine abwejchend gestaltete Zelle hervor, welche tief in die untern Lagen der Epidermis hineinragt und ohne selbst eine Cuticula zu besitzen, bis an die freie Fläche der Oberhaut emporreicht, also eine Unterbrechung des Cuticularsaumes darstellt. Von der Fläche betrachlet, erscheint die freie Oberfläche einer solchen Zelle als kleiner, mattglänzender Kreis, auf dem man bei höherer Einstellung deutlich die Haare als kleine Punkte wahrnehmen kann. (Taf. Il, Fig. 5). Wie durch längeres Liegen in der dünnen Kochsalzlösung, nehmen diese Zellen durch kurze Einwirkung der dïnnen Osmiumsäure einen andern Farbenton an, und zwar durch 
letzteres Agens einen leichten Sepiaton. Die Haare erhalten sich in ihm vorzüglich und die Fig. 4, welche eine solche Zelle am Rande der Mundpapille in situ darstellt, wie die Fig. 5 der Tafel ll, welche eine Anzahl der Zellen zwischen den Cuticularzellen von der Fläche gesehen präsentirt, sind nach Präparaten, denen das genannte Reagens zugesetzt war, gezeichnet. Diese Zellen nun lassen sich ebenso in dünner Osmiumsäure wie in Müller'scher Flüssigkeit gut isoliren. Sie stellen (Taf. ll, Fig. 6) dann sehr lange Elemente vor, deren Kern in einer kleinen Anschwellung des Zellkörpers liegt. Von diesem aus geht ein Fortsatz an die Oberfläche, tritt hier, sich verschmälernd, zwischen die Cuticularsüume der benachbarten Epithelzellen und erscheint auf der Oberfläche in der Fig. 5 dargestellten Weise als kleiner Kreis; hier ist er besetzt mit einer nicht immer gleichen Zahl kleiner, starrer, auch frisch in neutralen Flüssigkeiten vollkommen unbeweglicher Haare. Die Anzahl derselben variirt meist zwischen fünf und zehn. Nach der andern Seite aber tritt vom Zellkörper aus ein Fortsatz in die tiefern Schichten der Haut, und vermittelst desselben haften diese Elemente der Lederhaut fester an, als die andern Zellen. Aus diesem Grunde gelingt es nicht schwer, nach Maceration in Müller'scher Lösung einen grossen Theil der andern Epithelien von der Spitze einer Mundpapille zu entfernen und dann die haartragenden Flemente in zierlicher Anordnung halbisolirt sichtbar zu machen. Nicht selten reisst indess dieser centripetale Fortsatz ab und die Zellen bekommen dann eine Birnform. Die Multiplicität ihrer Haare wie der Mangel an Körnern unterscheiden sie von den Sinneszellen der Seitenorgane. Was nun ihre Verbreitung anlangt, so kommen sie sehr zahlreich, wie bemerkt, vor an den Spitzen der Mundpapillen. Nach der Basis der Papillen zu werden sie spärlicher, aber in dieser spärlichen Anordnung - elwa 16 auf einen Quadratmilli- 
meter - finden sie sich über den ganzen Körper zerstreut an allen Stellen der Haut. Nur an einer Stelle sind sie wieder zahlreicher: nämlich an der ersten Rückenflosse. Die freien Ränder der Flossen sind licineswegs grlatt: es erhebeh sich vielmehr auf dem der ersten Rückenflosse dicht nebeneinander zottenförmige Papillen, die bald den ganzen Rand dieser Flosse einnehmen, bald nur die hintere Hälfte derselben. Die zweite Rückenflosse und die Schwanzllosse zeigen breitere und flachere Erhebungen oder, wenn man lieber will, flachere Einkerbungen, und nur die Afterflosse hesitzt einen ganz glatten Rand. Beim Ammocoetes dagegen ist der ganze Flossensaum glatt. Die Papillen der ersten Rückenflosse nun sind wieder ein Ort, an dem unsere Haartragenden Zellen häufiger vorkommen; nach einer solchen Papille ist Fig. 2 der Tat. III gezeichnet: das Präparat lag vollkommen frisch in halbprocentigem Kochsalz.

Ausser dieser Verbreitung auf der äussern Haut kommen die gleichen Zellen, wenn auch spärlicher vor. auf der Schleimhaut der Mundläche, der Zunge und der Rachenhöhle bis zu dem von Rathke als Kehlkopf bezeichneten Knorpel am vordern Eingang des Bronchus.

Bei Ammocoetes fehlen die Orte häufigen Vorkommens dieser Zellen, die Mundpapillen und die Erhebungen des Flossensaumes. Dieselben kommen demnach überall spärlich aber gleichmässig verbreitet in der Haut vor; ebenso im Epithel der Mund- und Rachenhöhle. Sie fehlen, wie ich gleich hier bemerken will, den verästelten Barteln der Mundhöhle, die wir somit lieber mit August Müller als den Gitterstäben des Amphioxus analog ansehen wollen, als mit Heinrich Rathke als Sitz eines Sinnesorganes.

Gestalt, Festhalten an der Lederhaut, der centrale Fortsatz und mehr als alles Andere, das Büschel vollkommen starrer Haare lassen die eben beschriebenen Zellen mit hoher Wahrscheinlichkeit als nervöse erscheinen. Dazu 
kommt, dass die Menge wie die Vertheilung der Nerven der Haut vollständig mil der Verbrcitung dieser Zellen harmonirt. Die Mundpapillen und die Flossenpapillen sind die nervenreichsten Theile der Haut. Man kann hier mit Hülfe der verdünnten Essigsäure nach Entfernung des Epitheis cine solche Fülle von feinen blassen Nervenfasern zur Anschauung bekommen, dass ihr Gewirr schwer zu enträthseln ist. Am besten gelingt das noch an den Flossenpapillen und an ihnen lässt sich dann mit Leichtigkeit beobachten dass die Nerven durch Theilung aus breiteren, nicht ganz bis zum Grunde der Papillen emporreichenden Nervenfasern entstehen, in diese hineinziehen und nach wiederholter Theilung an die obere Grenze der Lederhaut gelangen, an der man ihre Enden gelegentlich hervortreten, gelegentlich als kleine Punkte an der Oberfläche scheinbar aufhören sehen (Taf. 1ll. Fig. 1) kann. All' das spricht für ein Eintreten der Nerven ins Epithel und die Verästelung der feinen Nerven, wie ihre Anzahl stimmen mit der Verbreitung unsrer haartragenden Zellen überein. In Taf. IIl Fig. 1 ist die eine Hälfte, d. $h$. die in der oberflärhlichen, dem Beschauer zugewandten Seite der Papillen liegende Nervenverästelung zweier solcher Flossenpapillen dargestellt, und ein Blick auf Taf. Ill Fig. 2, in der in ähnlicher Papille bei erhaltenem Epithel die Haarbüschel gezeichnet sind, wird das Gesagte bestätigen.

Diese Verbreitung der Nerven verleiht der Bezeichnung der haartragenden Zellen als Sinneszellen einen neuen Halt. Sehen wir uns nun bei andern Vertebraten nach ähnlichen Einrichtungen um, so bietet sich zunächst nirgends übereinstimmendes. Es sind bis jetzt bei keinem Wirhelthier einzelne haartragende Sinneszellen in der äussern Haut bekannt. Wohl kommen haartragende Sinneszellen vor: aber dann einmal in den Organen des sechsten Sinnes in eigener Anordnung und eigener Beziehung zu bestimmten 
Nerven - oder doch, wie in den von Leydig ${ }^{1}$ ) entdeckten, von F. E. Schulze ${ }^{2}$ ) näher untersuchten becherförmigen Organen in grösserer Anzahl beisammen und durch indifferente Zellen $\mathrm{zu}$ einem eigenen Organe vereinigt. Wir finden vollkommen ähnliche Elemente nur bei Wirbellosen, und ich begnüge mich hier auf die zahlreichen Beobachtungen über ähnliche Formen in den Klassen der Mollusken und Arthropoden hinzuweisen. Die Neunaugen bieten also in ihren isolirten Sinneszellen der Haul ein unter den Vertebraten isolirt dastehendes Verhalten, andererseits aber stimmt die Anordnung wie die Verbreituug dieser Elemente so vollkommen mit den Leydig'schen Becherorganen überein, dass die Fig. 2, der Tafel lll fast völlig der bei schwacher Vergrösserung gezeichneten Bartel des Schlammpeitzgers in F. E. Schulze's Abhandlung gleicht. Das Yorkommen unserer Zellen in der Schleimhaut von Zunge und Mundhöhle stimmt damit ebenfalls überein. Ich glaube also, diesen Apparat der einfachen, isolirten Sinneszellen als ein Homologon der Becherorgane ansprechen zu dürfen, das durch einfachen Bau ausgezeichnet, eine Vermittelung bietet zu den Sinneszellen in der Haut der Wirbellosen.

Bei der grossen Uebereinstimmung, die sich zwischen der Epidermis der Fische und der Amphibienlarven findet, ist es vielleicht gestattet, auch die eigenthümlichen Schaltzellen, welche sich bei der Salamanderlarve ${ }^{3}$ ) als kleinere Elemente zwischen die grossen Epithelien drängen, hier zu erwähnen. Ihnen kommen allerdings keine Haare zu, sic hängen nicht mit Nerven zusammen und besitzen eine cuticula. Aber sie unterscheiden sich doch so merklich von

3) Zeitschrift für wissensclaftliche Zoologie, Bd. III, pag. 3 .

2) ebds. Bd. XII.

3) Schultze's Archiv, Band 9, pag. 745. 
den andern Elementen, zwischen denen sie liegen, dass cine Erklärung für sie wünschenswerth /wäre. Und da scheint es mir immerhin nicht unwahrscheinlich, in ihnen einen ererbten, nicht zur vollen Ausbildung gekommenen Rest dieser Sinneszellen der niedern Formen zu sehen. Diese Anschauung würde uns die abweichende und auffallende Form der Elemente erklären, wie die Beziehung auf die Chromatophoren des Salamanders uns oben die eigenen Rundzellen in der Neunaugenhaut verstehen liess.

Die Lederhaut der drei niedern Vertebratenklassen zeichnet sich, wie Heinrich Rathke ${ }^{1}$ ) zuerst beschrieben, durch eine regelmässige Anordnung der Fibrillenbündel des Bindegeweles aus. Dieselben bilden ganz gleichartige Schichten, die abwechselnd längs und quer ziehend übereinander liegen. Zwischen ihnen fand Rathke beim Stör senkrecht aufsteigende Züge von Bindegewebe. Leydig ${ }^{2}$ ) hat diese Angaben für die Süsswasserfische, später auch für dic Plagiostomen ${ }^{3}$ ) bestätigt und die Existenz dieser senkrechten Züge auf dieselben ausgedehnt. Daneben sieht er umspinnende elastische Fasern an jeder Art von Fibrillenbündeln. Zwischen den Bündeln entstehen Lücken, von denen Leydig beim Stör ${ }^{4}$ ) erklärt, dass sie die Figuren der Bindegewebskörperchen vorgetäuscht haben. Eine eingehende Schilderung der Lederhaut speciell des Neunauges finden wir endlich in der angeführten Arbeit von Max Schultze ${ }^{5}$ ). Er beschreibt in Uebereinstimmung mit Rathke

') Müller's Archiv, 1847, pag. 338.

$\left.{ }^{2}\right)$ Zeitschrift für Zoologie, Bd. III, pag. 2.

3) Anatomische Untersushungen über Fische und Reptilien, pag. 34.

1) Beiträge zur Anatomie der Rochen nnd Haie, pag. 79.

5) 1. c. pag. 283 . 
die Systeme der Fibrillenbündel und namentlich die senkrechten Züge "Stützfasern", in denen er zum 'Theil Nervenfasern vermulhet.

Diesen Angaben vermag ich nur wenig hinzuzufügen. Die Lederhaut des kleinen Neunauges besteht aus sich kreuzenden Schichten von Fibrillenbündeln und wird durchselzt von senkrechten Zügen. Diese letztern sind zum Theil clastischer Natur, wie namentlich ihr Verhalten gegen Reagentien erweist, zum Theil aber nervös, wie z. B. auf Fig. 1, Taf. Il. Die Fibrillenbündel zeigen nun einen deutlich sichtbaren Belag von Bindegewebskörperchen, welche keineswegs, wie Leydig vermuthet, identisch mit den Lücken sind. Man kann ihre Kerne mit Karmin oder Blauholzextract leicht färben, und erkennt dann, dass sie genau der Längsaxe der einzelnen Bündel folgen, somit wie diese in rechtwinklich sich kreuzenden Reihen über einander angeordnet sind. Von umspinnenden Fasern vermochle ich nichts wahrzunehmen. Im Bereiche dieser dichten Lederhaut kommt nur selten eine Ablagerung von Pigment in den Zellen vor. Erhebungen zu Papillen finden wir nur an den schon besprochenen Stellen : am Saume der Flossen und am Mundrand des Neunauges, während beim Querder keine Papillen vorhanden sind. Am meisten hervorzuheben scheint mir aber, dass in dieser äussern Schicht des bindegewebigen Theiles der Haut weder Blut- noch Jymphgefässe existiren.

An diese "Lederhaut" schliesst sich nach unten eine Pigmentlage an, und mit derselben beginnt ein lockeres Gewebe, welches an den meisten Stellen des Jeibes reichliche Fettzellen enthält. Diese Fettzellen unterscheiden sich sehr bedeutend von denen der höhern Vertebraten: Es sind sehr grosse eiförmige Elemente ${ }^{1}$ ), welche bald mehr,

1) Dieselben stimmen vollkommen mit den Zellen überein, welche in dem Gallertgewebe um das Rückenmark herum vorkommen, und hier 
bald weniger Fett enthalten, aber ihre Gestalt in keiner Weise ihrem Fettgehalt akkomodiren. Sie behalten vielmehr Gestalt und Grösse, auch wenn sie nur wenige Fetlkörnchen enthalten und unterscheiden sich dadurch scharf von den zwischen ihnen liegenden Bindegewebskörperchen (Taf. II, Fig. 7). Letztere sind viel kleinere Zellen, oft platt, meist ramificirt, nie fotthaltig. Sie liegen zusammen mit den Fettzellen in einer hellen Grundsubstanz, die von unregelmässig-welligen, im Allgemeinen senkrecht aufsteigenden Fibrillen durchzogen wird.

\section{Von den Muskeln.}

(Tafel III, Figur 3 bis 10)

Die Muskulatur der Neunaugen bietet nach den Untersuchungen von Stannius ${ }^{2}$ ) sehr eigenthümliche und von den übrigen Vertebraten abweichende Verhältnisse. Jenn ausser den gewöhnlichen quergestreiften Primitivbündeln finden sich noch zwei vollkommen differente Formen: Die eine wird durch grössere aber flache Platten dargestellt und setzt das System der Rumpfmuskulatur zusammen, die andere durch Primitivbündel von gewöhnlicher Breite aber mit bleibend körniger Axe und ausschliesslich cortikaler Querstreifung.

zuerst von Stannius (Zootomie d. Fische pag. 126, Anmk.) beschricben, von Reissner (Müller's Archiv 1860, Taf. XV. Fig. 14) abgebildet wurden.

$\left.{ }^{2}\right)$ Göttinger Nachrichten, 1851, Fig. Nr. 17. Diese Angaben voll Stannius sind von Grenacher bestätigt worden. Zeitschrift fïr w. Zoologie XVII. 
Diese Form fand Stannius an den Augenmuskeln des Flussneunauges. - -

Die Muskeln des Rumpfes bestehen bekanntlich aus einer grössern Anzahl einzelner Segmente, welche durch ligamenta intermuscularia von einander getrennt werden. Diese ligamenta nehmen einen eigenthümlichen, von Johannes Müller zuerst geschilderten Verlauf; sie decken sich derart Dachziegelförmig, dass ein Frontalschnitt stets drei oder vier zugleich trifft.

Zwischen ihnen verlaufen eine grosse Anzahl kleiner, mit den Muskeln parallel ziehender bindegewebiger Lamellen welche den Raum zwischen je zwei ligamenta intermuscularia in eine Menge kleiner Fächer oder Kästchen theilen, von denen jedes dieselbe Jänge wie ein Segment des Körpers besitzt. Während aber die Länge aller Kästchen eines Segmentes die gleiche ist, nimmt ihre Höhe von der dorsalen Mittellinie nach der ventralen zu stetig ab. Dieselbe beträgt an der dorsalen Mittellinie ungefähr 3,5 bis 4 mm.; während sie ventral kaum 1,5 mm. erreicht. Jedes dieser Kästchen oder Fächer ist nun angefüllt mit einigen Muskelplatten, welche in Länge und Höhe vollkommen dieselben Dimensionen bieten, wie die Kästchen selbst. Wir werden also die Muskelplatten eines Segmentes alle von gleicher Länge, aber von schr verschiedener Höhe finden.

Diese Plalten lassen sich in der oben angegebenen Weise mit Salpetersäure gut isoliren. Eine Platte der Rumpfmuskulatur vom Rückenabschnitt (Taf. Ill, Fig. 3) hat ungefähr die Gestalt eines schiefen Parallelogrammes. Die kleine Seite desselben, 1,0 Mm. ist die Länge, die grosse Seite 3,5 bis 4 Mm., die Höhe der Platte. Sie ist vollständig quergestreift und scheint des Sarkolemma zu entbehren, die Muskelkörperchen, welche Grenacher vermisst hat, sind nicht schwer zu sehen und folgen in ihrer Richtung der Längsaxe der Platte. Ausser den Kernen dieser Kör- 
perchen aber findet sich noch eine grössere Anzahl von Spalten ${ }^{1}$ ), welche ebenfalls in der Längsaxe verlaufen und die ganze Platte unvollkommen in eine Anzahl übereinander gelagerter Abschnitte theilen, welche bald die Dimensionen eines gewöhnlichen Primitivbündels besitzen, bald aber erheblich höher sind.

Die einzelnen Platten vom ventralen Theil zeigen natürlich (Taf. Ill. Fig. 4) dieselbe Jänge, wie die des dorsalen. Aber ihre Höhe hat so sehr abgenommen, dass dieselbe nur noch das anderthalbfache der Jänge beträgt.

Während diese Maasse fast für die sämmtlichen Rumpfmuskeln gelten, zeigen sich an der vordern und hintern Grenze dieses Systems Abweichungen. Nach dem Schwanze zu nehmen alle Maasse allmälig ab. Am Kopfe aber sind nur die ventralen Theile, also die Muskeln des Halses durch Kleinheit ausgezeichnet. Eine Platte (Taf. Ill Fig. 5) misst nur 0,3 Mm. in der Höhe und 0,5 $\mathbf{M m}$. in der Länge.

Die interessanteste Abweichung bietet der vorderste Abschnitt des Seitenrumpfmuskelsystems. Derselbe ist beim Ammocoetes sehr stark entwickelt; ich habe schon oben erwähnt, dass seine Contour durch die Haut durchscheint und mit einer Reihe Epithelgruben umsäumt ist. In der Milte des obern Randes liegt in der Tiefe das kleine Auge und der Kand selbst senkt sich daselbst ein wenig nach unten. Sò entsteht ein kleiner oberer Theil des Muskels, welcher Platten von 2,3 Mm. Länge besitzl, während die Hauptmasse aus solchen von 4,0 Mm. Länge besteht (Fig. $8 \mathrm{c}$ ). Zwischen beide schieben sich einige Platten ein, welche durch das Auge dergestalt modificirt werden, dass sie einen hintern grössern Abschnitt besitzen, und einen vordern kleinern Fort-

1) cf. Grenacher, I. c. Taf. 36, Fig. 3. 
satz, der den untersten Abschnitt des Auges zum Theil deckt, Fig. 8 b). Nach der Metamorphose hat das Auge so zugenommen, dass dieser ganze Muskel zum grossen Theil atrophirt ist. Er besitzt viel geringere Dimensionen als beim Ammocoetes und besteht fast ganz aus Platten, die nur bis zum Auge reichen und mit den obern Platten des Larvenmuskels übereinstimmen (Fig. 7 a).

An diese schliessen sich nach unten einige Platten an, die wieder über den untersten Abschnitt des Auges hinwegziehen (Fig. 7 b) und somit den mittleren Platten des Larvenmuskels gleichen. Nur ist der, über dem Auge liegende Fortsatz viel schmaler, als bei jenen. Die grossen Platten des Muskels beim Ammocoetes (Fig. $8 \mathrm{c}$ ) fehlen dem Neunauge vollständig.

Zu dem System der Seitenrumpfsmuskeln gehören dem Bau nach noch die Muskeln der Flossen. Zu jeder Seite der beiden Rückenflossen findet sich eine Reihe kleiner Muskeln, die von Rathke ${ }^{1}$ ) beschrieben worden sind. Dieselben bestehen aus Platten, welche durch tiefe Spalten fast vollständig in. einzelne Elemente zerlegt werden und deshalb bei weit gehender Maceration auchleicht in solche zerfallen. Diese (Fig. 6) Spalten sind nicht, wie bei den Rumpfmuskeln, sagittal, sondern vertikal gerichtet. Dieselbe Richtung zeigen die Kerne und die Längsaxe der Platten ist somit eine vertikale. Sie ist ziemlich gross, ungefähr 1,8 Mm., während die Breite der Platten gering ist und $0,13-0,16 \mathrm{Mm}$. beträgt.

Wir sehen also in der That in vollkommener Uebereinstimmung mit den Angaben von Stannius das ganze System der Rumpfmuskeln aufgebaut aus eigenthümlichen Muskelplatten, von denen eine jede anscheinend einer grössern Anzahl

3) 1. c., pag. 25, 
von Primitivbündeln entspricht, welche durch die Längsspalten in den Platten noch unvollkommen von einander getrennt sind. Eine ähnliche Form des Muskelgewebes existirt bei keinem andern Fisch und es musste deshalb als doppelt wünschenswerth erscheinen, den Amphioxus daraufhin zu untersuchen. Es standen mir nur Exemplare dieses Thieres zur Verfügung, welche seit langen Jahren in Alcohol aufbewahrt waren, und an denen eine Maceration nur unvollkommen gelang. Trotzdem konnte ich Lamellen isoliren, welche, wenn auch nicht vollständig, so doch erheblich grösser waren, als die von Grenacher ${ }^{1}$ ) dargestellten Stücke. Ich glaube demnach, dass der Amphioxus im Baue seiner Seitenmuskeln sich enger an Petromyzon anschliesst, als, der genannte Forscher annimmt. Diese eigene Form der Muskulatur findet sich also nicht nur bei den Cyclostomen, sondern auch beim Amphioxus.

Während nun die Muskelplatten der Rumpfmuskseln vollkommen fertige, durchweg quergestreifte Elemente sind, trägt die zweite abweichende Form des Muskelgewebes, welche Stannius beschrieb, einen rein embryonalen Charakter. Es besteht dieselbe (Fig. 9) aus einzelnen Elementen, die in allen Dimensionen innerhalb der von den vollkommen entwickelten Primitivbündeln eingehaltonen Grenzen liegen. Aber diese Elemente sind nicht vollständig quergestreift, sondern sie besitzen nur einen relativ schmalen, cortikalen Mantel von quergetsreifter Substanz während im Innern ein körniger Cylinder mit Kernen während des ganzen Lebens persistirt.

Diese Elemente hat Stannius ${ }^{2}$ ) in den Augenmuskeln des Flussncunauges anfgefunden. Sic finden sich beim $P$. Planeri nicht nur in diesen, sondern auch an zwei andern

1) I. c. 'Tal. $X X X Y$, Fig. 7.

2) 1. c. pag. 229 . 
Stellen : nämlich an den Kiemen und an dem eigenthümlichen Mundsegel des Ammocoetes.

An den Kiemen liegt zwischen je zwei Kiemenöffnungen ein Muskel, der dorsal wie ventral an den sagittalen Theilen des knorplichen Kiemenkorbes sich befestigt ${ }^{1}$ ). Dieser Muskel besteht ans zwei Lagen : einer oberflächlichen und einer tiefern. Die oberflächliche Lage setzt sich ans zwölf bis fünfzehn kleinen Bündeln zusammen, von denen jedes ungefähr ein Dutzend Elemente enthält. Dieselben gleichen vollkommen denen der Augenmuskeln. Die tiefere Lage des Muskels besteht aus einer continuirlichen Lage gewöhnlicher Primitivbündel. Unter diesem Muskelsystem des Kiemenkorbes findet sich noch ein eigenes Muskelsyslem der Kiemensäcke, das von Joh. Müller entdeckt worden ist ${ }^{2}$ ). Es besteht aus einem Muskel, der in der Scheidewand zwischen zwei Kiemensäcken verläuft und eine sichelförmige platte Muskelmasse darstellt, deren Elemente gewöhnliche Primitivbündel sind, ferner aus einem eigenen Constriktor eines jeden Kiemensackes, der genau wie der oben erwähnte Scheidewandmuskel in der vertikalen Richtung seiner Fasern wie in ihrem ungetheilten Verlauf vollkommen mit den Constrictoren des Kiemenkorbes übereinstimmt, aber aus Fasern mit persistentem körnigen Cylinder besteht. Diesem Constrictor des Kiemensackes sitzen die einzelnen, transversalen Kiemenblättchen unmittelbar auf. Während nun der eben besprochene $\Lambda$ bschnitt der Kiemenmuskulatır bei Ammocoetes und Petromyzon vollkommen gleich gebildet ist, finden wir, wie oben bemerkt, die besprochene Form des

') Rathke, Pricke, pag. 29, theilt diesen Muskel ohne Grund in einen dorsalen, lateralen und ventralen Theil. Die Bündel verlauten continuirlich von der einen Insertion zur andern und lassen deshalb eine solche theilung nicht zu,

$\left.{ }^{2}\right)$ l. c. pag. 213 und 229. 
Muskelgewebes noch in einem Organ, das nur dem Ammocoetes zukömml und von Rathke ${ }^{1}$ ) beschrieben worden ist. Dic Muskeln dieses Mundsegels zeigen zum Theil die Form gewöhnlicher Primitivbündel, zum grossen Theil aber bestehen sie aus Elementen der beschriebenen Art. Das Organ bildet sich bei der Metamorphose zurück ${ }^{2}$ ) und es fehlt somit dem Neunauge ein Homologon.

Wir sehen somit eine zweite Form von Muskelgewebe bei den Neunaugen, welche, wie die oben besprochenen Platten, ebenfalls den meisten andern Vertebraten fehlt. Aber während wir an Stelle der Muskelplallen mil alleiniger Ausnahme des Amphioxus überall nur gewöhnliche Primilivbündel sehen, finden wir Elemente, die mehr weniger vollkommen mit denen der zweiten Form übereinstimmen, in weilerer Verbreilung. Regelmässig kommen nach den Untersuchungen Leydig's ganz gleich gestaltele Bündel am Spritzloch der Haie vor ${ }^{3}$ ). Als Ausnahmen aber sehen wir die Persistenz eines körnigen Axencylinders noch in allen anderen Klassen der Vertebraten, namentlich häufig in den Zellen des Herzens ${ }^{4}$ ). Aber auch andern embryonalen Formen der Muskulatur begegnet man in den eigenthümlichen Primilivbündeln der Seitenlinie vieler Knochenfische ${ }^{5}$ ) welche aus einer grössern Anzahl von Muskelsäulchen bestehen, die durch körniges Material isolirt und von gemeinschaftlichem Sarkolemma zusammengehalten werden. Ob diese Muskclform beim Nennange eine von den andern Primitivbündeln verschiedene Fntwickelung macht, ob wir Zellreilien, welche sekundïr verschmelzen, hier vor uns

1) Querder, pag. 79.

$\left.{ }^{2}\right)$ Angust Miiller in Miiller's Archiv, 185!, pag. 329.

$\left.{ }^{3}\right)$ Beiträge zur mikrosliop. Anatomie der Rochen und Haie, pag. 76.

4) Zur Histologie des Herzens. Virchow's Archiv, Bd. 58.

b) Beiträge etc. von Leydig, pag. 77. 
haben, oder gewöhnliche Primitivbündel, von denen nur die Corticalzone Querstreifung entwickelt, vermag ich leider diesmal nicht zu untersuchen.

Eine besondere Stellung ninmt beim Neunauge, wie bei allen andern Vertrebaten, die Muskulatur des Herzens ein. Bei einfacher Untersuchung des frisclien Gewebes erscheint die Uebereinstimmung mit den Kiemen und Augenmuskeln ziemlich gross. Die Elemente besitzen eine corticale quergestreilte Zone und einen körnigen Axencylinder mit Kernen. Die corticale Zone ist oft schmal und ihre Querstreifung dann nur mit starken Systemen wahrzunehmen. Daraus erklärt sich wohl, dass Stannius ${ }^{1}$ ) dieselbe anfangs übersehen hat, während er sie nachmals ${ }^{2}$ ) mit bessern Methoden auffand. Mit Macerationsmethoden, namentlich mit Salpetersäure oder 33\% iger Kalilauge kann man die Muskulatur des Herzens ebenso in einzelne kleinere Elemente zerlegen, wie alle andern Wirbelthierherzen. Dieselben besilzen meist die lange Spindelform der Herzzellen der niedern Vertebraten (Taf. III, Fig. 10) aber es kommen auch kürzere, breiter auslaufende Elemente vor, welche mehr an die Formen der Warmblüter erinnern. Ausserdem sind mehrkernige Zellen relativ häufig.

\section{Vom Skelet. \\ (Tafel IV, Fig. 1 und 2.)}

Das Skelet des Ammocoetes ist am genauesten von Johannes Müller ${ }^{3}$ ) beschrieben worden.

1) l. c. pag. $\left.226,{ }^{2}\right)$ Zeitsch. für wissensch. Zoologle, IV. pag. 26.6.

2) Weismann, Müller's Archiv, 1861.

cf. meine Arbeit, Virchow's Archiv, Band 58 .

') Osteologie, pag. 116. 
Es besteht wesentlich aus der Chorda mit ihrer Scheide, umgeben von einer festen Bindegewebslage: der skeletogenen Schicht. Diese bildet dorsal die Hülle für das Centralnervensystem. Vorn erweitert sie sich und überragt das Ende der Chorda um die halbe Länge des Gehirnes. Der erweiterte Theil über und vor der Chorda stellt die Schädelkapsel dar. Ausser den Strahlen der Rückenflossen und dem Kiemenskelet kommen nur am Schädel knorpelige Theile vor: nämlich ein paar dünner Leisten, welche jederseits dem vordern Ende der Chorda anliegen und sich über diese fortsetzen, um unter der Nase in einem Bogen zusammenzufliessen. Diese Leisten entsprechen in ihren hintern $A b-$ schnitlen den Körpern des occipitale und der beiden Keilbeine, in ihren vordern dagegen Theilen des harten Gaumens. Ihnen sitzen hinten jederseits die knorpeligen Gehörkapseln auf; die ganze übrige Schädelkapsel isł rein häutig, ebenso die Nasenkapsel. Die Beschreibung von Rathke bleibt fast in allen Punkten hinter der von Johannes Müller zurück, nur in einem Punkte hat er mehr gesehen; als Müller: nämlich an der Nase. Er giebt an ${ }^{1}$ ) dass die Schädelkapsel vorne durch ein kleines, muschelartiges, senkrecht stehendes und mit den Wänden der Kapsel innig verflossenes knorpelartiges Blättchen, an dessen vorderer Seite der nachher zu beschreibende Nasensack angewachsen ist, verschlossen" wird. Rathke findet somit beim Querder ein knorpliges Siebbein, während Johannes Müller dies vermisste.

Die oben besprochene Maceration in Salpetersäure leistet auch für die Erkennung des Skeletes gule Dienste. Sie zerstört allerdings mit Ausnahme der Chordascheide alle rein bindegewebigen Partieen. Dafür aber bleiben die knorp-

') Queviler, pag. 78.

Borichto der naturf. Gesellsch, z, Froiburg i. B, Bd, VI. Hoft III. 
ligen Theile gut erhalten und lassen sich in Alcohol beliebig conserviren. Mit HüIfe dieser Methode kann man zunächst die Angaben von Johannes MIüller leicht vollkommen bestätigt finden. $\Lambda$ ber man erhält doch noch einige feste Skelettheile mehr, nämlich zunächst jederseits vor dem Petrosum einen kleinen, nach Aussen horizontalgerichteten Fortsatz, (Taf. IV, Fig. 2 a) welcher, obwohl histologisch vollkommen mit den andern Knorpeltheilen übereinstimmend sich durch leicht gelbe Färbung von den bräunlichen Knorpelleisten unterscheidet. Das ist nicht ohne Interesse; denn es bestätigt die Deutung, welehe diesem Forlsatz seiner Jage nach zukommt. Derselbe entspricht vollkommen dem hintern Fortsatz am Schädel der Neunaugen, welcher sich bei diesen mit dem [Stützknorpel für die Zungenmuskeln verbindet und nach Johannnes Müller dem grossen Zungenbeinhorn der Myxine homolog ist. Seine Richtung ist allerdings eine andere: sie geht beim Querder rein horizontal, beim Petromyzon dagegen nach abwärts. Aber in der gelblichen Färbung stimmt dieser Fortsatz mit dem des Querders überein. Wichtiger als dieser Fortsatz ist ein Knorpelstückchen, das sich an der vordern Seite der Schädelkapsel erhält: ein kleiner Knorpel von der Form eines lateinischen U. Der Bogen desselben liegt dem obern Theil der vordern Wand des Schädels an, die Schenkel gehen sich verbreiternd in nach aussen convexem Bogen nach vorn und unten und hüllen so einen Theil der übrigens häutigen Nasenkapsel ein. Dieses ethmoideum ist zweifellos der hier von Rathke gesehene und nur unvollständig beschriebene Knorpel. Er steht ausser Verbindung mit dem Schädelknorpel und somit dürfte die Lage dieses rudimentären Siebbeines eine sehr gute Bestäligung der Ansicht von Johannes Müller sein, dass dieser Knochen anders entsteht, als die Wirbeltheile des Schädels und also nicht als solcher aufgeführt werden könne. 
Mit der gleichen Methode lassen sich die knorpeligen Theile des. Skelets vom kleinen Neunauge darstellen. Sie stimmen so vollständig mit den Verhältnissen überein, wie sie Rathke und Johannes Müller beim Flussneunauge beschrieben haben, dass ein weiteres Eingehen nur Wiederholung jener Beschreibungen wäre.

Nur in einem Punkte bleibt der knorpelige Schädel des kleinen Neunauges hinter dem des grossen zurück. Der bei diesem vollkommen geschlossene Knorpelring des occipitale bleibt bei jenem offen.

Histologisch ist der Skeletknorpel des Ammocoetes wie des Petromyzon Hyalinknorpel mit reichlichen Zellen. Die $Z$ wischensubstanz ist nur spärlich und zerfällt durch Linien sehr schön in Zellterritorien oder Zellkapseln. Untersucht man den Schädel des Neunauges auf Querschnitten, so fällt sofort in die Augen, dass die anscheinend gleicharlige Knorpelkapsel durch Anordnung der Zellen und der Zwischensubstanz in einzelne, scharf gesonderte aber doch nicht trennbare Theile zerfällt. Unter diesen hebt sich besonders klar jederseits ein rundlicher Theil ab, weIcher in Grösse und Anordnung genau der Knorpelleiste des Querders entspricht. (Taf. IV, Fig. 1 bei a). Ausserdem sondern sich die beiden Petrosa und endlich über und unter dem Anfang der Chorda je ein schmales Knorpelplättchen, welches die beiden Leisten verbindet.

Diese Sonderung ist in zwei Beziehungen von Bedeutung; sie erläutert einmal die innigen Beziehungen zwischen Larve nnd Geschlechtsthier, indem sie den knorpeligen Schädel der erstern beim letztern vollkommen erhalten nachweist, und somit die vollkommene Identität der Theile zeigt; und sie scheint mir ferner zu beweisen, dass die Entwickelung des Schädels in der Metamorphose nicht durch Wucherung der Larvenknorpel, sondern durch Bildung von Knorpel aus der skeletogenen Schicht erfolgt, denn 
wäre ersteres der Fall, so könnte nicht die form des Larvenknorpel im Geschlechtsthier deutlich gesondert zur Anschauung kommen. -

Ueber das Gewebe der skelelogenen Schicht und der Chordascheide vermag ich nach der eingehenden Bearbeitung, der sich diese Theile erst kürzlich ${ }^{1}$ ) erfreut haben, keine weitern Angaben zu machen. Nur das möchte ich erwähnen, dass durch die Einwirkung der Satpetersäure die innere, von Gegenbaur als cuticular bezeichnete Lage der Chordascheide vernichtet wird, die äussere oder elastica dagegen sich erhält und dann von der Fläche her sehr deutlich zahlreiche Poren erkennen lässt, die als kleine helle Punkte erscheinen. Für die Untersuchung des skeletogenen Gewebes leistet namentlich dic Härtung in starker Osmiumsäure ausgezeichnete Dienste und gestattet leicht die Beobachtungen Gegenbauer's zu wiederholen.

Nur in Bezug auf den Bau der Chorda selbst kann ich den genannten Angaben nicht vollkommen beistimmen. Die periphere Lage kleiner Zellen, die von Leydig zuerst beim Stör gesehen und von Gegenbaur bei den Cyclostomen nachgewiesen wurde, ist leicht aufzufinden. Aber zwischen diesen kleinen Elementen und den 'andern Zellen der Chorda kann ich keinen Uebergang finden in der Art wie ihn Gegenbaur ${ }^{2}$ ) von Petromyzon marinus abbildet. Den kleinen Zellen liegen vielmehr beim kleinen Neunauge und Querder unmittelbar die grossen, Protoplasma-armen Elemente der Chorda auf, und diese haben an der Pheripherie wie im Innern gleiche Dimensionen. Sie lassen sich durch Salpetersäure wie Müller'sche Flüssigkeit isoliren, und zwischen

') C. Gegenbaur, Ienaïsche Zeitschrift, Band III, pag. 376 und Band V, pag. 13 .

$\left.{ }^{2}\right)$ l, c. Band V, pag. 47. Taf. I, Fig. 4. 
ihnen existirt keine Zwischensubstanz. Der Anschein einer solchen wird vielmehr nur durch die aneinanderstossenden Membranen der Zellen hervorgebracht Es scheint mir somit nothwendig, die scharfe Trennung, welche Johannes Müller aus so wichtigen Gründen zwischen dem Gewebe des Knorpels und der Chorda vornahm, wieder einzuführen und nicht die Chorda à conto einer in der That nicht existirenden Zwischensubstanz weiter zu einem Gewebe zu stellen, von dem sie sich scharf genug sondern lässt. Denn wenn auch die Zwischensubstanz des Knorpels ähnlich den Zellmembranen durch die Thätigkeit der Zellen entsteht, so existirt doch im fertigen Knorpel überall zwischen den Zellen und eventuell ihren Hüllen eine differente Gewebslage, von welcher in der Chorda des Neunauges auch keine Andeutung vorhanden ist.

\section{Vom Verdauungsapparat.}

(Tafel IV, Fig. 2 bis 7, Tafel V, Fig. 1 bis 5.)

Am Verdauungsapparat sowohl des Ammocoetes als des Neunauges haben wir zunächst einen vordern Abschnitt zu unterscheiden, welcher im Bau seiner Wand vollkommen mit der äussern Haut übereinstimmt und somit wohl als Mundhöhle zu bezeichnen ist. Bein Ammocoetes entspricht dieser Abschnitt vollkommen dem von Rathke als Mundhöhle beschriebenen Theil ${ }^{1}$ ). Er beginnt am Saum der beiden Lippen und endet mit einer Falte, welcher die grössten der verästelten Papillen aufsitzen, die dann nach vorn sich auf die Oberlippe bis fast zum Lippenrande er-

1) Querder, pag. 78. 
strecken. Beim Neunauge aber macht dieser $\Lambda$ bschnitt nur einen Theil der Rathke'schen ${ }^{1}$ ) Mundhöhle aus. Rathke bezeichnet nämlich mit diesem Namen denjenigen Abschnitt des Traclus, welcher vom Lippenrande bis zum hintern Ende des vordern Deckknorpel des Mundes reicht, von dem aus ein kleines Schleimhautfältchen nach unten vorspringt, das er velum palatinum nannte. Soweit reicht der, ebenso wie die Mundhöhle des Ammocoetes gebaute $\mathbf{\Lambda b -}$ schnitt nicht; derselbe begrenzt sich vielmehr hinten unmittelbar hinter den hintersten Zähnen, also entsprechend dem Labialknorpel.

Dieser Abschnitt ist bei der Larve wie nach der Metamorphose mil einem mehrschichtigen Epithel ausgekleidet, dessen oberste Zellen eine dicke Cuticula tragen. Zwischen ihnen kommen, wenn auch ziemlich selten, haartragende Sinneszellen, wie ich sie oben beschrieben habe, vor. Die Körnerzellen aber wie die Kolben fehlen dem Epithel der Mundhöhle. Ausserdem finden wir in diesem ersten Theile des Verdauungskanals beim Ammocoetes die verästelten Barteln, beim Petromyzon die sogenannten Hornzähne. Die verästelten Barteln sind mit einem zweischichtigen Epithel bekleidet, dessen obere Lage eine relativ feine Cuticula besitzt. Sinneszellen kommen auf ihnen nicht vor; und mit Hülfe der geeigneten Agentien gelingt es nur hin und wieder einen feinen Nerven in ihnen $z u$ finden. Ich kann mich demgemäss der Ansicht der älteren Autoren über die Bedeutung dieser Papillen nicht anschliessen. Sie hielten dieselben für den Sitz des Geschmackssinns ${ }^{2}$ ) oder des Tastsinnes ${ }^{3}$ ). Der Mangel an Sinneszellen spricht vielmehr

1) Pricke, pag. 31.

$\left.{ }^{2}\right)$ Rathke, Querder, pag. 98.

') J. Müller, „Ueber den eigenthümlichen Bau des Gehörorgans etc." pag. 29. 
für die Auffassung von August Müller ${ }^{1}$ ), welcher die Barteln als Gilterstäbe bezeichnel. Sie würden dann functionell mit dem Gitter des Amphioxus und der Ascidien übereinstimmen und einen rein mechanischen Schutzapparat darstellen. Die Zähne der Neunaugen sind durchaus keine Cutikularbildungen, sondern sie sind ächte Hornsubstanz, bestehend aus mehreren Lagen verhornter Epithelien, wic dies F. E. Schulze ${ }^{2}$ ) beschrieben hat. - Becherzellen finden sich auch hier nirgends.

Auf diesen vordern Abschnitt folgt ein zweiter, hinterer Abschnitt der Mundhöhle oder eine Rachenhöhle, welche bis zum Anfang des Oesophagus und Bronchus beim Petromyzon sich erstreckt. Dieser Abschnitt ist mit einem zweischichtigen Pflasterepithel bekleidet, welches sich in ganz derselben Weise auf dem freien Theil der Zunge findet. Nur auf der Zunge konnte ich Sinneszellen, welche vollkommen mit denen der äussern Haut übereinstimmten, in grösserer Anzahl finden, sonst sind sie im Rachenepithel sehr selten. Alle andern Elemente der obern Schicht tragen eine feine Cuticula.

Vollkommen stimmt damit die Epithelbekleidung des Bronchus, wie des eigenen Knorpels an seinem lingang, den Rathke als Kehlkopf beschreibt, überein. Nur auf diesem finden sich kleine Papillen, die unter geringer Betheitheiligung der bindegewebigen Grundlage wesentlich vom Epithel gebildet werden. Besondere Zellen fanden sich nicht in ihnen; hingegen kommen einzelne Sinneszellen vor.

Beim Ammocoetes wird der hinter den Mundpapillen beginnende Raum zunächst durch die beiden Mundsegel

1) Nüller's Archiv, 1856, pag. 329 .

2) Schultze's Archiv, V. pag. 310. 
in einen vordern und hintern Abschnilt geschieden. Der vordere Abschnilt und die Mundsegel sind mit einem zweischichtigen Epithel bekleidet, das wie bei Petromyzon eine feine cuticula trägt. Nur an einer Stelle ist diese cuticula verdickt, nämlich auf den einander zugewandten medialen Flächen der beiden Mundsegel; hier erhebt sie sich, zeigt eine geringe Verdickung, die nach der Mittellinie allmälig zunimmt und an den sich berührenden Theilen der Segel in kegelförmige Zapfen mit rauher Fläche (Taf. IV, Fig. 4) erhebt. Diese Zapfen erscheinen bei der Flächenansicht (Taf. IV, Fig. 3) als unregelmässig begrenzte Kreise in dor Mitte der platten Epithelien.

August Müller hat die Vermuthung von Rathke, der Strom des inspirirten Wassers trete beim Querder durch den Mund ein, ausführlich bestätigt. Dieser Inspirationsstrom muss zwischen den einander berührenden Flächen der Mundsegel hindurch und es ist wohl zweifellos, dass die Cuticularbildung auf dem Epithel diescr Flächen im Wasser enthaltene feine weiche Theile zerreiben kann. Wir werden so ein functionelles Aequivalent der Zähne in diesen Cuticularbildungen zu sehen haben.

Mikroskopisch stimmen dieselben vollkommen mit den Cuticularbildungen überein, die F. E. Schulze aus der äusseren Haul von Hippocampus brevirostris ${ }^{1}$ ) beschrieben hat, nur erreichen die kleinen Zapfen beim Querder nicht die anschnliche Grösse der „Flammen" bei dem erwähnten Teleostier.

Hinter diesem Mundsegel finden wir beim Ammocoetes ein weite Kiemenhöhle, und erst nahe ihrem Ende beginnt die Speiseröhre. Die Epithelauskleidung dieses ganzen

1) Schultze's Archiv, V. Band 301. 
zweiten Abschnittes ist ein zweischichtiges Pflasterepithel, dessen obere Zellen eine sehr feine Cutisula tragen.

Ueber die Auffassung der übrigen Abschnille des Verdauungstractus findet sich in allen bisher erschienenen Arbeiten eine sehr merkwürdige Uebereinstimmung. Der Verdauungsapparat besteht nämlich aus einem vordern engeren Abschnitt, welcher beim Ammocoetes an der hintern Grenze der Kiemenhöhle beginnt, beim Neunauge aber viel weiter vorn seinen Anfang nimml; dieser enge Theil liegt unmiltclbar dem Scelet der Wirbelsäule auf und geht an der Leber in einen zweiten weitern Abchnitt über, welcher dann allmälig an Volumen verlierend bis zur Cloake sich erstreckl. Alle Autoren nun bezeichnen den vorderen engeren $\mathbf{A}$ bschnitl als Speiseröhre und sehen in dem ersten erweiterten Theil des zweiten Abschnittes den Magen. Ich muss dieser Ansicht entgegentreten. Die Einmündung des Gallenganges liegt unmitlelbaran dieser Erweiterung; hart daneben liegt cine zweite Drüse, welche von Bojanus beim Neunauge entdeckt, von Rathke bestätigt und von August Müller als Pancreas bezeichnet wird. Die Lage dieser Drüsen nun kennzeichnet in der ganzen Wirbelthierreihe den Anfang des Mitteldarmes und es ist somit unerlässlich den vorderen engen Theil des Tractus als Homologon des ganzen Munddarmes, d. h. als Oesophagus und Magen aufzufassen.

Auf ihn folgt dann, mit einer Erweiterung beginnend der Milteldarm, und dieser geht ohne scharfe Grenze in den E.nddarm über.

Der Munddarm lässt eine Zusammensetzung aus drci Häuten erkennen. Aussen liegt eine (Taf. IV. Fig. 5 bei 5 ) ziemlich dicke Tunica serosa, deren Elemente, Fibrillen, Zellen und elastische Fasern vorzugsweise dic Querrichtung innehalten und so leicht den Anschein einer Quermuscularis hervorrufen können. Auf diese Bindgewebshaut folgt nach Innen eine ziemlich dünne Muscularis (Fig. 5 m.) bestehend 
aus glatten Fasern, deren Längsachse parallel mit der des Munddarmes verläuft. Daran schliesst sich nach Innen die mucosa. Sie erhebt sich (Taf. IV., 5 p.) in drei Längsfalten, besteht wesentlich aus einem gefässreichen fast cavernösen Bindegewebe und entbehrt der Drüsen vollständig. Sic ist nach Innen bekleidet mit einem einschichtigen, sehr hohen Cylinderepithel, dessen Zellen wohl durchgängig mit Flimmercilien bekleidet sind. (Fig. 5 , e.)

Dieser Munddarm schliesst sich beim Ammocoetes durch eine Klappe gegen den Mitleldarm ab. Unmittelbar unter dieser Klappe erweiterl sich der Darmkanal bedeutend, ändert vollkommen die Structur seiner Wandungen und es bettet sich vor Allem eine Drüse in die Wandungen ein, welehe bisher beim Querder nicht beobachtet worden ist. Sie ist mit blossem Auge nur als kleine weissliche Stelle an der linken Seite des Anfanges vom Mitteldarm wahrzunehmen; das Mikroskop zerlegt (Taf. V, Fig. 1, pag.) sie in eine Anzahl von Lappen oder Acini, die unmiltelbar am Uebergange des Munddarmes in den Mitteldarm gelegen sind, und eine im ganzen mit einem Siegelringe zu vergleichende Drüsenmasse darstellen. Die Platte des Ringes liegt an der Aussenseite links; der Ring hat an der rechten Seite eine Lücke und hier senkt sich (Taf. V Fig. 1 bei d. ch.) der Gallengang in den Mitteldarm.

Beim Neunauge verwischen sich die so prägnanten Unterschiede des Volumens der beiden Darmtheile wieder, indem der ganze Darmkanal cine Art regressiver Metamorphose durchmacht und ganz enorm an Grösse verliert. Dafür hebt sich aber an der Uebergangsstelle eine Drüsenmasse so deutlich ab, dass sie (nach Rathke) schon von Bojanus gesehen und von Rathke ${ }^{1}$ ) beim Flussneunauge bestätigt

1) I. c. pag. 39 . 
worden ist. August Müller spricht dieselbe als Pancreas all, und da die unmittelbare Nähe des Gallenganges diese Deutung . vollkommen sicher stellt, so werden wir in der intraparielalen Drüsenmasse des Querders eben auch eine Bauchspeicheldrüse sehen müssen. Ueber dieser Drüse strallen die letzten Fasern der Musculatur des Vorderdarmes aus, und der Mitteldarm zeigt im Bau seiner Wandungen eine ganz fundamentale Differenz. Aussen liegt wieder einc bingewebige serosa (Taf. IV, Fig. 6 bei 5). Dieselbe ist mit einem bei Ammocoetes wimperlosen, bei Petromyzon aber stellenweise wimpernden, niedern Cylinderepilhel bekleidet, dessen Zellen ungefähr die Würfelform haben. Auf die serosa folgt aber kein tunica muscularis, sondern es schliesst sich unmitelbar ein Gewebe an, das vorzüglich Sitz der Gefässe ist und somit als mucosa bezeichnet werden muss Fig. 6, m). Es ist ein fast cavernöses Gewebe, in welchem eine grosse Zahl weiter Gefässe ihren Verlauf nehmen. Auf dieses Gewebe nun folgt nach Innen eine sehr gut entwickelte Tunica muscularis, die sich mit grosser Klarheit in eine äussere transversale (Fig. 6, m. I.) und eine innere longitudinale (Fig. 6. m. l.) trennen lässt. Beide bestehen aus blassen Fasern, die in keinem wesentlichen Punkte von denen der anderen Vertebraten abweichen. Die äussere Querlage ist namentlich unmittelbar am pancreas sehr entwickelt und stellt hier eine Art Sphincter für den Munddarm dar. Unmiltelbar der Längsmuskularis sitzt das liohe Cylinderepithel auf. Drüsen fehlen überall.

Der Darm des Querders ist nach Rathke's Entdeckung ausgezeichnet durch eine Längsfalte, welche sich dorsal entwickelt, aber mit kurzer Windung an die ventrale Seite des Darmes gelangt. Diese Lüngsfalte ist auf Taf. IV., Fig. 6 dargestellt; sie besteht wesentlich aus denselben Schichten, wie der übrige Darm; nur das cavernöse Gewebe ist hier so reich entwickelt, dass Rathke schon beim 
Flussneunauge seine Structur crkannte. In der Falte verläuft ein grosses Gefäss, das nach der Structur seiner Wandungen eine Arterie ist. Von derselben gehen (z. B. Fig. 6 bei a) kleinere Aeste aus, sowohl nach der Oberfläche der Falte als auch (Fig. 7 a) circular in die cavernöse Schicht hineil. Diese Aeste entsenden feine Capillaren nach der Oberfläche hin, die sich wesentlich im Bereiche der Musculalur verzweigen und dann erst in die tieferen und weiten Gefässe übergehen, welche das cavernöse Gewebe der eigentlichen Mucosa durchsetzen. Sie bilden hier ein so enges Netz weiter Gefässe, (Fig. 7, c), dass in der Flächenansicht kaum Raum für den geringen Rest von Gewebe übrig zu bleiben scheint, dessen Existenz die Durchschnitte (Fig. 6, m) erweisen. Diese weiten Gefässe sind sehr dünnwandig und gleichen fast vollkommen den radialen Gelässen, die sich im Knochenmark der Säuger vorfinden; es wird also die nicht sehr exakte Bezeichnung capillärer Venen auch auf sie anzuwenden sein. Aus ihnen sammelt sich das Blut in einer weitern Vene, welche dorsal verläuft, und meist vollkommen in die Darmwand eingeschlossen ist (Fig. 6. v.); stellenweise wird diese Vene indess auch frei und liegt dann dem Darme nur lose an. Dieses weite Gefäss ist die Pfortader: sie empfängt feine Venen, von der dorsalen Wand der Bauchhöhle her aus Harn- nnd Geschlechtsorganen und trilt mit kurzer Biegung nach rechts in die untere Spitze der Leber ein, welche sie dadurch fest mit dem Darm verbindet.

Diese Circulationsverhältnisse sind zum Theil schon von Rathke beschrieben. Er kannte die Arterie, welche von der Aorta aus vorn in den Darm tritt und in dessen Falte verläuft (a. coeliaca, Pricke, pag. 67). Aber er sieht bei Petromyzon fluviatilis in der Falte neben der Arterie eine Vene, welche sowohl zur Leber einen als Pforlader bezeichneten Ast schickt als auch direct mit der linken 
Cava ascendens sich in Verbindung setzt (1. c. pag. 71). Ueber die Verhältnisse bei Petromyzon Planeri und Ammocoetes macht Rathke hingegen nur die Angabe, dass in der Falte des Darmes ein Gefäss liege (Querder pag. 89), und dorsal ein meist loses Gefäss verlaufe, das in die Leber übergeht. Der dorsale Verlauf der Pforlader stimmt im Ganzen gut überein mit dem Verhalten des gleichen Ge-fässes bei den Myxinoiden ${ }^{1}$ ) nur fehlt der Pfortader des Ammocoetes der Pfortadersack der genannten Fische und die Verbindungen mil dem Venensystem der oberen Körperhälfte.

Von den Epithelien des Milteldarmes ist es lange bekannt, dass sie mit Flimmercilien bekleidet sind. Aber Johannes Müller giebl an, der Darm des Neunauges flimmere nicht, und diese Bemerkung hat deun auch ihren sehr guten Grund, denn der Flimmerbesalz ist kein continuirlicher, sondern vielmehr ein vielfach unterbrochener. Flimmernde Zellen (Taf. 5, Fig. 2a) wechseln ab mit solchen, die ohne Flimmercilien mit einer einfachen Culicula bekleidet sind (Fig. $2 \mathrm{~b}$ ). Während im Anfang des Mitteldarmes die beiden Zellarten vielleicht gleich häufig sind, nehmen nach unten zu die Flimmerzellen immer mehr ab und die einfachen Cuticularzellen überwiegen. Mögell aber die Flemente mit Cilien oder mil einfacher Cuticula bekleidet sein, immer sind es hohe Cylinder (Fig. $2 \mathrm{a}$ und b), deren Kern in der untern Hälfte liegl. Die Zellen lassen sich frisch in dünner Osmiumsäure teicht isoliren und es erscheint dann ihre untere Grenze als feine, vollkommen ebenc oder ganz leicht gezähnelte Linie. Von Fortsätzen existirt auch keine Andeutung. Aber der unter dem Kerne gelegene Theil ist etwas dunkler als der periphere Abschnitt der Zelle, wie dies auf

1) Johannes .Müller, vergl. Augiolngie etc., pag. 17. 
Figur 2b angedeutet isl. Nach Maceration in Müller'scher Flüssigkeit erscheint dieser Abschnitt zugerundet und glänzend (Fig. $2 \mathrm{a}$ ).

Im Darm der Neunaugen sind von keinem Beobachter Becherzellen gesehen worden. Selbst F. E. Schulze giebt ausdrücklich ihr Fchlen an und ich kann ihm darin nur beistimmen. Und doch kommen imAnfangstheil des Mitteldarmes Zellformen vor, welche an so manche Becherabbildung erinnern (Taf. V, Fig. 3). Es sind Elemente, die mit Körnern so gefüllt sind, dass sie ihre Nachbarn aufs Aeusserste im Raum beschränken, und bei der Flächenansicht auch über sie zII prominiren scheinen. Aber die Profilansicht isolirter Zellreihen lehrt stets, dass trolzdem die Cuticula vollkommen erhalten ist und man also mit Recht das Fehlen der Becherzellen hier behauptet hat. Diese eigenen Zellformen fanden sich nur im obern Abschnitt des Mitteldarmes; weiter nach unten wurde die Anfüllung der Zellen mit Körnern eine gleichmässige und es konnte nicht einmal der Anschein einer Becherbildung entstehen.

Von Interesse musste es sein, die Nerven des Darmkanales zu verfolgen. Allen Cyclostomen fehlt bekanntlich der Sympathicus; er wird ersetzt durch den ramus intestinalis des Vagus. Während aber nach Johannes Müller bei den Myxinoiden beide rami intestinales sich zu einem einzigen Nerven vereinen, konnten beim Neunauge Schlemm und d'Alton jeden ramus intestinalis als getrennten Nerven auf den Magen verfolgen ${ }^{1}$ ).

An eine Verfolgung dieses Nerven beim Ammocoetes ohne Mikroskop war nicht zu denken; ich griff daher gleich zum altbewährten Holzessig und konnte nach 2/tstündiger Einwirkung dieses Reagens denn auch an jeder Seite des

2) Müller's Archiv, 1838, pag. 272. 
Munddarmes ein Stämmchen blasser Nerven auffinden. Dasselbe liegt unmittelbar über der longiludinal verlaufenden Muskelschicht, d. h. zwischen dieser und der Serosa und giebt im Verlaufe nach abwärts eine Anzahl von Zweigen ab. Im Stamm sowohl als in den Zweigen liegen multipolare Ganglienzellen; wenige im Stamm, in den Zweigen dagegen soviel, dass ein sehr gut entwickelter Nervenplexus entsteht, der unmittelbar über der Muskularis gelegen, den ganzen Munddarm umgreift und namentlich nach unten zu gegen das Pankreas hin an Reichthum zunimmt. Am Anfang des Mitteldarmes ändert sich das Verhalten der Nerven: zunächst hören die Stämme vollkommen auf. Vom rechten ramus intestinalis aus geht ein ansehnlicher Zweig auf den duclus choledochus über; der Rest dieses Astes und der ganze linke gehen in dem gut entwickelten Plexus auf. Dieser aber liegt nicht mehr an der untern, d. h. der serosa zugewandten Seite der Schleimhaut, sondern entsprechend der eigenthümlichen Lage der Muskulatur an der obern Seite der mucosa, zwischen dieser und der querlaufenden äussern Schicht der muscularis. Ich habe in dem Durchschniltsbild des J)armes (Taf. IV, Fig. 6 bei g) eine Ganglienzelle abgebildet, welche die Lage des plcxus veranschaulichen wird. Die Abhängigkeit des Nervenflechtes von der Muskulatur tritt am schönsten an der Längsfalte zu Tage. Auf ihr findel sich, wie oben bemerkt, unmiltelbar unter dem Epithel die doppelte Lage der muscularis; der Raum zwischen muscularis und serosa wird so ein sehr bedeutender: der Nervenplexus aber folgt der muscularis und stellt eine Reihe von Ganglienzellen dar, welche in dem convexen Theil der Falle (Fig. 6 bei $\mathrm{g}^{1}$ ) gelegen sind.

Was die feinere Structur dieses Nervengeflechles anlangt, so erinnert dieselbe, wie Taf. V, Fig. 4 zeigt, am meisten an den Meissner'schen Plexus der warmblütigen Verlebraten. Die einzelnen Ganglien bestehen aus rundlichen 
Zellhaufen, und unterscheiden sich im wesentlichen nur darin von denen des Meissner'schen Plexus, dass sie meist ärmer an Zellen und ärmer an Zahl sind. Selten nur finden sich Haufen von vier Zellen, und in den meisten Fällen bildet eine Zelle das ganze Ganglion. Die Entfernung der Ganglien von einander ist oft eine bedeutende: Fig. 4, Taf. V ist eine besonders reiche Partie des Plexus; nicht selten waren die einzelnen Ganglien bis zu $0,07 \mathrm{Mm}$. von einander entfernt und die feinen Verbindungsstränge schwer nachzuweisen: Isolationen von Ganglien ergaben, dass die einzelnen Zellen meist multipolare Elemente sind und mit wohl erkennbarer Scheide (Taf. V, Fig. 5) versehen.

Was nun die feinere Verbreitung der Nerven von diesem Plexus aus anlangt, so erfolgt diese im Mund und Mitteldarm im gleichen Sinne. In beiden gehen die feinern Aeste in die Muskulatur des Darmes. Sie wenden sich also am Munddarm wie am Mitteldarm nach Innen.

\section{Von der Leber. \\ (Tafel V, Figur 6 bis 8).}

Die Leber des Ammocoetes unterscheidet sich dadurch von der des Petromyzon Planeri, dass ihre Zellen wenig oder gar kein Felt enthalten. Sie sieht demgemäss grünlich aus und ist geeigneter zur Untersuchung als die gelbröthliche fettgefüllte Leber des Neunauges. Die Pfortader tritt in die untere Spitze der Leber ein, welche dadurch mit der rechten Seite des Darmes fest verbunden wird. Sie durchsetzt nur die Substanz der Leber, indem sie entweder unmittelbar oder nach kürzerem Verlaufe an der concaven Seite in sie eindringt und sich allmählig, durch Ramification 
kleiner werdend, nach der Gallenblase zu verzweigt. An der ventralen, convexen Seite der Leber entsteht die Lebervene aus mehreren $\Lambda$ esten. Die Drüsenmasse nun ordnet sich im Ganzen um die Pfortader derart an, dass sie in radiärer Richtung sich an sie anschliesst. Von einer Bildung von Acinis existirt keine Spur.

In der Umgebung der Pfortader (Taf. V, Fig. 6 v. p.) findet sich eine reiche Menge von Bindegewebe und in demselben liegen Gallengänge in grosser Zahl, charakterisirt durch ihr helles Epithel und deutliches Lumen (Fig. 6, d ch). An diesen Strang von Bindegewebe schliessen sich nun in radiärer Richtung Drüsencanäle an, welche einen exquisit tubulösen Bau zeigen. Es sind Kanälchen mit deutlichem Lumen, begrenzl von einer Zellenschicht, und ihre Struktur tritt um so klarer hervor, als der periphere Theil der Zellen meist nur den hellen Kern enthält, der centrale, dem Gange zugewendele dagegen allerlei Pigmente und Körner. Ueber den Zusammenhang dieser Kanäle konnten nur Isolationen Aufschluss geben, und es gelangen mir solche einige Male mil Hülfe der oben angegebenen Salpetersäure. Man konnte an diesen isolirten Kanälen leicht den directen Uebergang von Gallengängen in Lebergänge nachweisen, ganz in dem Sinne Hering's und Eberth's. Aber die Grenze der Epithelien beider Gänge war in sofern keine ganz scharfe, als zwischen ihnen eine Art von Schaltstück existirte, in dem die Elemente mit voller Sicherheit weder der einen noch der andern Form zugerechnel werden können (Taf. $V$, Figg. 7 und 8 bei b). Die Gallengänge verzweigen sich auf's Mannigfachste, ehe sie so in Lebergänge übergehen. Aber auch diese verzweigen sich wieder (Fig. 6) und communiciren in weit gehender Weise mil andern Gängen, z. B. anf Fig. 7 durch den Gang e. Neben diesen Communicationen existiren aber auch blinde Kanälchen, blinde Enden oder vielmehr Anfänge von solchen, und

Borichto dor naturf. Gescllach. z. Froiburg i. B., Bd. VI. Hoft IIr. 
ich habe gerade von diesen einige gute Specimina abgebildet, weil ihre Existenz bei höheren Vertebraten noch Gegenstand der Controverse ist. Beim Ammocoetes ist das nicht wohl möglich. Die blinden Enden, wie ich sie in Fig. 7 und 8 bei $d$ gezeichnet habe, sind leicht zu sehen.

Die Leber des Querders ist also eine zusammengesetzte tubulöse Drüse und ähnelt somit in den meisten Punkten der Leber der Reptilien und Amphibien, die in Ietzter Zeil am meisten untersucht wurden. Aber sie unterscheidet sich von ihnen im Mangel der Acini und in der Leichtigkeit, mit der man die Anfänge der Lebergänge sichtbar machen kann.

Das Bindegewebe zwischen den Gängen ist reichlich; es gleicht ungefähr dem in der Marksubstanz unserer Nieren. Eine tunica propria aber fehlt ebenso wie eine innere Cuticula der Gänge.

\section{Vom Geruchsorgan.}

(Tafel VI, Fig. 1 bis 3 )

Das Geruchsorgan des Neunauges besteht aus drei Absclnnitten: dem häutigen Nasenrohr, der Nasenkapsel und dem blind endenden Nasengaumengang. Die Nasenkapsel liegt beim Flussneunauge in einem kleinen, rundlichen Knorpel, dem Siebbein. ${ }^{1}$ ) Dasselbe hat, nach der Beschreibung ${ }^{2}$ ) und Abbildung ${ }^{2}$ ) von Johannes Müller ungefähr die Gestalt einer Halbkugel, deren Convexität nach oben und hinten gerichtet ist. Der obere Abschnitt ist median etwas aus-

1) Pricke, pag. 82.

Osteologie der Myxinoiden etc. pag. 114.

') ebds. Taf. IV, Fig. 1 und 2. 
geschnitten uud wird hier durch Bindegewebe verschlossen. Der hintere Theil legt sich an die Vorderwand der Hirnkapsel und ist von zwei grossen 0effnungen durchbohrt, welche zum Theil ebenfalls von Bindegewebe verschlossen werden, und den Geruchsnerven zum Durchtritt dienen.

Die nach vorn und unten gerichtete Oeffnung der knorpeligen Halbkugel wird in der Mitte dadurch etwas beschränkt, dass der knorpelige Abschnitt über den grössten Kreis hinüber nach vorn sich verlängert, und dann durch Bindegewebe vollkommen schliesst. Nach oben setzt sie sich in das häutige Nasenrohr, nach unten in den häutigen Nasengaumengang fort. An das Siebbein und das feste, seine Lücken zur mehr weniger vollkommenen Kugel ergänzende Bindegewebe setzt sich innen eine dicke kohlschwarze Schleimhaut, welche eine Anzahl sagittaler Falten bildet. $\left.{ }^{1}\right)$

Damit stimmen die Verhältnisse beim kleinen Neunauge vollständig überein. Man kann mit Hülfe der SalpetersäureMaceration das Siebbein darstellen: es zeigt genau die Gestalt wie beim grossen Neunauge. Die Schleimhaut ist in sagittalen Falten angeordnet und von schwarzer Farbe (Taf. VI, Fig. 1). Aber diese Pigmentirung bezieht sich nur auf den bindegewehigen Theil.der mucosa, welcher eine grosse Anzahl verzweigter Chromatophoren enthält; das Epithel ist farblos. Die sagittalen Falten, 16 bis 18 an Zahl, sind aber nicht gleichmässig entwickelt. Es zeichnet sich vielmehr ventral wie dorsal eine genau in der Mittellinie verlaufende Falte durch Grösse vor den andern aus, und von diesen übertrifft wieder die ventrale (Taf. VI, Fig. 1 bei s) die dorsale (etwa bei $s^{1}$ ) um das Doppelte. Die andern Falten sind einander ungefähr gleich an Höhe, und viel kleiner

1) Rathke, Pricke, l. c. 
als jene beiden. Die Falten der Mittellinie stellen somit eine, wenn auch unvollkommene Scheidewand her und wir sehen nicht nur in der doppelten Durchbohrung der hintern Siebbeinwand, sondern auch in der Anordnung der Längsfalten eine unvollkommene Theilung der einfachen Nase. Die ventrale Medianfalte läuft nach vorn in zwei Fältchen aus, die eine unvollständige Grenze zwischen Nasenrohr und Nasenkapsel sowohl, als zwischen diesen und dem Nasengaumengange herstellen.

Beim Ammocoetes ist die Nasenkapsel viel kleiner als beim Geschlechtsthier; ich habe oben (pag. 34) bereits das Siebbein genauer beschrieben, welches derselben zur Stütze dient. Aus der verhältnissmässig geringen Entwickelung des Knorpels folgt, dass das Bindegewebe sich in ausgedehnterem Maasse beim Aufbau der Nasenkapsel betheiligt, als beim Petromyzon. Die Kapsel ist von einer Schleimhaut ausgekleidet, in der Rathke ${ }^{1}$ ) wie Johannes Müller ${ }^{2}$ ) die Falten vollkommen vermissten. Dem ist nicht so. Die Falten der pigmentlosen Mucosa sind allerdings, entsprechend den Grössenverhältnissen des ganzen Organes, viel kürzer als beim Neunauge: aber sie sind dennoch zweifellos vorhanden. Sie verlaufen ebenfalls rein sagittal: aber sie sind weder so hoch, noch so zahlreieh wie die des Petromyzon, sie schwanken zwischen 10 und 12 (Taf. VI, Fig. 2). Von den beiden Falten der Miltellinie fehlt dic obere, dafür zeigt sich die untere sehr viel reicher (Fig. 2 bei s) entwickelt, als wir es oben beim Neunauge gesehen, und übertrifft somit alle übrigen Falten sehr bedeutend. Im Bindegewebe dieser untern, medialen Falte kommen bei einzelnen Exemplaren wenige Pigmentzellen vor (Fig. 2 bei a).

1) Querder, pag. 97.

) l. c. pag. 118 . 
Wir sehen somit beim Ammocoetes die Theilung der einfachen Nase in zwei Seitenhälften womöglich noch deutlicher ausgesprochen, als beim erwachsenen Thiere.

In Bezug auf das Verhalten des Nasenanhanges und Nasenrohres vermag ich den Angaben von Jolıannes Müller nichts hinzuzufügen.

Die histologischen Verhältnisse des Geruchsorganes der Cyclostomen sind, soweit ich die Literatur übersehe, nie Gegensland der Untersuchung gewesen. Es war mir daher um so interessanter, dieselben zu untersuchen, als gerade in jüngster Zeit wieder $Z_{\text {weifel }}{ }^{1}$ ) gegen Max Schultze's ${ }^{2}$ ) Arbeiten über die Riechschleimhaut laut geworden sind.

Das Nasenrohr besitzt eine Epithelbekleidung, welche im Wesentlichen mit der der äussern Haut übereinstimmt. Im Nasenanhang und dem $\mathrm{zu}$ ihm führenden Nasengaumengang findet sich ein zweischichtiges Pflasterepithel, welches mit dem des Bronchus vollkommen übereinstimmt. In der eigentlichen Nasenkapsel aber treffen wir auf sehr differente Formen. Das Epithel ist in den Gruben zwischen den Falten ganz niedrig; es setzt sich continuirlich auf die Falten fort, nimmt aber beim Uebertritt auf dieselben plötzlich um mehr als das Doppelte an Dicke zu und bekleidet so gleichmässig die ganze Falte. Mit diesen Unterschieden sind solche der Elemente selbst verbunden. Das niedere Epithel zwischen den Falten ist ein zweischichtiges Epithel, dessen obere Zellen eine Cuticula tragen. Bisweilen schienen mir auch hier Wimpern vorzukommen. Am Epithel der Falten aber haben wir eine kleine nur die Faltenhöhe einnehmende Partie von der Hauptmasse an den Seiten der Falte zu unterscheiden. Jene stellt ein mehrschichtiges

1) Wiener Sitzungsberichte vom December 1870 und Januur 1872.

') Untersuchungen über den Bau der Nasenschleimhaut. Halle 1862. 
Epithel mit oberer Cuticula dar. An der Seite der Falten dagegen, an den einander zugekehrten Flächen sehen wir bei Larve wie Geschlechtsthier das eigentliche Riechepithel. Es ist ein einschichtiges hohes Cylinderepithel und setzt sich aus zwei Zellformen zusammen : die eine wird gebildet von sehr hohen und schmalen Zellen von circa $0,056 \mathrm{Mm}$. Länge, welche mit leicht gezähnelter Grundfläche dem Bindegewebe aufsitzen (Fig. 3 a), unmiltelbar über derselben einen cylindrischen Zellkörper mit Kern entwickelı, dann sich etwas verschmälern und endlich, wiederum verbreitert, die obere Grenze des Epithels erreichen. Hier sind sie mit ziemlich langen Flimmerhaaren bedeckt, welche einem stärker Licht brechenden Saume aufsitzen. Ob ausser diesen Zellen noch ähnlich gestaltete vorkommen, die nicht die untere Grenze des Epithels erreichen, vermag ich mit Sicherheit nicht anzugeben. Wohl aber findet sich zwischen diesen Zellen eine andere Form, deren Leib und Kern an der Stelle der Verschmälerung der beschriebenen Elemente liegt (Taf. VI, Fig. 3 b). Von diesem Leib aus geht ein feiner Fortsatz nach unten um die untere Grenze des Epithels zu erreichen, oft aber auch kurz abgebrochen aufzuhören. Nach oben zu wendet sich ein elwas stärkerer Fortsatz, erreicht die obere Grenze des Epithels, zeigt hier eine kleine Anschwellung und ist mit einigen kurzen, starren Haaren besetzt, welche sich durch ihre geringe Länge, ihre Starrheit und ihre geringe Anzahl von den Flimmerhaaren sehr prägnant unterscheiden. Die Länge dieser Zellen vom Leibe bis zur obern Grenze ist kleiner. als die der Flimmerepithelien; sie schwankt um $0,04 \mathrm{Mm}$. Diese Elemeute stimmen im höchsten Maasse überein mit den in der Haul beschriebenen Sinneszellen, und ihre ganze Form macht es wohl unzweifelhaft, dass wir in ihnen die eigentlichen Endzellen des Olfactorius vor uns haben, obwohl ich eine directe Beobachtung des Zusammenhangs nicht beibringen kann. Die regio 
olfactoria umfasst somit die Seiten der Falten : die Höhe derselben, wie die Thäler tragen indifferente Epithelien. Hinten vereinen sich die Längsfalten zum Theil und dadurch entsteht eine Anzahl rundlicher Maschen zwischen ihnen, von denen namentlich eine ziemlich gross ist. In diesen rundlichen Räumen fand ich ebenfalls nur indifferentes Epithel übereinstimmend mit dem im Grunde der Falten.

Diese Verhältnisse sind namentlich in Rücksicht auf die ohen berührte Controverse momentan von Interesse. Wir sehen beim Neunauge zwei wohl charakterisirte Zellformen: der entscheidende Unterschied liegt nicht sowohl in dem Maasse des einen oder des andern Fortsatzes darin kommt, wie ich Exner zugebe, eine gewisse Breite der Variation vor. Es kann die Zelle ihren Leib tiefer unten, oder höher oben haben, die Fortsätze können in ihren Durchmessern variiren, aber immer ist die Gestaltung der Oberfläche fundamental verschieden. Die eine Art der Elemente ist bekleidet mit langen Flimmerhaaren, die andere mit kurzen starren Haaren, wie sie weder hier noch sonst wo Flimmerbewegung zeigen. Damit ist denn im Princip die Ansicht Max Schultze's für die Neunaugen gewahrt und die physiologisch so wichtige Existenz eigenthümlicher Zellen an der Endausbreitung des Olfactorius für dieselben erhalten. $O b$ auch die Flimmerzellen mit Nerven zusammenhängen, darüber kann ich nichts aussagen, es ist diese Frage jedenfalls von der andern scharf zu scheiden und für die Auffassung des Geruchsorganes von ganz secundärer Bedeutung.

Vergleichen wir nun den Befund bei den Neunaugen mit dem bei den andern Vertebraten, so sehen wir einige auffallende Momente. Die indifferenten Epithelien der regio olfactoria zeigen nur beiden Plagiostomen ${ }^{1}$ ) stets deutliche

1) Max Schultze, I. c. pag. 26.

Exner, Wiener Berichte vom Januar 1872, pag. 10. 
Wimperung; in allen andern Gruppen der Vertebraten wurde dieselbe vermisst. Es schliessen sich also in dieser Beziehung die. Cyclostomen direct an die Selachier an, und os wird somit die Wimperung dieser Elemente wohl als das primäre, der Mangel an Flimmerhaaren als eine secundäre Erscheinung aufzufassen sein. Die Existenz von Haaren am freien Saume der Riechzellen, der sog. Riechhärchen von Max Schultze kommt nach den Forschungen desselben keinen andern Fischen zu, sondern nur den Amphibien, Reptilien und Vögeln, und die Riechhäärchen dieser drei Klassen zeichnen sich durch erheblich grössere Länge vor denen des Neunauges aus. Wir sehen somit in diesem Punkte bei den Cyclostomen ein Verhalten, das allen andern Fischen verloren gegangen ist und erst bei den Amphibien wieder auftritt.

Im Bindegewebe der Schleimhaut fehlt die eigenthümliche Uebergangszone zam Epithel, die namentlich Exner so eingehend geschildert hat; das Bindegewebe der mucosa ist überhaupt seiner reichen Pigmentirung wegen schwer zu untersuclien und gestattete deshalb auch keine genügende Verfolgung des N. olfactorius. All' das bezieht sich nur auf Petromyzon; vom Ammocoetes habe ich nur das Epithel der regio olfactoria genau untersucht.

\section{Vom Auge.}

(Tafel VI, 4 bis 6$)$.

Der durchsichtige Theil der Haut, welcher das Auge vom Petromyzon überzieht, und als Cornea anzusehen ist, steht in so inniger Verbindung mit der übrigen Haut, dass 
man den ganzen Bulbus mit anhängenden Muskeln etc. leicht in toto entfernen kann, ohne dass jene Verbindung dabei im Mindesten gelockert würde. Der Augapfel, den man so isolirt, wird von einer continuirlichen Membran umgeben, deren hinterer bei weitem grösserer Abschnitt dunkel pigmentirt ist, während vorn ein klciner, der cornea entsprechender Theil vollkommen farblos und durchsichtig erscheint. Beide Theile aber hängen fest zusammen, sie bilden eine einzige membranöse Kugel. Schneidet man den vordern hellen Theil derselben ab und unterwirft ihn der mikroskopischen Untersuchung, so stellt sich heraus, dass er aus einer sehr zähen, starken elastischen, vollkommen homogenen Haut besteht, welche an der, dem Innern des Bulbus zugekehrten Fläche von einem einschichtigen Plattenepithel überzogen wird. Dieser $\Lambda$ bschnitt der einhüllenden Membran ist somit die membrana Descemetii. Der hintere pigmentirte Theil lässt uns viele Chromatophoren, eingebettet in eine helle Grundsubstanz, erkennen: er entspricht der lunica chorioidea. Innen legt sich dieser Membran das Retinalpigment an, aussen mit dünnen, bindegewebigen Häuten die Augenmuskeln. An der tunica chorioidea lassen sich weder auf Schnitlen noch durch Zerzupfen bestimmte Schichten in der Weise unterscheiden, wie bei den höhern Vertebraten. Zivischen den pigmentirten Lagen kommeu helle Schichten vor, aber es fehlt ihnen jede Regelmässigkeit der Anordnung.

Querschnitte durch das Auge lassen das Verhalten der Häute noch deutlicher hervortreten. Taf. VI, Fig. 4 stellt einen Theil eines solchen dar. Man sieht unmittelbar unter der hellen Cornea die dicke elastische Haut (m. D) in conlinuirlichem Zu sammenhange mit der choroides (ch). An letzterer hängen stellenweise Muskeln an (m), befestigt durch dünne Bindegewebsmembranen. Aber solche Schnitte lehren noch mehr: sie zeigen, dass sich die chorioidea vorn 
nicht mit ihrer ganzen Substanz in die Descemet'sche Hau fortsetzl, sondern dass sie sich am vordern Ende der NetzLaut ( $r$ ) spaltet und ein inneres pigmentirtes Blatt, die Iris (i) nach der Linse (I) zu entsendet, welches mit freiem Rande auf dieser aufhört. Die åussere Hälfte der Chorioidea allein setzt sich in die Descemet'sche Membran fort. Innen liegt der Choroides die sehr dicke Retina auf; dieselbe endet, wie es scheint, an der Spaltungsstelle der pigmentirten Haut. Nicht selten sieht man von ihrer Innenfläche eine dünne Membran auf die Linse übertreton. Doch konnte ich nicht ganz genau entscheiden, an welcher Stelle dieser Uebertritt erfolgte, jedenfalls liegt die Umschlagsstelle sehr weit vorn. Die retina umschliesst einen kleinen Glaskörper und eine sehr grosse runde Linse. Vor der Descemetii liegt der bindegewebige Theil der cornea; er gleicht vollkommen dem sog. corium der Haut und setzt sich continuirlich in dasselbe fort. Vor inm liegt das Epithel, welches nur durch den Mangel an Kolben und Körnerzellen von dem übrigen Hautepithel ausgezeichnet ist.

Mit dem Bindegewebe der Haut steht in directem Zusammenhange das Bindegewebe, welches entweder allein oder mit Hülfe der knorpeligen Theile des Schädels die orbita constituirt.

Wir finden somit am Auge des Neunauges fast alle wesentlichen Theile des Auges der andern Vertebraten wieder. Es besitzt beide Kammern und den Glaskörper, zeigt eine dicke Netzhaut und eine gut entwickelte Aderhaut. Aber die letztere steht in continuirlichem Zusammenhange mit der Descemetii, eine Sklera ist nur durch unbedeutende Bindegewebshäutchen, die sich an die Muskeln anschliessen, vertreten, und die cornea existirt in dem Sinne der höheren Vertebraten nicht. Sie ist aufgelöst in einen chorioidealen Antheil, die Descemet'sche Haut, und in einen sehr mächtigen cutanen Antheil. 
Ganz anders liegen die Verhälınisse beim Ammocoetes. Bei ilım ist das Auge. wenig entwickelt, es ist klein und liegt tief unter der Haut, so dass sich zwischen ihm und dem durchsichtigen Theil der Haut ( Taf. VI, Fig. 5 c.) noch eine bis zu $0,3 \mathrm{~mm}$. dicke Schicht von Unterhautzellgewebe (s. c.) einschiebt. Erst unter dieser Schicht liegt der kleine Bulbus; er ist eben so leicht isolirbar, wie der des Neunauges. Mit dem subcutanen Gewebe vor dem Bulbus hängt continuirlich das Bindegewebe zusammen, welches die Wand der Orbila bildet ( 0 ); in diesem Gewebe kommen Pigmentzellen ziemlich zahlreich vor; ich habe sie indessen, um das Bild nicht zu verwiren auf der Figur nicht angedeutet. Die äussere Hülle des Bulbus wird, wie beim Neunauge, von einer pigmentirten Membran gebildet, aber dieselbe ist nicht nur dünner, als bei jenem, sondern sie entbehrt stellenweise der Chromatophoren noch gänzlich. Die in der Fig. 5 mil ch. bezeichnete Haut entspricht nicht nur der chorioidea, sondern zugleich dem Retinalpigment. Aussen findet sich nur stellenweise (Fig. 5 bei $\mathrm{m}$ ) ein wenig lockeres Bindegewebe zur Befestigung der schwach entwickelten Muskeln an der Chorioidea. Vorn geht die Chorioidea über in einen dicken glänzenden homogenen Körper, welcher bis zur Linse reicht und somit die vordere Kammer vollständig ausfüllt. Dieser Körper stellt eine stark verdickte Descemet'sche Membran dar. An ihn schliesst sich ausser der Linse die Iris. Dieselbe ist aber ganz anders gebaut, als beim Neunauge. Sie besteht nämlich wesentlich aus einem kleinen vordern, verdünnten Abschnitt der Netzhaut, (Fig. 6) und diesem liegt nur ein ganz sclimales bindegewebiges Blatt auf (Fig. 6 i. ch), welches sich von der fast ganz in die Descemetii übergehenden Chorioidea abspaltet. An der Umschlagstelle der Iris verdickt sich die retina bedeutend und schliesst sich innen an die chorioidea an. Der Raum, den sie im Bulbus übrig lässt, wird fast 
vollkommen von der grossen Linse ausgefüllt; dem Glaskörper bleibt nur wenig Platz.

Wir sehen somit beim Querder manche $\Lambda$ bweichungen vom Auge des Petromyzon. Im Mangel einer Sclerotica wie in der Trennung der cornea in verschiedene Schichten stimmen beide überein: aber diese Trennung ist beim Querder noch weiter entwickelt, indem sich zwischen dem cutanen Antheil der Hornhaut und der Descemetischen Membran ein reiches subcutanes Gewebe einschiebl, das beim Neunauge nur in einer lockeren unteren Lage des cornealen Corium noch existirt. Die Chorioidea spaltet sich bei beiden Thieren in die Descemet'sche Haut und in die Iris. Aber jene ist beim Querder weit mächtiger, diese weit schwächer entwickelt, als beim Neunauge, und der letzteren gesellt sich ein vorderer Abschnitt der Netzhaut zu, von dem beim Neunauge nichts deutlich zu erkennen war. Dieser Abschnitt ist von besonderem Interesse. Die retina (Taf. VI. Fig. 6) verdünnt sich an der Stelle, wo sie unter fast rechtem Winkel an die Linse tritt, bedeutend. Ihre sämmtlichen Schichten wandeln sich in ein einschichtiges Cylinderepithel um, während das äussere Blatt der Augenblase in ziemlich gleicher Dicke, wie hinten, vor jenem Epithel liegt und am freien Rand in dasselbe übergeht. Diesem relativ mächtigen retinalen Theil gesellt sich ein sehr schmales bindegewebiges Blatt zu (Fig. 6, c. ch), das der choroides entstammt, deren Hauptmasse in die dicke membrana Descemetii übergeht (Fig. 6, D). Von einer vordern oder hintern Kammer existirt keine Spur; die vordere wird durch die dicke membrana Descemetii ausgefüllt, die hintere fehlt vollkommen.

Der Bau des Auges, wie wir ihn so bei Ammocoeles und Petromyzon Planeri kennen gelernt haben, findet sich in gleicher Weise bei keinem andern erwachsenen Wirbelthiere. Wir begegnen jedoch ganz ähnlichen Verhältnissen, 
wenn wir auf die Entwickelungsgeschichte zurückgreifen. Das war bei Ammocoetes in Rücksicht auf seine Stellung zu Petromyzon von vornherein wahrscheinlich, und ist auch bei ihm am Auffallendsten, namentlich in Bezug auf die Iris. Ueber die Entwickelung dieses Gebildes hat kürzlich Leonhard Kessler ${ }^{1}$ ) ganz neue, von den frühern Anschauungen fundamental differente Angaben gemacht; welche sich auf das Hühnchen und den Triton beziehen und bei beiden eine sehr wesentliche Betheiligung der nervösen Augenblase an der Bildung der bis dahin für rein bindegewebig gehaltenen Regenbogenhaut fesstellen. Für die Richtigkeit dieser Angaben liefert das Verhalten der gleichen Theile beim Ammocoetes eine gute Stütze, die Fig. 6 der Talel VI. gleicht fast vollkommen den Kessler'schen Bildern, und wir sehen somit beim Querder einen Zustand der Iris, der sonst nur vorübergehend ist, Jahre lang persistiren, und erst mit der Metamorphose andern Verhältnissen Plalz machen. Wie weit nach derselben die retina sich noch an der Zusammensetzung der Iris betheiligt, konnte ich, aus Mangel an frischen Präparaten, nicht genau fesstellen; jedenfalls aber erreicht der bindegewebige Antheil derselben eine weit stärkere Entwickelung.

Abweichend von den Beobachlungen Kessler's ist dagegen das, Verhalten der chorioidea und cornea. IJie letztere zerlegt sich in drei Abschnitle: einen cutanen, einen subculanen und die Descemel'sche Haut. Nur die letztere ist continuirlich mit der Chorioidea verbunden: eine Continuität mit der sklera fehlth da diese selbst nur stellenweise vorhanden isl. Aber auch diese Verhältnisse gleichen Embryonalzuständen höherer Thiere. Herr Professor Manz

') Untersuchungen über die Entwickelung des Auges angestellt am Hühnchen und Triton. Diss. Jorpat, 1871. 
hatte die Freundlichkeit, mir mitzutheilen, dass er bei seinen Untersuchungen über die Entwickelung des Auges, welche demnächst in dem Handbuch von Graefe und Sämisch veröffentlicht werden, bei Säugethieren und menschlichen Embryonen aus dem $z$ weiten bis vierten Monat eine vollkommene Continuität zwischen der Descemet'schen Membran und der Chorioidea gefunden hat. Die Sklera existirte zu der Zeit wie boi unsern Thieren nur andeutungsweise, wenn auch etwas mehr entwickelt im Anschluss an die Augenmuskeln, und in loser Verbindung mit einer vor der Membrana Descemetii gelegenen Gewebsschicht (Cornea propria). Davor lag eine dünnere Schicht der Kopfplatten in directer Verbindung mit der Haut. Die Descemet'sche Membran ist zu Anfang sehr dick; sie bildet einen dicken Körper, der, nach Hensen ${ }^{1}$ ) bei Schaaf, Kaninchen und Meerschweinchen, vollkommen die vordere Kammer füllt. In diesem Stadium bleibt sie während des ganzen Ammocoetes-Lebens der Neunaugen; bei den Säugern aber nimmt sie schnell an Masse $a b$, erreicht das Maass des Neunauges und endlich das noch bescheidenere erwachsener Säuger. Die Sklera entwickelt sich aus dem Gewebe unter den Muskelansätzen, und eine Continuität mit der Substanz der cornea stellt sich erst relativ spät her. Während also diese Verhältnisse genau mit denen der Neunaugen übereinstimmen, sprechen die Untersuchungen des Herrn Professor Manz ebenso wie meine Befunde gegen die Ansichten Kessler's über die Entstehung der Hornhaut.

Bei Ammocoetes und Petromyzon zeigen somit die Augen einen Bau, wie er vorübergehend den höhern Vertebraten zukommt- und bieten dadurch trotz der anscheinend so abweichenden Verhältnisse, ein sehr vollkommenes Bei-

3) Schultze's Archiv II, 420 . 
spiel für die Uebereinstimmung, welche im Grossen und Ganzen zwischen der individuellen Entwickelung und der Phylogenie besteht.

\section{Von der retina.}

(Taf. VII.)

Ein Schnitt durch die Eintrittsstelle des Sehnerven in die retina (Taf. Vll, Fig. 1) zeigt, dass bei Petromyzon Planeri der Nerv nicht die ganze retina durchläuft, um sich dann an ihrer inneren Oberfläche auszubreiten, wie bei den übrigen Vertebraten, sondern dass er nur einen Theil der Netzhaut durchsetzl, während ein anderer Theil continuirlich über die Eintrittsstelle des Nerven fortzieht. Der letztgenannte Theil ist ziemlich mächtig, er nimmt ungefähr den dritten Theil der ganzen Netzhautdicke in Anspruch und besteht aus zwei Schichten, einer feinen membrana limitans interna (1) und einer mächtigen inneren granulirten Schicht (2). Aussen von dieser letztern breitet sich der Sehnerv aus, und zwar in der Weise, dass ein Theil seiner Fasern während der Durchbohrung eine Art von Kreuzung macht, wie dies in der Fig. 1 angegeben ist. Die Sehnervenlage oder Faserschicht (3) ist nicht überall von gleicher Stärke: sie nimmt nach dem Aequator des Auges zu ab, theils indem Fasern in die äussern Lagen eintrelen, theils auch, indem Bündel von solchen in die granulosa interna sich begeben und somit nicht an deren äusseren Grenze, sondern in ihrer Substanz selbst verlaufen. Sie bedingen dadurch eine Schichtung in derselben (Fig. 1 bei b) ganz ähnlich den Schichtungen, wie sie in der gleichen Lage - bei anderen 
Wirbelthieren schon von Heinrich Müller beobachtet worden sind. An der Fintriltsstelle selbst liegen zwischen dem Sehnerven und der Granulosa interna eine Anzahl von Kernen, die wohl wesentlich bindegewebigen Elementen angehören; sonst sind im 0plicus keine anderen Kerne vorhanden. Auf die Faserschicht folgt nach aussen eine ziemlich dicke Lage innerer Körner (Fig. 1 bei 4), und auf diese eine sehr merkwürdige Schicht, die ich auf Fig. 1 mit 5 bezeichnet habe und als Ganglienschicht benennen will. Diese Lage ist aber, wie die vergrösscrte Abbildung in Taf. VII, Fig. 2 zeigt, keine einfache Ganglienschicht: sie besteht vielmehr aus zwei Reihen von Ganglienzellen, einer niedrigen inneren und einer höheren äussern, in deren Mitte eine zweite Faserschicht verläuft. $\Lambda$ uch die Elemente dieser Schicht sind zum grossen Theil Opticusfasern; aber sie hängen, wie aus Fig. 1 hervorgeht, nicht direct mit dem eintretenden Sehnerven zusammen, sondern beziehen ihre Fasern wohl von der oben genannten Faserschicht (Fig. 1, 3) aus. Auf die Ganglienschicht folgt eine granulosa externa (Fig. 1 bei 6) und dann eine gut entwickelte äussere Körnerschicht, (Fig. 1 bei 7). An diese schliesst sich die limitans interna (8) an; auf sie folgt die Stäbchen- und Zapfenschicht (9) und endlich das Pigmentepithel (10).

Die ersten Angaben über eine abweichende Schichtung der retina der Neunaugen hat Max Schultze in den Sitzungsberichten der Niederrheinischen Gesellschaft für Natur- und Heilkunde in Bonn ${ }^{1}$ ) gegeben. Er fand beim Flussneunange eine Schichtenfolge, deren wichtigste Abweichung in der Lage der Ganglienzellen und Opticusfasern bestand. Beide schliessen sich unmittelbar an die äussere granulirte Schicht

1) pag. 133, euthalten in den Verhandlungen des Naturhistorischen Vereins der preussischen Rheinlande und Westphalens. Band 28. 
an, und erst innen von den Opticusfasern folgen die innern Körner mit der innern granulirten Schicht.

W. Krause ${ }^{1}$ ) hat gegen diese Angabe von Max Schultze Widerspruch erhoben: wir sehen indess, dass die Verhältnisse beim kleinen Neunauge im Ganzen vollkommen mit derselben übereinstimmen, und somit nur zur Bestätigung der Entdeckung von Max Schultze dienen können. Nur fanden wir unter der, den Ganglienzellen anliegenden Faserschicht, die ich oben als secundäre bezeichnet habe, noch eine zweite Ganglienlage, und dann innen von den inneren Körnern die primäre Hauptausbreitung des Sehnerven.

Wir haben somit bei zwei Arten der Cyclostomen für die Retina eine auffallende Abweichung des Baues von dem allgemeinen Typus der Vertebraten, und zwar eine Abweichung, welche wenigstans in einer Beziehung von Bedeutung ist. Es sind diejenigen Elemente, deren nervöse Natur unbestreitbar ist, die Ganglienzellen, so nahe an die Stäbchen- und Zapfenschicht gerückt, dass für die Erkenntniss eines Zusammenhanges die wesentlichsten Hindernisse weggeräumt erschienen, und es musste ein genaues Eingehen auf die feineren Structurverhältnisse deshalb sehr lockend erscheinen. Dasselbe ergab denn in fast allen Lagen der Netzhaut wieder besondere Eigenthümlichkeiten, von denen wenigstens einige für das Verständniss einiger Verhältnisse bei anderen Vertebraten von Interesse sind.

Die Pigmentepithelien zeigen keine Abweichungen von dem gewöhnlichen Verhalten. lhre äussere Hälfte ist farblos und enthält den Kern, ihre innere Halfte entsendet eine Anzahl pigmenthaltiger Ausläufer zwischen die Elemente

2) Prager Vierteljahrsschrift, Band 116. citirt nach Waldeyer's Bericht in Cannstadt's Jahreshericht für 1872. 
der Stäbchen- und Zapfenschicht. Diese Pigment-haltigen Ausläufer sind relativ dick.

Jie Stäbchen- und Zapfenschicht besteht aus zwei Arten von Elementen. Die einen stellen nach der Form ihrer Aussenglieder zweifellos Stäbchen dar, obwohl sie eine Reihe von Eigenschaften besitzen, welche meist den Zapfen zuzukommen pflegen.' Sie scheiden sich in ein kürzeres Aussenglied, welches sehr leicht in Querplättchen zerfällt, und in ein längeres Innenglied. An der obern Grenze des letzteren liegt ein ovaler Körper, der durch Osmium eine dunkelbraune Farbe annimmt, und $0,005 \mathrm{Mm}$. lang ist. Das ganze Innenglied misst $0,02 \mathrm{Mm}$., das Aussen-glied etwas weniger. Wenn das Aussenglied in Plättchen zerfallen, vom Innenglied sich gelöst hat, so bleibt in dünner Osmiumsäure häufig ein Theil einer zarten Scheide zurück, welcher leicht längsstreifig erscheint (Fig. 5 und 8). Oft aber bleibt nicht nur ein Theil, sondern die ganze Scheide dem Innenglied anhaften, und von solchen Präparaten zeigt die Fig. 5 bei $s_{1}$ und $s_{2}$ zwei Darstellungen.

Der ovale Körper ist meist durch einen hellen Saum vom übrigen Innenglied getrennt. Dieser Saum rührt wohl von einer Contraction des Körpers durch Einwirkung des Reagens her. Ueber das Innenglied sieht man meist sehr deutlich feine Linien in der Längsrichtung verlaufen; dieselben stehen in directer Verbindung mit den gleichen Jinien in der Scheide des Aussengliedes, wie man gelegentlich an den Seiten des ovalen Körpers sehen kann. Sie gehoren auch am Innenglied der Membran desselben an : denn an Präparaten, an denen durch. Einwirkung des reagens der Inhalt des Innengliedes sich von der Membran zurücligezogen hat (Fig. 5 hei $\mathrm{s}_{3}$ ) folgen sie nicht dem Inhalt, sondern bleiben der Membran. Im Inhalt des Innengliedes konnte ich kein Liniensystem mehr nachweisen. 
Die untere Grenze des Innengliedes erscheint fast immer leicht gezähnelt.

Dieser untern Grenze liegen feine verzweigte Fasern an, welche in ihrem Verhalten vollkommen mit dem Bindegewebe der granulirten Schichten übereinstimmen. Diese Fasern bilden eine Verstärkung der membrana limitans externa, welche sich dadurch von dem gleichen Gebilde der anderen Vertebraten unterscheidet.

An das Innenglied der Stäbchen setzt sich unmittelbar ein äusseres Korn. Dasselbe sitzt dem Innengliede meist direct auf, wie beim Frosch, und wie sonst die Zapfenkörner den Zapfen, (Fig. 5, si); gelegentlich ist das Verbindungsstück indess etwas länger (Fig 5, ss) und selten rückt das Korn noch weiter nach abwärts (Fig. 5, s2). In den Fällen, in denen das Korn nicht unmittelbar dem Innengliede aufsitzt, sondern durch ein längeres Verbindungsstück mit ihm verbunden ist, kommt gern eine Retraction des Inhaltes im Innengliede des Stäbchens, wie ich sie soeben erwähnt und Fig. 5 bei sı gezeichnet habe, zu Stande. In dem Stäbchenkorn findet sich ein ovaler Kern; unterhalb desselben nimmt die Stäbchenfaser erheblich an Dicke ab um dann unmittelbar über der äussern granulirten Schicht wieder zuzunehmen und mit einer Anschwellung in diese sich zu inseriren.

Von den Stäbchen unterscheiden sich die Zapfen (Fig. 57) bei nur wenig grösserer Breite durch Kürze und konische Gestalt des Aussengliedes. Sie messen nur 0,0176 Mm., von denen 0,0064 auf das Aussenglied kommen. Dasselbe zerfällt ebenfalls gern in Plättchen und zeigt eine homogene oder leicht streifige Scheide, wie das der Stäbchen. Im Innenglied finden wir einen ovalen Körper von ungefähr denselben Dimensionen wie bei den Stäbchen; aber dieser wird durch Osmium weniger dunkel und enthält gröbere Granula. Unter dem ovalen .Körper zeigt das Innenglied feine Längsstreifen, die auch hier aus denselben Grïnden, 
die ich oben für die Stäbchen anführte, der Membran zuzuweisen sind. Seine untere Grenze ist entweder eine leicht gezackte Linie oder der Zapfen spitzt sich unten etwas zu.

In beiden Fällen setzt er sich in eine Faser fort, welche erst nach einigem Verlaufe, sich verbreiternd, einen Kern aufnimmt und so zum Zapfenkorn wird. Das Zapfenkorn liegt somit hier viel näher an der äussern granulirten Schicht als sonst, ja es ist, mil einem Worte, das Verhalten der Körner beim kleinen Neunauge umgekehrt, wie bei den Säugern. Die Stäbchenkörner verhalten sich wie sonst meist die Zapfenkörner, und vice versa: dabei liegen aber die Zapfenkörner nicht alle in derselben Höhe, sie sind bald weniger, bald mehr von der granulosa externa entfernt, und dem entsprechend wechselt auch das Verhalten ihres unteren Endes. Sitzt das Zapfenkorn der granulosa externa fast auf, so verschmälert sich die Faser nur wenig, um gleich darauf mit breiter Anschwellung in die granulosa sich zu inseriren. Ist das Zapfenkorn weiter von der granulosa entfernt, so entwickelt sich aus inm eine regelrechte Faser, die erst nach kurzem Verlaufe mit einer Anschwellung in die granulosa übergeht. Dabei findet sich der untere Theil der Faser oft breiter, oft ebenso breit und nur selten feiner als der zwischen Korn und Zapfen gelegene Abschnitt derselben.'

Die Elemente der Stäbchen- und Zapfenschicht der Petromyzonten sind mehrfach, wenn auch nur kurz, berücksichtigt worden. Heinrich Müller erwähnt zuerst die Existenz beider Gebilde bei Petromyzon marinus ${ }^{1}$ ). Max Schultze degegen findet boim Flussneunauge nur einerlei

1) Auge des Chamäleons, pag. 25. 
Form, die er früher für Stäbchen zu halten geneigt war ${ }^{1}$ ), neuerdings aber für Zapfen ${ }^{2}$ ) crklärt und in kurze und lange trennte. W. Krause kehrt dem gegenüber ${ }^{3}$ ) zu der Müllerschen Ansicht zurück. Beim Petromyzon Planeri finden sich, wie wir sahen, beiderlei Formen, wenn auch in eigenthümlichen Modificationen. Doppelzapfen sind mir nie begegnet.

Die Limitans externa zeichnet sich, wie oben bemerkt, durch eine feine Schicht retikulärer Bindesubstanz aus, welche sich unmittelbar an die Membranen der Innenglieder anlehnt. In einzelnen Fällen ist diese Lage stärker entwickelt und füllt in dem ganzen obern Viertel der äusscren Körnerschicht den Raum zwischen den einzelnen Körnern. Ausserdem erheben sich stellenweise von der äussern granulirten Schicht zarte Bindegewebsfasern zwischen die Körner und ihre Fortsätze, und diese Fasern besitzen gelegentlich kleine Anschwellungen (Fig, 6 bei b), welche das Ansehen von körnigem Protoplasma haben und bis an die Limitans externa reichen. An andern Stellen nehmen die Anschwellungen zu und enthalten einen grossen ovalen Kern (Fig. 8 und 9 bei b). Wir haben somit beim kleinen Neunauge in der äusseren Körnerschicht ausser den mit den Stäbchen und Zapfen in Verbindung stehenden Elementen auch wahre Bindegewebskörperchen, wenn auch weit seltener als jene, und damit einen neuen fundamentalen Unterschied von den anderen bis jetzt untersuchten Vertebraten. Diese Zellen stehen in continuirlichem Zusammenhange mit der äussern granulirten Schicht, welche aus einem

') Stricker's Gewebelehre. pag. 1009. Anm. 4.

$\left.{ }^{2}\right)$ l. s. c. pag. 34 .

3) I. s. c. 
feinen Netzwerk besteht, dessen Knotenpunkte, meist ein wenig verdickt, leicht den Eindruck von Körnchen machen.

An den Zapfen- und Stäbchenkörnern kann man, wenn auch nicht an jedem Präparate, Inhalt und Membran unterscheiden. Es gelingt dies auch hier wieder namentlich dann, wenn die letztere sich vom Inhalt abgehoben oder umgekehrt der Inhalt sich retrahirt hat. Das ist namentlich in der unmittelbaren Nähe des Kornes häufiger der Fall (Fig. 6) während an der Faser ein gleiches Verhalten schwerer zu constatiren ist. Unmittelbar über der Grenze der granulosa externa zeigen sämmtlicke Fasern eine Anschwellung. Jieselbe ist fron dreieckiger Gestalt, aber sie ist nicht solide, sondern hohl; sie hat mit einem Worte genau die Form eines Kelches. Dem entsprechend kann man eine vordere und hintere Wand und dazwischen einen Hohlraum an ihr unterscheiden (Fig. 7). Die Ränder des Kelches sind ausgezackt und so löst sich derselbe in eine Menge feiner Fasern welche continuirlich übergehen in das Netzwerk der granulosa externa (Fig. 7 und 9). Die kelchartige Anschwellung sitzt an manchen Zapfenfasern fast unmittelbar dem Korn selbst auf, und erscheint der grössern Substanzmenge wegen, meist dunkel gefärbt. Dennoch lässt sich ihre Kelchgestalt wie ihr Verhalten zur granulosa externa leicht feststellen.

Ausser diesem aus dem Kelche der Fasern hervorgegangenen Netz, aus dem sich dann nach oben hin die Bindegewebszellen und Fasern der äusseren Körnerschicht entwickeln, enthält die äussere granulirte Schicht nur wenige nervöse Elemente, die wir unten besprechen wollen.

An die granulosa externa schliesst sich unmittelbar die äussere Lage der Ganglienzellen an. Die Zellen sind im Allgemeinen würfelförmig und stehen fast wie niedere Cylinderepithelien nebeneinander. (Fig, 2 und 10). Sie 
zeigen, isolirl, an der einen, nach Aussen gewandten Seite eine grössere Anzahl von Forlsätzen, an der entgegengesetzten, nach unten oder innen gewandten Seite läuft dagegen nur von einem Winkel ein breiterer Fortsalz aus, welcher sich direct in eine Opticusfaser fortsetzt (Fig. 11). Ihr Kern ist ziemlich gross; das Kernkörperchen steht meist excentrisch.

Diese Elemente bilden aber nicht den einzigen Bestandtheil der Ganglienschicht: zwischen ihnen finden sich allerlei bindegewebige Fasern, welche in directem Zusammenhange mit der granulosa externa stehend, zwischen den einzelnen Ganglienzellen unvollständige Scheidewände bilden (wie in Fig. 12), nnd ferner kleinere Zellen, die in Fig. 110 in situ, in Fig. 8 isolirt dargestellt sind.

Auch diese Zellen setzen sich nach innen in starre Fäden fort; und nach aussen scheinen sie ebenfalls in die granulosa überzugehen. Ihre nach aussen gerichteten Ausläufer scheinen sich direckt in das Netzwerk dieser Schicht aufzulösen (Fig. 8). Ich möchte somit auch diese Elemente als bindegewebige bezeichnen.

Vor Allem interessant ist nun das Verhalten der Ganglienzellen. Dieselben entsenden nach aussen, wie bemerkt und auf Fig. 11 abgebildet, eine grössere Anzahl von Ausläufern. Dieselben müssen, wie ein Blick auf Fig. 10 lelirt, in die granulosa externa eintreten. Nie aber sieht man sie jenseits dieser Schicht wieder zum Vorschein kommen, obwohl die Länge z. B. der grössten Ausläufer der Zelle in Fig. 11 schon den Dickendurchmesser der granulosa externa übertrifft. Andererseits erhält man sehr oft Präparate, in denen einer sonst vollkommen isolirten Ganglienzelle eine Anzahl der kelchförmigen Anschwellungen der Stäbchenoder Zapfenfasern aufsitzen, umgeben von einer grössern oder geringern Menge Substanz der granulirten Schicht 
(Fig. 12 und 13). Auch in diesem Falle sind nur die Anfänge der pheripheren Ausläufer der Ganglienzellen zu sehen, welche direct den Kelchen jener Fasern zustreben.

Endlich glaube ich in einzelnen Fällen im Innern der kelchförmigen Anschwellung noch die Fortsetzung des Ganglienzellenausläufers gesehen zu haben. Bei der Schwierigkeit des Objectes die in der Regel durch Längsfalten der Kelche noch gesteigert wird, kann ich diese Beobachtungen nicht als vollkommen zweifellos hinstellen; sie sind eben nur so sicher, als es ein gutes Immersionssystem 10 von Hartnack gestattet.

Damit würden wir denn über das Verhalten der Ganglien zu den Zapfenfasern und denen der Stäbchen zu einer Anschauung gelangen, die im Ganzen mit den jüngst von Landolt ${ }^{1}$ ) bei Amphibien ver(retenen Ansichten harmonirt; und im Ganzen auch von Max Schultze ${ }^{2}$ ) acceptirt worden ist. Am Zapfen wie Stäbchen hätten wir eine bindegewebige Hülle von einem nervösen Inhalt zu trennen (Landolt, Merkel); diese Hülle geht durch die kelchartige Anschwellung in das wesentlich bindegewebige Netzwerk der äusseren Körnerschicht über, ein Uebergang, der zuerst von Max Schultze ${ }^{3}$ ) vollkommen beweisend geschildert ist, und dann von Landolt als bindegewebig angesprochen wurde. Derselbe Forscher hat auch die Kelchgestalt der Anschwellung bei Amphibien zuerst beschrieben ${ }^{4}$ ). In den Kelch nun senken sich zweiffellos nervöse Elemente hinein, deren Natur nur durch die äusserst günstige Umlagerung der Schichten beim Neunauge so klar zu erkennen ist, und von denen Landolt

1) Schultze's Archiv, Band VII.

2) Schultze's Archiv, Band VII.

) ebendas. Band II.

4) ebendas. VII, Band 84. 
bei den Amphibien nur einzelne zusammenhanglose Partien in Gestalt verschiedener Körner beobachtet hat. Es würde diese Beobachtung zugleich ein zwingender Beweis gegen die Anschauungen W. Krause's und für die von Heinrich Müller und Kölliker zuerst aufgestellte und seitdem von Max Schultze so consequent vertheidigte nervöse Natur der Hauptmasse der Stäbchen und Zapfen sein. Ueber die feineren Verhältnisse von diesen selbst wie sie der letztgenannte Forscher neuerdings ${ }^{1}$ ) beschrieben hat, lehrte uns unser Object nichts Neues.

Mit den beschriebenen Verhältnissen sind indess die Abweichungen, welche die retina unseres Thieres darbietet, noch nicht erschöpft. Auf die secundäre Faserschicht folgt eine zweite Ganglienreihe, die in Fig. 2 dargestellt ist. Die Zellen derselben sind kleiner, als die der äusseren Reihe, sie sind ähnlich angeordnet, wie diese und durch Bindegewebe von einander getrennt.

Ihnen schliessen sich die inneren Körner an, man kann nicht nur zwei, sondern drei Arten derselben unterscheiden: einmal bindegewebige Zellen, welche mit 'eigenthümlichen Verbreiterungen der aus der inneren granulirten Schicht austretenden Radialfasern in Zusammenhang stehen (Fig. 4 b); sodann gewöhnliche nervöse innere Körner, wie sie allen Vertebraten zukommen; endlich aber kleine GanglienZellen, die ein wenig grösser sind, als diese Körner (Fig. 4 a) und in der Richtung ihrer Ausläufer nicht mit ihnen übereinstimmen.

Auf die inneren Körner folgt die primäre Opticusfaserschicht, welche indess, wie oben bemerkt, von wechselnder Stärke ist und ihre Lage bisweilen in den äussern Theilen der inneren Granulusa nimmt.

') Schultze's Archiv, Band VII. 
In der letzteren sieht man schon bei schwachen Vergrösserung en durch Tinction zwei Reihen von Kernen, die eine sehr regelmässige Lage besitzen (Fig. 1). Die eine Reihe liegt hart an der Limitans interna, die andere ungefähr an der inneren Grenze des mittlleren Drittheils der inneren granulosa. Beide Reihen von Kernen zeigen zwei Arten von Elementen: kleinere und grössere. Die erstern gehören sehr kleinen Zellen an, welche mit ihrem Igeringen Leib in continuirlicher Verbindung mit dem rein reticulären Gewebe der granulosa interna stehen (Fig. 3 a). Sie liegen gelegentlich den im Ganzen nicht sehr stark entwickelten Radialfasern eng an, welche an der limitans interna entspringend, die granulosa interna durchsetzen und in die innere Körnerschicht eintreten. Die grossen Kerne dagegen gehören echten verästelten Ganglienzellen an, die in hellen Räumen innerhalb der granulosa interna liegen, und zwar ihre Fortsätze in sie senken, sonst aber in keiner Verbindung mit ihr stehen. In Fig. 3 bei $b$ habe ich eine solche fast unmittelbar an der limitans interna liegende Ganglienzelle abgebildet. In der inneren Zellenreihe der granulosa interna überwiegen die Ganglienzellen, in der äusseren die Bindegewebskörper.

Die limitans interna (Fig. $3 \mathrm{~b}$ ) zeigt wie sonst die nahe aneinander stehenden Anschwellungen der Radialfasern; sie ist ziemlich dünn.

Die Abweichungen, welche die inneren Schichten rom allgemeinen Typus der Vertebraten bilden, sind, wie wir so eben gesehen haben, ebenfalls ziemlich beträchtlich. Es ist mir indess nicht gelungen, über den Verlauf der nervösen Elemente in ihnen irgend wie ins Klare zu kommen. Ich muss deshalb ausdrücklich auf die Möglichkeit hinweisen, dass ausser dem oben besprochenen Znsammenhang der Stäbchen und Zapfen mit nervösen Elementen noch ein anderer existiren kann. Es könnten sich neben den Fort- 
sätzen der äusseren Ganglienzellen noch andere nervöse Elemente in die Kelche der äusseren Körner einsenken, und diese andern Elemente könnten aus den inneren Schichten der Netzhaut stammen. Einen Anhaltspunkt für ein solches Verhalten habe ich freilich so wenig gewonnen, dass ich dasselbe mit Grund als unwahrscheinlich bezeichnen kann.

Die retina des Ammocoetes ist zunächst, obwohl absolut noch ziemlich ansehnlich, so doch viel dünner, als die des Petromyzon. Sie lässt (Fig. 15) deutlich folgende Schichten erkennen:

1. limitans interna

2. granulosa interna mit denselben zwei Reihen von Kernen, die wir in der gleichen Schicht des Neunauges gefunden hatten.

3. opticusfaserschicht

4. innere Körnerschicht

5. Ganglienschicht, bestehend aus zwei Lagen von unvollkommen entwickelten Ganglienzellen, mit schwacher Andeutung einer zwischen ihnen liegenden, secundären Nervenfaserschicht. Eine granulosa externa ist noch nicht deutlich erkennbar.
7. äussere Körnerschicht
8. limitans externa.

Alle Schichten stehen an Ausbildung der Elemente, wie an Dicke zurück hinter denen des reifen Thieres: von einer Stäbchen- oder.Zapfenschicht findet sich keine Spur. Sehr eigenthümlich ist das Aussehen der limitans externa. Wir hatten oben gesehen, dass derselben beim Neunauge eine kleine Menge retikulärer Bindesubstanz beigesellt ist. Dasselbe findet sich nun beim Ammocoetes, nur ist diese 
Bindesubstanz ziemlich mächtig entwickelt, wie die Fig. 16 in starker Vergrösserung zeigt. Es wäre möglich, dass diese Bindesubstanz kleine Fortsätze der äussern Körner; als erste Anfänge der Stäbchen und Zapfen, verdeckt. Doch gelang es mir selbst bei den stärksten Vergrösserungen nicht, dergleichen wahrzunehmen. Das Pigmentepithel entbehrt, entsprechend diesem Verhalten, vollständig der Fortsätze.

Die Netzhaut des Ammocoetes bleibt somit, wie das ganze Auge dieses Thieres auf einem Stadium der Entwickelung, welches von den andern Vertebraten schnell durchlaufen wird, lange Zeit stehen, und die Blindheit des Querders hat ihren Grund nicht nur in der tiefen Lage seines Auges, sondern in dem Mangel an percipirenden Elementen. -

\section{Vom Centralnervensystem.}

\section{Vom Rückenmark.}

(Tafel VIII, Fig. 1.)

Das Rückenmark des kleinen Neunauges liegt in einem von dem skeletogenen Gewebe gebildeten Canal. Aber dieser Canal übertrifft das Volumen des Markes sehr bedeutend, der Raum zwischen beiden ist oben am grössten, unten und an den Seiten kleiner. Er wird ausgefüllt von cinem weichen aber soliden Gewebe, welches sowohl nach dem festen Bindegewebe der skeletogenen Schicht hin, als nach dem Rückenmark zu eine festere Grenzschicht besitzt. Beide Grenzschichten sind von den anliegenden Geweben, der skeletogenen Schicht und dem Rückenmark, leicht in 
continuo trennbar; von dem weichen Gewebe zwischen ihnen jedoch nicht. Sie sind von den meisten Autoren als gesonderte Häute bezeichnet und ilınen die Namen der dura und pia beigelegt worden. Das weiche Gewebe, welches dann als arachnoides betrachtet wird, ist von Stannius ${ }^{1}$ ) zuerst genauer beschrieben worden. Es besteht aus zwei Arten von Zellen : kleinen verästelten Bindegewebskörpern und grossen ovoiden, oft zum Theil mit Felt gefüllten Zellen, die letztern sind im peripheren Theil spärlich oder fehlen auch ganz, während sie im inneren Abschnitt sehr zahlreich sind. Sie gleichen vollkommen den oben besprochenen Elementen der tela subcutanea ${ }^{2}$ ). Zwischen diesen Zellen liegt eine helle, homogene Intercellularsubstanz, radiär durchzogen von breiten, oft geschlängelten, elastischen Fasern, welche dem weichen Gewebe einen ziemlich hohen Grad von Starrheit verleilien, sodass dasselbe auch nach Entfernung des Rückenmarkes nicht collabirt. Ausserdem durchziehen dasselbe Gefässe, welche an der innern Grenzschicht ein reiches Capillarnetz bilden, wie von Reissner ${ }^{3}$ ) beschrieben wurde. Beide Grenzschichten unterscheiden sich nur durch ein Prävaliren von circulären faserigen Elementen von dem weichen Gewebe.

In dem so verengerten Canale liegt nun das platte Ruickenmark. Dasselbe ist wiederholt Gegenstand mehr weniger eingehender Untersuchung geworden. So von Owsjannilio ${ }^{4}$ ), Virchow ${ }^{5}$ ), Stilling ${ }^{6}$ ), Reissner ${ }^{3}$ ) und

1) Zontomie der Fische, pag. 126, Annerk. 2.

2) Tafel I, Figr. 7.

3) Müller's Archiv 1860, pag. 547.

4) Disquisitiones microscopicae de medullae spinalis structura. Dorpat. 1854.

$\left.{ }^{5}\right)$ Neue Untersuchungen über den Ball des Rückepmarkes. Cassel 1859, pag. 1115.

-) Cellularpathologie, 1. Aufl., pag, 244. 
Kutschin ${ }^{1}$ ). Die Irrthümer, welche Owsjannikow's Schilderung enthält, sind in Arbeiten der anderen Autoren, namentlich in der sehr genauen Arbeit von Reissner berichtigt worden und das Ergebniss meiner Untersuchungen reicht nur in Einzelheilen über diese Arbeit hinaus.

In der Mitte der medulla spinalis befindet sich der Centralkanal (Fig. 1). Er ist meist nicht drehrund, sondern von elliptischem Durchschnitte, so dass die Längsachse der Ellipse senkrecht steht. An ihn schliesst sich jederseits die graue Substanz an in Gestalt eines einfachen Hornes, das anfings horizontal zieht, dann aber, entsprechend der Gestalt des ganzen Rückenmarkes, nach unten umbiegt und mit leichter Anschwellung aufhört. Von einzelnen Autoren wurden noch andere Theile mit zur grauen Substanz gerechnet: von Owsjannikow ein Theil der untern Stränge, von Reissner ${ }^{2}$ ) ein vom Centralkanal direct nach unten ziehender Bindegewebszug. Meine Schilderung stimmt mit der von Stilling überein.

Ueber und unter dem Centralkanal liegt eine schmale, graue Commissur. An beide schliesst sich die weisse Substanz an, denn von den Längsfurchen des Rückenmarkes stellt nur die vordere eine ganz flache Furche dar; eine hintere Furche fehlt ganz. Vom Centralkanal (Fig. 1a) aus geht ein feiner Zug von Bindegewebe bis zur Circumferenz des Rückenmarkes. Derselbe ist am Centralkanal ziemlich breit, er stellt hier einen kernhaltigen dreieckigen Aufsatz auf denselben dar, der schon von Reissner beobachtet (1. c. pag. 550) wurde, nach oben zu nimmt er an Breite ab. Dieser Bindegewebszug stellt, wenn auch in weniger ausgeprïgter Form, dasselbe dar, wie die abortiven

1) Schultze's Archiv, II, 525

2) 1. c. pag. 549 . 
Epithelzellen, welche Stieda ${ }^{1}$ ) kürzlich beim Amphioxus an derselben Stelle beobachtet hat: die Narbe der Yerwachsung der Primitivrinne.

In der grauen Substanz unterschied zuerst Reissner ${ }^{2}$ ) drei Arten von Zellen: die inneren grossen Zellen, die äussern grossen Zellen und die kleinen Nervenzellen. Die ersteren liegen jederseits in einfacher Reihe dem Centralkanal unmiltelbar an, in unverkennbarer Aehnlichkeit mit der von Stieda heschriebenen einfachen Reihe grösserer Zellen beim Amphioxus. Sie entsenden eine grössere Anzahl von Ausläufern, und darunter nach Reissner's Beobachtungen solche, welche in die Bahn der obern Wurzel einlenken. Dies Verhältniss, welches ich ebenfalls beobachtet habe, lässt die alte Bezeichnung Stillings, welcher diese grossen Zellen als Hinterhörner ansieht, sehr gerechtfertigl erscheinen. Die grossen Zellen der peripheren Gruppe liegen bald zu mehren, bald einfach im Unterhorn und betheiligen sich an der Bildung der untern Wurzel. Zwischen ihnen finden sich kleinere Nervenzellen, die an der Bildung beider Wurzeln Theil nehmen sollen.

Die weisse Substanz zerfällt, wie Stilling ausgeführt in Vorder-, Seiten- und Hinterstränge oder richtiger in Unter-, Seiten- und Oberstränge. Die ersteren enthalten die grossen Joh. Müller'schen Fasern in Menge, nur ihre periphere Partie besteht aus kleinern Fasern. Die Seitenstränge enthalten in ihrem innern vordern Abschnill ebenfalls Müller'sche Fasern, wenn auch weniger, als die Unterstränge. In den obern kommen nur feine Nervenfasern vor. In der weissen Substanz beobachtele Reissner zuerst stellenweise

8) Studien über Amphioxus lanceolatus. Mem. der Petersburger Academie $\mathrm{V}^{\prime} 1 \mathrm{I}, 19$, No. 7, 1873, pag. 28.

2) 1. c. pag. 553. ff. 
Ganglienzellen, namentlich im lateralen Abschnitt der Seitenstränge (Fig. 1 f.)

Alle Nervenfasern sind marklos (Stannius) ebenso entbehren sie der Hülle. Die colossalen Axencylinder der Müller'schen Fasern haben wiederholt zu einer Annahme eines leigenen blassen Nervenmarkes geführt. Ich kann davon nichts wahrnehmen; die betreffenden Angaben z. B. die von Stilling beruhen auf Retraction des Axencylinders in dem vom Bindegewebe des Rückenmarkes für ihn gebildeten Raume. Wohl aber existirt eine, wenn auch nicht scharf gesonderte Zone in ihnen, welche genau im Centrum liegt und mit Reihen von Körnchen von nicht einmal übermässiger Foinheit durchzogen ist. Dieselben erscheinen bei jeder Behandlung, auch frisch in $1 / 10 \%$ Osmiumsäure; sie gleichen vollkommen den bekannten Körnchen im Innern der Ganglienzellen und sie schwinden nach der Peripherie der Faser zu allmählig.

Alle nervösen Elemente des Rückenmarkes liegen in einem Bindegewebsgerüst, das in ähnlicher Weise wie die granulirten Schichten der Netzhaut gerade hier mit grosser Deutlichkeit sich analysiren lässt. Es besteht nämlich ganz ausschliesslich aus den Deiter'schen Bindegewebskörperchen, deren zahlreiche Fortsätze das streifige Gewebe darstellen, welches Reissner erwähnt. Nur selten konnte ich an lsolationen mit der Rindfleisch'schen Methode ${ }^{1}$ ) (Osmium und Glycerin) diesen Zellen einzelne Körnchen aufliegen sehen, und so bildet offenbar auch hier das Neunauge ein sehr günstiges Object für die Erkenntniss von Verhältnissen, die bei höheren Vertebraten weniger einfach liegen.

Dasselbe hat aber noch eine bemerkenswerthe Eigenthümlichkeit: es liegen nämlich die Kerne der Deiters'schen

1) Schultze's Archiv, VIII, 453. 
Zellen fast ausnahmslos nur in der grauen Substanz. Selbst an den besten Haematoxylin-Färbungen konnte ich mit Sicherheit in der weissen Substanz nur vereinzelte Kerne wahrnehmen und zwar in dem Abschnitt der Seitenstränge, in welchem die Ganglienzellen vorkommen. An diesem Theile findet sich eine feste Verbindung zwischen dem Rückenmark und dem umgebenden Bindegewebe; während an der ganzen übrigen Circumferenz keine organische Verbindung existirt. Diese festere Verbindung präsentirt sich als einfacher Bindegewebsstrang (Fig. 1 l. d.) der von der inneren Schicht des Bindegewebes (der pia mater) sich in das Rückenmark einsenkt. Sie ist nicht continuirlich, vielmehr häufig unterbrochen und stellt so eine Art von ligamentum denticulatum dar. Während an dem übrigen Umfange des Rückenmarkes keinerlei Gefässe in dasselbe eintreten, scheint mir in diesem Bande ein kleines Gefäss in die Substanz des Markes zu dringen. Doch vermag ich das mit Sicherheit nicht anzugeben, da ich keine Injectionen gemacht habe. Die Armuth des ganzen Rückenmarkes an Gefässen, welche Reissner hervorhob, kann ich nur bestätigen: ich habe nie sicher ein Blutgefäss in ihm beobachtet, während nach oben hin in dem verlängerten Mark dieselben leicht zu sehen sind. Der Zusammenhang zwischen dem Rückenmark und dem lig. denticulatum wird übrigens durch chromsaures Kali leicht gelockert, während er an Alcoholhärtungen sich erhält.

\section{Vom Gehirn.}

$$
\text { (Tafel VIII, IX, X.) }
$$

Rathke, Schlemm und d'Alton namentlich aber Johannes Müller haben sehr eingehende Beschreibungen rom Gehirn 
des Flussneunauges geliefert. Das kleine Neunauge stimmt fast in allen Beziehungen damit üherein, nur in wenigen Punkten kann ich jene Beobachtungen vermehren.

Den ersten Abschnitt des Gehirnes (Taf. X, Fig. 1) bilden die bulbi olfactorii; sie bilden einen Kugelabschnitt, der etwas mehr als eine Halbkugel ausmacht, und sind mit ihrer hintern Fläche mit dem zweiten $\mathbf{A b s c h n i t t ~ d e s ~ G e h i r - ~}$ nes (Fig. 1, 1) den Hemisphären, verschmolzen. Diese sind vorn, wie die bulbi olfactorii von einander getrennt. Hinten ragt der dritte Abschnitt des Gehirnes, der lobus ventriculi tertii zwischen sie hinein (Fig. 1, II). und sendet nach oben den sog. schnabelförmigen Fortsatz über ihre Oberfläche median nach vorn. Unten verbindet sich mil dem lobus ventriculi tertii ein Hirnanhang (Fig. $1 \mathrm{H}$ ), den Johannes Miiller als der Hypophysis + infundibulum + tuber cinereum aequivalent bezeichnet. An den lobus ventriculi tertii schliesst sich hinten der vierte Abschnitl des Gehirnes, die eminentia bigemina (III). Sie ruht auf den crura medullae oblongatae ad cerebrum und ist durch einen tiefen Einschnitt vom verlängerten Mark getrennt. Hinter diesem Einschnitt erhebt sich die medulla oblongata fast bis zur Höhe der eminentia bigemina. Sie ist hier oben geschlossen und den schliessenden Querbalken bezeichnet Rathke wie J. Müller als Aequivalent des Kleinhirnes. Auf ilnn folgt oben der sehr ansehnliche sinus rhomboidalis und nach seinem hintern Schlusse geht die medulla oblongata allmählig in das Rückenmark über.

Das Hirn des kleinen Neunauges zeichnet sich somit nur durch relative Grösse der medulla oblongata und dem entsprechend durch den tiefen Einschnitt zwischen dieser und der eminentia bigemina vor dem des grossen aus.

Der vierte Ventrikel mit grossem sinus rhomboidalis nimmt unter dem als cerebellum bezeichneten Querbalken die Form eines T an (Tafel IX, Fig. 2) geht dann dem Ein- 
schnitt entsprechend, in eine längliche Spalte über (Tafel IX, Fig. 3), welche alsbald durch seilliche Ausbuchtung in jede Hälfte der eminentia bigemina wieder die T-form annimmt. Nach vorn setzt sich die Höhle in eine kleinere Spalte fort, der Einbuchtung zwischen eminentia bigemina und lobus ventriculi tertii entsprechend. Im letzteren nimmt die Spalte rasch an Höhe zu, kommunicirt mit dem Hirnanhang und öfnet sich endlich nach oben, entsprechend der obern 0effnung des schnabelförmigen Fortsatzes. Sie sendet dann in die Hemisphären nicht blos, wie Johannes Müller angibt, eine kleine Ausbuchtıng, sondern tritt vielmehr mit einem echten rundlichen Seitenventrikel (Taf. $X$, Fig. 2) in Verbindung, der eine Höhle in der Substanz der Hemisphäre darstellt, und nach Aussen und vorn mit einer Höhle, einem echten Ventrikel im lobus olfactorius kommunicirt.

Auf sagiltalen Schnitlen sieht (Fig. 1, Taf. X) man diesen Ventrikel in dem lateralen Theil der bulbi vom Seitenventrikel getrennt, mehr nach der Mittellinie zu oben mil ihm in Verbindung.

Während somit das Höhlensystem des Gehirnes im Ganzen, wie die äussere Form, mit dem grossen Neunauge übereinstimmt, konnten wir mit Hülfe der neueren Methoden auch in den Hemisphären nnd den Riechkolben Ventrikel auffinden, welche mit dem dritten Ventrikel communiciren. Die Höhlen des Gehirnes sind mit flimmerndem Cylinderepithel ausgekleidet.

Was nun die mikroskopische Analomie des Gehirns anlangt, so habe ich versucht mit Hülfe der Stilling'schen Methode Einiges über dieselbe zu ermitteln. Ich härtete in Alcohol oder in Müller'scher Flüssigkeit und dann noch einige Tage in Alcohol und untersuchte dann die Schnitte in Glycerin. Gelegentlich machte ich Haematoxylin-Färbungen, um über die Ausbreitung der 
Bindegewebskerne ins Klare zu kommen. Karmintinktionen haben mir keine wesentlichen Dienste geleistel.

Die Angaben, welche ich über den Bau des Gehirns machen kann, beziehen sich im Ganzen nur auf die Vertheilung der Ganglienzellen. Sie sind dabei jedoch so wenig abgeschlossen, dass ich nur in einzelnen Fällen Beziehungen zu den Arbeiten ${ }^{1}$ ) über das Centralnervensystem höherer Vertebraten, in specie der Knochenfische, versuchen werde.

Nach vorn verändert das Rückenmark allmählich seine Gestalt, indem es von der Bandform in die eines etwas höheren Ovals übergeht. An der Grenze der medulla obongata treten wichtige Veränderungen in der Anordnung der einzelnen Theile ein (Taf. VIII, Fig. 2). Der Centralkanal nimmt an Durchmesser zu, der Bindegewebsstrang, welcher von ihm aus nach unten ziehend, die beiden unteren Stränge von einander trennt, wird zu einer breiteren Raphe (Fig. 2 R) und die Bindegewebssubstanz unmittelbar am Kanal gewinnt bedeutend an Ausdehnung. Dadurch entsteht eine Zone von gelatinöser Substanz am Centralkanal, in der namentlich durch Haematoxylin die Kerne deutlich hervortreten. Diese gelatinöse Substanz bildet jederseits eine Art von Horn; die nervösen Zellen umgeben sie in einer fast elliptischen Linie, welche mit der Iängsachse quer steht und nur unten durch die unteren Stränge eine Unterbrechung erleidet. Damit haben gleichzeilig die nervösen Zellen bemerkenswerthe Modificationen der Anordnung erfahren. Die centralen grossen Zellen, welche im Rückenmark in einfacher Linie jederseits am Centralkanal verliefen, erscheinen nun als doppelte Reihe, so dass fast ein

2) Stieda, Studien über das Centralnervensystem der Wirbelthiere. Zeitschrift für wissensch. Zoologie, Bd. VIll, pag. 1. XIX, pag. 1. $\mathrm{XX}$, pag. 273. 
jeder Querschnitt deren jederseits zwei aufweist. Die grossen Zellen der Unterhörner haben sich zu ciner vollkommen geschlossenen Gruppe vereinigt (Fig. 2 a), welche je drei bis vier Elemente in einem Querschnitt zeigt und unmittclbar nach aussen von den unteren Strängen liegt. Zwischen ihnen und den centralen grossen Zellen oder den grossen Zellen der oberen Säulen zieht sich ein breiter Bogen kleinerer Nervenzellen hin, in dem nur zu Anfang die eine oder die andere grössere Zelle lagert. In der weissen Substanz lassen sich die lateralen Ganglienzellen (cf. Fig. $1 \mathrm{f}$ ), wenn auch nicht auf jedem Schnitt, noch auffinden und zu ihnen hin zieht von der grauen Substanz aus eine unregelmässige Zone von Kernen bindegewebiger Natur, wie wir dies oben beim Rückenmark gesehen haben. Gleichzeitig zeigen sich aber in der weissen Substanz in doppelter Hinsicht Abweichungen vom Baue des letztern: einmal sieht man an verschiedenen Punkten der Circumferenz Capillaren (Fig. 2 v) in das Mark eintreten, welche nach einfach schlingenförmiger Umbiegung in der grauen Substanz auf demselben Wegc, auf dem sie gekommen, zu dem umgebenden Gewebe zurückkelıren. Ferner aber erscheint ein anfangs schmaler, bald etwas zunehmender Zug querer Nervenfasern, welcher die Raphe kreuzt und zum Theil eine einfache Commissur darstellt, zum Theil aber einen Austausch feiner Nervenfasern zwischen beiden Hälften des Markes besorgt (Fig. $2 \mathrm{c})$.

Von der Zellengruppe der untern Hörner nehmen die Wurzeln des Hypoglossus ihren Ursprung, d. h. sie treten in der Richtung der Fortsätze derselben aus dem verlängerten Mark aus.

Nach vorn hin nimmt nun der Centralkanal rasch an Lumen zu, und gleichzeitig beginnt die Eröfnung desselben sich einzuleiten, indem wie bei den Knochenfischen ron oben her ein tiefer sulcus superior sich in das ver- 
längerte Mark einsenkl, so dass nach wenigen Schnitten schon der Verschluss des Centralkanals nur durch eine schmale Faserbrïcke gebildet wird, welche zwischen ihm und dem sulcus superior sich ausspannt (Fig. 3). Damit hat sich denn auch in der Anordnung der inneren Theile Einiges geändert. Das Epithel des Centralkanales kleidet denselben allerdings noch vollkommen aus: aber die Zellen haben nicht mehr, wie auf der vorigen Figur, eine überall gleiche Höhe, sondern sie nehmen nach oben hin schnell an Durchmesser ab und verstärken hier nur wenig die dem Durchbruch nahe Decke des Kanales.

Die gelatinöse Substanz ist in ähnlicher Weise modificirt, wie die Epithelzellen : nach unten und aussen hin ist sie noch ziemlich reich entwickelt, nach oben ganz geschwunden. Von den Ganglienzellen sind die grossen centralen Zellen oder die der Oberhörner in Grösse wie Zahl reducirt; sie liegen bald einfach, bald zu zweien am Dach des Ventrikels, eingeengt zwischen dem niedern Epithel nnd der Masse der obern Stränge (Fig. $3 \mathrm{~d}$ ). Die grossen Zellen der Unterhörner aber bilden unverändert, ja sogar reicher entwickelt, als vorher, eine abgeschlossene Gruppe zur Seite der untern Stränge (Fig. $3 \mathrm{e}$ ) und von ihnen aus zieht zwischen unteren und Seitenstrang eine reiche Fasermasse in der Richtung unterer Wurzeln nach unten und aussen, um schon auf dem diesem folgenden Querschnitt als Anfang oder hinteres Ende der untern Vaguswurzel die medulla oblongata zu verlassen. Von ihnen zieht bis zur lateralen Grenze des obern Stranges ein Bogen kleiner Ganglienzellen, der auf der Figur nur durch die Maschenräume, in denen die Zellen liegen, angedeutet ist. In der weissen Substanz sind die lateralen Zellen verschwunden; aber die Commissur (Fig. 3 c) ist sowohl in ihren kreuzenden, als in ihren verbindenden, queren Fasern reicher entwickelt. 
Mit dem folgenden Querschnitt ist die Oeffnung des vierten Ventrikels vollendet; indess finden sich davon in sofern Ausnahmen, als sie gelegentlich etwas langsamer sich macht und dann noch eị ähnlicher Schnitt gewonnen werden kann. Damit schwinden nun zunächst allmählig die grossen centralen Zellen oder die Zellen der Oberhörner; sie lassen sich noch vereinzelt an einigen folgenden Schnitten nachweisen, um dann ganz aufzuhören. Die Epithelien des Centralkanales sind in gleicher Modificirung der Gestalt fernerhin anzutreffen; unter ihnen aber zieht ein circulärer, von der Raphe ausgehender Faserzug, der nach vorn zu an Mächtigkeit zunimmt, und auf allen tolgenden Schnitten des verlängerten Markes getroffen wird.

Von den Ganglienzellen nimmt die Gruppe der Unterhörner an Mächtigkeit zu; sie verbreitert sich, erstreckt sich weit in den Bogen der kleinen Ganglienzellen hinein und entsendet reiche Fasern in der Richtung der unteren Wurzeln, welche als hintere Vaguswurzeln austreten. Meist konnte ich drei bis vier aufeinanderfolgende Schnitte anlegen, welche diese Wurzel zeigten. Auf dem dritten derselben (der erste schliesst sich unmittelbar an Fig. 3 an) zeigen sich auch im weiteren Verlauf des Bogens der kleineren Nervenzellen grössere Elemente, welche Fasern nach Aussen entsenden. In der Richtung dieser Faserzüge verlässt die vordere oder obere Wurzel des Vagus die medulla oblongata; sie reicht weiter nach vorn, als die untere oder hintere Wurzel desselben und erscheint somit meist noch auf einem Querschnitte, der bereits die untere Wurzel nicht mehr zeigt (Fig. 4). Dem entsprechend ist auf diesem Querschnitle die Gangliengruppe der Unterhörner etwas geringer entwickelt (Fig. 4 bei e), wenn auch immer noch so mächlig, dass ich eine besondere Dárstellung ihrer grössten Ausdehnung unterlassen zu können glaubte. In voller Entwickelung aber zeigt sich die Zellengruppe, deren 
Ausläufer in der Richtung der obern Vaguswurzeln verlaufen (Fig. 4 bei f), ohne dass ich indess einen sicheren Zusammenhang beobachten konnte. Entsprechend dieser Gruppe erscheint im sinus rhomboidalis ein l.ängswulst, während in der Raphe eine Furche ${ }^{1}$ ) aufgetreten ist. Die quere Commissur in der weissen Substanz ist sehr reich entwickelt; sie erstreckt sich als starker Zug circulärer Fasern von der Raphe durch die Peripherie der Unterund Seitenstränge bis zu dem Zuge der obern Vaguswurzel. Ueber diesem und zwischen beiden erwähnten Gangliengruppen liegen kleinere Nervenzellen, wie oben, in der Zeichnung nur angedeutet.

Mit dem eben genauer besprochenen Bild der Fig. 4 stimmt meist ein nach vorn folgender Querschnilt noch überein: dann aber ändert sich das Aussehen der Schnilte sehr erheblich. Es folgt eine Anzahl von ihnen (ich erhielt meist fünf bis sechs) in denen kein Nerv das verlängerte Mark verlässt, dafür aber im Innern die erheblichsten Veränderungen vor sich gehen. An Stelle der Zellengruppe der Unterhörner tritt zunächst jederseits eine ganz colossale Ganglienzelle. Die grossen Ganglienzellen des Rürkenmarkes zeigen nach Kutschin's und meinen eigenen Messungen in der grössten Dimension 0,06, in der kleinen nur 0,03 $\mathrm{mm}$; die grossen Zellen der Unterhörner in den bis jelzt besprochenen Querschnitten im Mittel ebenfalls 0,06 und 0,03 mm. als Maasse für den grossen und kleinen Durchmesser. Die Zellen der Oberhörner haben im Rückenmark die gleichen Maasse; mit ihrer Vermehrung nehmen sie anfangs nicht ab, dann aber sinken sie auf 0,038 und 0,032 , später gar auf 0.038 und 0,018: die Ganglienzellen der obern seillichen Gruppe (f. in Fig. 4) stehen den grossen nahe; sie erreichen

') Stieda's sulcus centralis longitulinalis. I. c. pag. 30. 
ihre Maasse in einzelnen Fällen, meist aber bleiben sie bei 0,05 und 0,022 stehen. Dem gegenüher zeigen dic grossen Ganglienzellen, welche unmittelbar vor dem Vaguskern liegen, einen Durchmesser von $0,1 \mathrm{~mm}$. in beiden Richtungen, ihr Kern überschreitet $0,02 \mathrm{~mm}$. und ihr nucleolus erreicht mit 0,0065 fast die Durchschnittsgrösse menschlicher Blutkörperchen $(0,0075)$; dieselben liegen, jederseits ungefähr ein Dutzend, aber mit einer Unterbrechung, hiuter und zum Theil nebeneinander. In den jener Wurzel nach vorn folgenden drei Querschnitten habe ich sie stets gefunden: erst je eine, dann je zwei hart nebeneinander. Sie entsenden mehrere Fortsätze nach vorn und hinten wie nach aussen und unten, mit einem Fortsalz aber drängen sie sich zwischen die Müller'schen Fasern der Unterstränge und die Raphe. Auf sie folgen nach oben einige kleinere aber noch ziemlich ansehnliche Elemente, dann ist das obere Ganglion stets gut entwickelt (Fig. 4 bei f). Sonst zeigen sich keine Veränderungen gegen jene Figur.

In den folgenden drei Querschnitten fehlen die colossalen Zellen : nur die kleineren nach oben und aussen sich an sie anschliessenden Elemente sind vorhanden; ebenso die obere seitliche Zellgruppe. In diesen Schnilten aber vollzieht sich eine Kreuzung der bis dahin fast unveränderten Müller'schen Fasern, entsprechend der von Deiters ${ }^{1}$ ) und Stieda ${ }^{2}$ ) beobachteten Kreuzung der Mauthner'schen Fasern der Knochenfische. Zuerst kreuzen sich die kleineren äusseren derselben, dann allmählig auch die immeren, und ziehen nach aussen und oben üher die obere laterale Zellgruppe hinaus zu ganz eigenthümlichen Ganglienzellen, welche hier ihre Lage finden. In Taf. IX, Fig. 1 ist eiu

1) Gehirn und Kückenmark, pag. 190.

) 1. c. pag. 34 . 
sehr günstig gefallener Schnitt durch das Chiasma der Müller'schen Fasern dargestellt. Man sieht bei g. eigen gestaltele Zellen, die nur als Verdickungen jener Fasern erscheinen.

Behandelt man die lebensfrische medulla oblongata nach der oben erwähnten Methóde von Rindfleisch, so kann man aus ihr Müller'sche Fasern isoliren, welche direct in Ganglienzellen übergehen. Diese Zellen, deren Existenz verschiedentlich behauptet worden ist (Owsjannikow, Kutschin, Stieda) zeigen Eigenthümlichkeiten, die mich vermuthen lassen, dass sie doch wohl keinem der citirten Beobachter in guten Präparaten vorgelegen haben. Sie sind nämlich (Taf. 10, Fig. 4) zunächst im Ganzen ziemlich klein : nicht nur im Verhältniss zur Müller'schen Faser, mit der sie oft im Durchmesser übereinstimmen, oft eine nur geringe Anschwellung der Faser zeigen, sondern namentlich im Verhältniss zu den grossen Zellen des verlängerten Markes hinter denen sie mit 0,04 und 0,014 als gewöhnlichen Durchmesser erheblich zurückbleiben. Sodann erscheint die Zelle nur als ganz unbedeutende Anschwellung der colossalen Faser und ihr Kern ist kleiner als die Kerne aller grösseren Ganglienzellen der medullae spinalis et oblongata. F.ndlich aber entwickelt sich aus der andern Seite der Zelle ebenfalls ein Fortsatz, oder dem Bilde entsprechender, die Müller'sche Faser verschmälert sich unter Kerneinlagerung zu einem Fortsalze, welcher nur den dritten Theil der Breite der Faser selbst besitz.t. Trotzdem gehört derselbe zu den breitesten Nervenfasern und er bekleidet sich nach kurzem Verlaufe mit einer kernhaltigen Scheide: ein absolut sicherer Beweis dafür, dass er das Centralnervensystem verlassen hat und zu einem peripheren Nerven geworden ist (Fig. 4 bei a).

Diese Zellen also liegen, nachdem das Chiasma fibrarum 
Müllerianarum vollendet ist, aussen und oben voll der oberen seitlichen Gangliengruppe.

Zugleich treten in den Unterhörnern wieder colossale Nervenzellen von den oben besprochenen Dimensionen auf: erst eine jederseits, dann mehrere. Zwischen jenem Chiasma und dem oberen Schluss des vierten Ventrikels durch den von Rathke und Johannes Müller als cerebellum angesprochenen Querbalken kann man meist drei bis vier Schnitte legen von wesentlich demselben Aussehen. Anfangs zeigen sich auf ihnen noch einige Müller'sche Fasern an der alten Stelle in den Untersträngen : allmählich verschwinden auch sie, während sowohl die colossalen Zellen als namentlich die obere seitliche Gruppe von Ganglienzellen zunehmen und über ihr die Zellen der Müller'schen Fasern lagern. Kurz vor dem Schluss des Ventrikels beginnt neben diesen Zellen die Wurzel des $\mathrm{N}$. acusticus, ohne dass sich ein $\mathrm{Zu}-$ sammenhang zwischen beiden erweisen liesse. Ist der Schluss vollendet (Taf. IV, Fig. 2) so erscheint über dem Acusticus wohl der facialis aus breiteren Fasern bestehend und ohne Ganglienzellen, während von den Ganglienzellengruppen der medulla oblongata nur noch das laterale obere Ganglion gut entwickelt ist ( $f$ ).

In dem schliessenden Querbalken, dem cerebellum, finden sich keine grösseren Ganglienzellen, und die Elemente, die Johannes Müller daher erhalten hat, entstammen somit wohl dem lateralen Ganglion.

Dies Ganglion nimmt im Verlauf der beiden folgenden Schnitte ab, um im dritten (Taf. IX, Fig. 3) ganz geschwunden zu sein. Der erste dieser Schnilte zeigt den Rest der Facialiswurzel; im folgenden findet sich kein abgehender Nerv und erst in der Fig. 3 tritt wieder ein solcher, und zwar der ansehnlichste von allen auf, der Quintus; gleichzeitig hat sich die Höhle des Ventrikels von der T-Form auf eine einfache Längsspalte reducirt. Es ent- 
spricht der Schnitt also ziemlich genau der Einbiegung zwischen eminentia bigemina und medulla oblongata (Taf. 10, Fig. 1). Ueber den Fasern des Quintus und ganz ohne Beziehung zu ihnen trill nun eine Gruppe von Zellen (Fig. 3 bei 0 ) auf, welche mit denen der Fig. 1 vollkommen übereinstimmen und auch in der That ein Bündel breiter Nervenfasern nach innen und unten entsenden, das ich in Hinblick auf die folgenden Zeilen als tractus oculomotorius benenuen kann.

Von den folgenden Querschnillen zeigt nur der erste noch einen Theil der Quintuswurzeln. In ihnen entwickelt sich allmählig die von Joh. Müller beschriebene T-förmige Höhle des eminentia bigemina und das Bündel breiter Fasern zieht allmählig scharf getrennt von der umgebenden Substanz durch die Grösse seiner Fasern nach unten und innen durch die Substanz der crura medullae ad cerebrum weiter, um endlich an der Mittellinie jederseits unter dem aequaductus Sylvii anzulangen. Die folgenden beiden Schnitte zeigen nun eine Kreuzung dieser beiden Bündel unmiltelbar unterhalb jenes Ventrikels; neben den gekreuzten Fasern liegen mittelgrosse Ganglienzellen in grösserer Menge, aussen von ihnen einige grössere Zellen und über ihnen zu den Seiten des Ventrikels in diesem wie den vorhergehenden Schnitten nicht ganz regelmässig je eine colossale Ganglienzelle: und all' diese Elemente vereinen sich jederseits zur Wurzel eines nicht grossen aber aus breiten Fasern bestehenden Nerven : des 0culomotorius (Taf. X, Fig. 1,0). Nach seinem Abgang ist keine breite Nervenfaser mehr zu sehen; die colossalen Ganglienzellen finden sich noch im folgenden Querschnitt, hören dann aber auch auf. Bei dem Reichthum von Elementen, den das Chiasma der tractus oculomotorii darbietet, ist entschuldbar, wenn ich nicht mit Sicherheit angeben kann, ob die breiten Fasern des tractus oculomo- 
torius sich vor ihrem Austritt mit Zellen, etwa den erwähnten lateralen Ganglien, verbinden.

Fast noch besser, als an Querschnitten, kann man auf sagittalen Längsschnitten den $\mathbf{Z u g}$ des tractus oculomorius verfolgen. Schnitte, welche möglichst weit lateral gefallen sind, zeigen dicht vor und über dem Ursprung des Quintus unmiltelbar hinter der Einbuchtung zwischen eminentia bigemina und medulla oblongata hart unter der Oberfläche die Zellgruppe, von der der tractus entspringt. Diesen selbst sieht man an nicht zu dünnen Schnitten in der auf Taf. $X$, Fig. 1 durch die Linie (t) angedeuteten Richtung nach vorn und unten ziehen, um dann nach der Mittellinie hin umzubiegen und sich hier mit dem Tractus der andern Seite zu kreuzen. Auf Sagittalschnitten, welche etwas mehr median gemacht sind, sieht man nun von der vordern Lippe des schnabelförmigen Fortsatzes des lobus ventriculi tertii jederseits einen starken und durch Einwirkung des chromsauren Kali gelb gefärbten Faserzug nach unten und hinten ziehen um ebenfalls in die Gegend der Oculomotoriuswurzeln sich zu begeben. Auf Querschnittsserien ist dieser Zug schwerer zu verfolgen. Line Verbindung mil dem dritten Hirnnerven habe ich nicht sicher beobachtet; doch ist sie mir wahrscheinlich. Jedenfalls verbindet sich der Faserzug der einen Seite mit dem der andern durch eine bogenförmige, nach oben concave Commissur, welche über dem Chiasma des tractus dicht unter dem sulcus centralis longitudinalis liegt.

Was nun den Faserverlauf wie die Ganglienzellen vor der Oculomotoriuswurzel, an der mit den colossalen Zellen die letzten Spuren der Unterstränge des Rückenmarkes verschwinden, anlangt, so kann ich nur üher einen Punkt noch Einiges melden: nämlich über den Verlauf des tractus opticus. Ungefähr in demjenigen Querschnitt des lobus ventriculi tertii, zu dessen Seiten die hinteren Enden der 
Hemisphären sich zeigen, tritt unter diesen an der Aussenseite des lobus jederseits ein breiter Zug heller Fasern auf; er zieht ähnlich dem tractus oculomotorius nach vorn; innen und unten und macht endlich ein reines, vollkommenes Chiasma mil der andern Seite in der Weise, dass der eine tractus vor dem andern verläuft. Nach dem Chiasma, das noch innerhalb der Substanz des lobus ventriculi tertii geschieht, verlässt jeder tractus als $N$. opticus der andern Seite diesen Lappen, um gerade nach aussen zum Auge zu ziehen (Taf. 10, Fig. 3 ).

An Sagittalschnitten kann man den oberflächlich verlaufenden tractus opticus leicht sehen: er erscheint auch hier aut halber Höhe des lobus ventriculi tertii. Nach oben hin strahlen seine Fasern büschelförmig auseinander.

Ueber diesen Punkt finden sich mehrere Angaben, die der eben vorgetragenen Ansicht nicht vollkommen entsprechen. Schlemm und d'Alton ${ }^{1}$ ) berichten: der Sehnerve entspringt an der Grundfläche und dem vordern Ende der mittleren Abtheilung des Gehirnes, ist in seinem Anfang durch eine Commissur mit dem der andern Seite verbunden und hängt mit dem Mark zusammen, was wir als Sehhügel bei dem Gehirn näher bezeichnet haben. Er geht auf jeder Seite quer auswärts zum Augapfel.

Kurz vorher sagen sie: das vordere geschlossene Ende (des von Johannes Müller sog. Hirnanhanges) ist dem Chiasma zu vergleichen. Johannes Müller ${ }^{2}$ ) sagt: "Beide Sehnerven entspringen neben einander und hängen beim Ursprung durch eine Querverbindung zusammen" und ") "die nervi optici (von Bdellostoma) sind, wie auch bei Petromyzon, ohne Kreuzung und entspringen nebeneinander."

') Müller's Archiv, 1858, pag. 265.

2) Neurologie, pag. 3..

${ }^{3}$ ) ebendas. pag. 25 . 
Im Gegensatz dazu meldet Rathke ") „die Augennerven liegen dicht vor der elliptischen Erhöhung an der unteren Hirnfläche, und scheinen allerdings aus jener Erhöhung ihren Ursprung zu nehmen, so dass der rechte aus der linken, der linke aber ans der rechten Hälfte dieser hervorgeht. Uebrigens liegen die platten, bandartigen Augennerven nur übereinander, und zwar der rechte auf dem linken, durchkreuzen sich aber nicht im Mindesten."

Wie sich aus dem vorherrschenden ergiebl, hat Rathke nun zwar darin geirrt, dass er die optici aus dem Gehirnanhang herleitet, und Johannes Miller hat darin mit Recht inn berichtigt. Aber die Existenz einer Kreuzung hat er vollkommen klar ausgesprochen und dieselbe genau beschrieben. Seinen Angaben darüber schliesse ich mich, wie aus meiner Beschreibung hervorgeht, vollkommen an. Die Hirnmasse des lobus oplicus (Taf. $X, 3$ bei a), welche das Chiasma unten deckt, ist zwcifellos die Querkommissur der andern Autoren.

Werfen wir einen Rückblick auf die Beschreibung des Gehirnes, wie ich sie hier gegeben, so zeigen sich nur wenig klare Resultate. Vor allem behält das verlängerte Mark durch die Anordnung der Substanzen in weiterer Ausdeltnung einen dem Rüclienmark ähnlichen Bau als bei anderen Wirbelthieren.

Wir konnten die grossen centralen Zellen der Oberhörner bis weit in die medulla oblongata hinein verfolgen, diejenigen der Unterhörner sogar, wenn auch mit Unterbrechungen, bis fast zum vordern linde des Mitlelhirnes. Wir sahen zwischen beiden eine Gangliengruppe auftreten, welche der substantia reticularis der. Säuger und den aus ihr sich entwickelnden Ganglien entspricht und konnten

1) Pricke, pag. 77. 
dieselbe bis in die crura medullae ad cerebrum nach vorn begleiten. Wir sahen das Chiasma der Müller'schen Fasern, die tractus oculomotorii und das Chiasma der tractus optici in der Substanz der verschiedenen Hirntheile. Aber nur wenige Nervenwurzeln konnten wir mit einiger Sicherheit bis zu Gangliengruppen oder Kernen verfolgen. Dies gelang beim hypoglossus, beim Vagus, und beim oculomolorius sogar doppelt zu einem Kern im crus medullae adcerebrum, zu einem andern in dem vordersten Theile des verläng erten Markes.

Dem stehen bedeutende Lücken in der Verfolgung der andern Hirnnerven gegenüber. Facialis und acusticus konnten mit keinem Ganglion in nähere Beziehung gebracht werden. Es ist mir zwar wahrscheinlich, dass die colossalen Zellen einerseits, die Zellen der Müller'schen Fasern andererseits mit dem facialis in Beziehungen stehen: aber beweisende Bilder konnte ich nicht erhalten und eine Zellgruppe, welche dem Facialiskerne der Säuger entspricht, liess sich nicht auffinden. Ebenso beim Quintus. Auch von ihm vermuthe ich, dass die starke Entwickelung des obern lateralen Ganglion mit ihm in Beziehung steht -wofür namentlich die Stieda'schen Beobachtungen an Teleostiern sprechen - aber erweisen kann ich das nicht.

Wohl aber stehen die Müller'schen Fasern mit dem motorischen Theile des fünften Hirnnerven in directer Beziehung. Wir sahen oben, dass die schmalere Faser der Müller'schen Faser-Zelle sich mit einer Scheide bekleidet - also peripher wird. Fasern von gleichem, immer noch relativ sehr grossem Durchmesser, kann man auf Schnitten, wie in Salpetersäure-Isolationen in der motorischen Partie des Quintus auffinden. Sie sind die-breitesten $(0,012$ nud 0,02) Filemente dieses Nerven, über doppelt so breit als selbst die peripheren Fortsätze der Ganglienzellen (s. unten), und sie verlieren im Verlaufe an Durchmesser, 
indem sie entweder direct sich theilen (Taf. 10, Fig. 5) oder schmale Seitenäste abgeben, in Fig. 6 einen von 0,0048 mm. Durchmesser.

Die Gehiruhäute stimmen im Ganzen mit denen des Rückenmarkes überein: das cerebrum wird von einem weichen Gewebe umgeben, das zwei festere Grenzschichten entwickelt. In dem weichen Gewebe sind die grossen ovoiden Zellen dicht gedrängt und zwischen ihnen kommen zahlreiche vereinzelte Pigmentzellen vor. Nur an einer Stelle zeigen sich andere Verhältnisse: das ist über dem sinus rhomboidalis und noch weiter nach vorn hin bis zum Schnabel des lobus ventriculi tertii. Hier geht die ganze Schicht des umgebenden Gewebes in der Art, dass unter Schwund der weichen Masse beide Grenzschichten sich vereinen, über in einen eigenthümlichen Körper, der aus einem Fachwerk spärlichen Bindegewebes besteht mit niederem Cylinderepithel ausgekleidel. Obwohl dieser Körper leicht zu isoliren ist, hängt er doch in der beschriebenen Wcise direct mit den Häuten des Hirnes zusammen, er ist also als Modification des ganzen, das Cerebrum umgebenden Gewebes zu bezeichnen. Die Gestalt desselben ist schon von Carus, Rathke ${ }^{1}$ ) uud Johannes Müller ${ }^{2}$ ) genau beschrieben worden. Carus und Müller sahen in ihm einen plexus choroideus, Rathke ein cerebellum. Letzterer stützt sich auf den Mangel an Gefässen. Es gelang mir fast immer in den lialten des Bindegewcbsgerüstes Blutgefässe in nalürlicher Injection zu sehen, wenn auch eben nicht zahlreich. Aus der Art des Zusammenhanges mit dem Gewebe der Schädelhöhle folgt, dass im Bereiche dieses Körpers keine andere Gewebeschicht zwischen Hirn und Schädeldach existirt. Von

') Pricke, pag. 75.

2) Neurologie, pag. 30 , 
dem Körper aus senkt sich ein Fortsatz zwischen medulla oblongata und eminentia bigemina hinein, ein anderer dringt, wie Rathke beschrieben, in die 0effnung des lobus ventriculi tertii. Ueber der vordern Lippe des schnabelförmigen Fortsatzes geht der Körper wieder über in das von zwei Grenzschichten umgebene weiche Gewebe.

\section{Vom peripheren Nervensystem.}

(Tafel IX, Fig. 4 und 5).

Rathke ${ }^{1}$ ) und Johannes Müller ${ }^{2}$ ) und Schlemm und d'Alton ${ }^{3}$ ) hatten nur an den vordersten Spinalnerven den Ursprung mit zwei Wurzeln beobachten können. Erst neueren Untersuchern ( 0 wsjannikow) gelang es, dieselben allgemein zu beobachten. Eines Spinalganglion geschieht

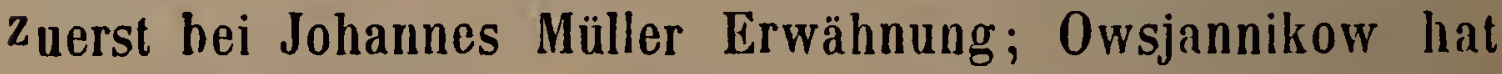
auch hier die Verbreitung derselben über sämmtliche Spinalnerven zuerst beobachtet. Die Ganglien liegen unmittelbar der skeletogenen Schicht aussen an; und zwar zum Theil dem ramus dorsalis, zum grösseren aber an der Theilungsstelle der Spinalnerven. Alle rami dorsales liegen, wie dies Schlemm und d'Alton von denen des vordersten Abschnitles des Rückenmarkes angegeben haben, dem N. lateralis aussen unmittelbar auf.

Die Zellen der Ganglien sind am Ganglion Nervi lateralis von Stannius ${ }^{4}$ ) genaner untersucht worden.

2) Pricke, pag. 78.

2) Neurologie, pag. 28.

') l. c. pag. 272 .

4) Göttinger Nachrichten, 1851, No. 18. pag. 237. Das periphere Nervensystem der Fische, 1849. pag. 94. 
Derselbe fand an ihnen, übereinstimmend mit dem Verhalten der andern Fische, constant zwei Fortsätze. Von diesen Fortsätzen aber war der eine, der centrale, schwäche als der andere, periphere. Ein gleiches Verhalten fand sich bei Caranx, Belone und Accipenser.

Diese für die Auffassung der fanglienzellen zweifellos sehr bedeutungsvolle Beobachtung ist in neuester Zeil wie mir scheint, nicht genügend berücksichtigt worden. Und doch lässt sie sich nicht nur für das Ganglion Nervi lateralis, sondern für sämmtliche Spinalganglien wie für diejenigen der Kopfnerven ${ }^{1}$ ) sehr leicht' bestätigen, und zwar mit Hülfe der oben besprochenen Salpetersäuremaceration. Leider aber beschränken sich die Dienste dieser Methode auf die marklosen Nerven der Cyclostomen bei markhaltigen Nerven gelang es mir nicht, befriedigende Präparate zu gewinnen.

Behandelt man ein Neunauge in der angegebenen Weise mil Salpetersäure, so kann man leicht die Ganglien der Kopfnerven wie die der spinalen isoliren. Durch Klopfen mil Glasstab oder Finger zerfallen sie in ihre einzelnen Zellen, am leichtesten das grosse Ganglion des Quintus; weniger leicht die übrigen. Die Isolationen, welche man so erhält, sind vorzüglich. Die beiden Ausläufer der Ganglienzellen sind meist erhalten und zuweilen in einer Ausdehnung, die den Durchmesser der Zelle um mehr als das $L$ wanzigfache übertrifft. Die Zellen sind von verschiedener Grösse: neben den grossen Elementen kommen bedeutend kleinere vor. Die $\Lambda$ usläufer entspringen meist genau polar entgegengesetzt. Aber bei andern Zellen, namentlich denen,

') Nur die Ganglienzellen des Acusticus habe ich nicht untersucht. 
welche die von Auerbach sogenannte opponirte Stellung zeigten, rückten sie näher aneinander, so dass der Zellkörper dem einheitlichen Nerven gleichsam aufsitzt. In allen Fällen aber zeigen beide Fortsätze einen vollkommen durchgreifenden Unterschied: der eine (Taf. IX, Fig. 4 a) ist schmal, wenig gekörnt und scheint sich nur, so zu sagen, an den Leib der Zelle zu inseriren; der andere aber (Fig. 4 b) ist bedeutend breiter, slärker gekörnt, er erscheint als directe Fortsetzung des Zellleibes. Dabei werden beide ebenso wie die Zelle selbst von der bekannten endothelialen Scheide gleichmässig überzogen. Von den Fortsälzen nun ist der schmale derjenige, welcher vom Centralnervensystem kommt. Der breite ist nach der Peripherie zu gerichtet. Eine Verästelung kommt in der Nähe der Zellen bei keinem von beiden Ausläufern vor.

Dies Verhältniss gilt für sämmtliche an Hirn- und Rückenmarksnerven liegende Ganglienzellen. Es entspricht dem Verhalten nervöser Zellen zwar nicht der Spinalnerven der höheren Vertebraten, sondern der äusseren Körner der retina und zwingt uns jedenfalls in der Ganglienzelle mehr zu suchen, als einen Knotenpunkt von Fibrillenbündeln.

Die peripheren Nerven in den einzelnen Organen habe ich, soweit ich Beobachtungen über sie gemacht, bei diesen erwähnt. Nur eines Ortes will ich noch hier Erwähnung thun, an dem ihre Verästelung Eigenthümlichkeiten darbietet: das sind die Flossen. In den gröbern Nervenstämmen derselben finden sich nämlich zahlreiche Ganglienzellen. Dieselben sind ganz erheblich kleiner, als die eben erwähnten Zellen der Spinalganglien, aber es sind doch wohl characterisirte Ganglienzellen (Taf. IX, Fig. 5). Sie sind meist bipolar: doch kommen davon nicht selten Ausnahmen vor, indem nach der einen und zwar nach der peripheren Seite hin, zwei Ausläufer die Zelle verlassen oder der eine Ausläufer sich alsbald in zwei Aesle theilt. Auch diese 
kleinen Ganglienzellen verhalten sich im Allgemeinen den oben besprochenen darin gleich, dass ilır centraler Ausläufer erheblich dünner ist, als der periphere. $\Lambda$ ber das gilt hier nicht ohne Ausnahmen; es fanden sich auch Elemente, an denen ein solches Verhalten nicht zu beobachten war. Die Untersuchungsmethode ist die gleiche, wie oben.

\section{Vom Lymphgefässsystem.}

(Tafel $X$, Fig. 7 bis 10. )

Oben habe ich eines subcutanen "Lymphraumes" Erwälınung gethan. Dieser Raum liegt unter der Haut des Kopfes, den er unmittelbar hinter den Mundpapillen vollständig umgreift. Er erstreckt sich oben weiter als unten, denı während er unten auf den vordersten Theil der Mundhöhle beschränkt bleibt, reicht er oben (Taf. 10, Fig. 7) bis zur Schädelkapsel, so dass der Nasengang ihn durchsetzt. Nach innen reicht er zwischen beide Labialknorpel hinein, bis zur mucosa des Mundes. Der Raum ist durchzogen von mehreren Bindegewebsbalken (Taf. Il, Fig. 1), von denen sich namentlich zwischen dem vordern Ende des hintern Lippenknorpels (Fig. 7 t. p) und der Dorsalfläche des vordern eine grössere Anzahl membranartig ausspannt. Er wird von einfachem Endothel ausgekleidet und zeigt somit soviel Uebereinstimmung mit den Lymphräumen der Amphibien, dass man ihn wohl auch hier zu dem gleichen Systeme in Beziehungen bringen kann.

Injicirt man diesen Raum, so füllt sich zünächst cin grosser Behälter in der Bauchhöhle, welcher mit dem von Ratlke ${ }^{1}$ ) bei der Pricke beschriebenen in Lage, Form und

1) Pricke, pag. 49. Beim kleinen Neunauge vermisste ihn Rathke. Querder, pag. 101. 
Bau vollkommen übereinstimmt. Ansserdem füllt sich eine Reihe von Gefässen in einzelnen Organen, deren ich kurz Erwähnung thun will. Endlich dringt die Masse in die Venen und in's Herz.

Zuerst füllt sich die Reihe der Mundpapillen und es zeigt sich, dass (Fig. 8) in ihnen weite Gefässe injicirt sind, die mit einem engmaschigen basalen Geflecht in Verbindung stehen, von dem aus in die Muskulatur weite Gefässe eindringen. Ferner füllt sich an einigen Stellen der Haut des Kopfes ein Netz weiter Gefässe, welche unterhalb der Pigmentschicht liegen.

All' diese Gefässe machen ihrer Gestalt, Weite und Anordnung wegen durchaus den Eindruck von Lymphgefässen. Aber einmal findet sich an Thieren, welche in Alcohol getödtet sind, im abdominalen Blutbehälter, wie im subcutanen Raum namentlich zwischen beiden Labialknorpeln coagulirtes Blut, in Uebereinstimmung mit den Angaben von Rathke und Johannes Müller ${ }^{1}$ ) und sodann standen mir, als ich an die Untersuchung dieser Verhältnisse ging, keine lebenden Thiere ${ }^{2}$ ) mehr zur Verfügung, so dass ich keine Injectionen des Blutgefässsystemes mehr machen konnte. Ich traue mich demnach nicht zu entscheiden, ob die injicirten Gefässe in der That Lymphgefässe sind, wenngleich ihre Form dafür spricht, und kann überhaupt über das Verhalten des Blutgefässsystemes zu dem Lymphsystem keine Auskunft geben.

Diese Angaben können somit nur dazu dienen, der Vermuthung von Johannes Müller, dass der Blutbeliäller der Bauchhöhle vielleicht zugleich ein Lymphraum sei, eine Stütze zu verleihen, ohne die wichtigen Fragen, welche sie anregt, sonst wesentlich zu fördern.

1) Ich hatte früher bei einer Anzahl frischer Exemplare EinstichInjectionen in den Kopfraum gemacht. 
Erwähnea will ich noch, dass bei Einstich in die Flossen sich in diesen ebenfalls ein weites System von Gefässen füll, das ich von einer Papillen-besitzenden und einer sie entbehrenden Stelle in Fig. 9 und 10 abgebildet habe.

\section{S c h l u s s.}

Es würde überflüssige Wiederholung sein, wollte ich zum Schluss die Ergebnisse dieser Untersuchungen zusammenstellen. Nur einen Punkt möchte ich noch mit einigen Worten besprechen: nämlich die Unterschiede zwischen Larve und Geschlechtsthier. Die wichtigen Differenzen im Bau des Skcletes, des Respirationsapparats und des Mundessind seit den Arbeiten Rathke's und Johannes Müller's bekannt. Diesen schliesst sich das Verhalten des Darmes an, welcher bei der Larve weit voluminöser, besser entwickelt ist, als nach der Metamorphose. Damit stehen die Unterschiede im Aussehen der Leber, die lange bekannt sind, offenbar in Beziehung. und wir fanden in dem Epithel der Mundsegel dazu noch einen provisorischen Kauapparat, welcher später verloren geht. Voul den Sinnesorganen erreichen Nase und Haut im Wesentlichen schon bei der Larve ihre volle Ausbildung. Dic Seitenorgane wie die einzelnen Sinneszellen der Haut sind bei illr vollkommen entwickelt und wenn auch nach der Hetamorphose die letzteren in den Lippenpapillen und den Erhebungen auf der ersten Rückenflosse Orte eines häufigeren Vorkommens gefunden haben, so ist das nur eine quantitative Differenz.

Im Geruchsorgan kommen die charakteristischen Riechzellen dem Querder ebenso zu, wie dem Neunauge; nur sind sie beim letzteren in der faltenreichen mucosa zahlreicher, als bei der Larve, deren ethmoideum ebenfalls kleiner ist; als das des Geschlechtsthieres. Ganz anders verhält sich das Auge: dasselbe bietet in der Entwickelung 
seiner Häute, namentlich der Iris und der membrana Descemetii, mehr noch in der Ausbildung der retina prägnant embryonale Verhältnisse und erreicht erst nach der Metamorphose seine volle Entwickelung. Hand in Hand damit geht seine Vergrösserung und die Metamorphose des ersten Seitenmuskels. Endlich fehlt dem Querder jede Andeutung des subcutanen Lymphranmes.

Ueber das Gehörorgan und Uro-genital-Apparat konntc ich meine Untersuchungen nicht mehr ausdehnen, und zwar, weil die Neunaugen, wie August Müller bemerkt, bald nach der Laichzeit sterben und dann nur noch die Larven, aber keine Geschlechtsthiere mehr zu finden sind. Wenn ich nun auch durch Conservirung in verschiedener Weise diesem Uebelstande etwas vorgebeugt hatte, so lässt sich doch an conservirten Exemplaren nie so arbeiten, wie an frischen und es scheint mir darum geboten, die Arbeit abzubrechen. Ich verbinde damit einen vorläufigen Abschluss, weil ich nicht mit Sicherheit eine baldige Wiederaufnahme derselben vorausbestimmen kann.

Ich betone somit zum Schluss ausdrücklich, dass diese. Untersuchungen entfernt nicht auf den Titel einer Monographie Anspruch machen. Wohl aber war es mein Plan, eine möglichst vollständige Bearbeitung eines niedern Wirbelthieres zu liefern und ich wählte dazu der Häufigkeit seines Vorkommens in unseren Schwarzwaldbächen halber auf deu Rath des Herrn Hofrath Ecker das kleine Neunauge: aber der im Sommer bald eintretende Mangel an frischen Thieren hat die empfindlichsten Lücken hervorgerufen. Ich musste nicht nur, wie eben bemerkt, von der Bearbeitung einiger Organe ganz absehen: auch andere sind aus dem glcichen Grunde nur ganz aphoristisch behandelt worden. So namentlich das Gefässsystem, das Gehirn, ferner der Bau der Iris des Geschlechtsthieres u. a.m. Diese Mängel bitte ich für diesmal entschuldigen zu wollen. 


\section{Erklär'ung der Abbildungen.}

\section{Tafel I.}

Fig 1 bis 3 Anordnung der Epithelgruben beim Neunauge.

Fig. 1 Dorsal-, Fig. 2 Lateral-, Fig. 3 Ventral-A usicht.

a. Reibe auf der Oberlippe; aus ihr entwickelt sich

b. die Hauptseitenlinie, welche hinter dem Auge bei

$b_{1}$ fortzieht und bei

$b_{2}$ bis zum hintern Ende der ersten Rückenflosse reicht.

c. die andere Reihe, welche aus der Oberlippenreihe hervorgeht und bei

$c_{1}$ ventral his zum Ende der Kiemenlöcher reicht.

d. erste dorsale Querreihe,

$d_{1}$ zweite dorsale Querreihe aus der

$d_{2}$ die Rückenlinie hervorgeht, welche bei

$d_{3}$ zum Schwanze reicht.

e. untere Seitenlinie.

Fig. 4 Dorsalansicht des Vordertheils vom Querder Bezeichnungen wie oben.

o. Auge, verdeckt von Haut und Unterhautgewebe.

Fig. 5 Frontalschnitt durch eine Kopf-Epithelgrube vom Querder $1000: 1$ nach Härtung in Osmiumsäure.

a. Sinneskegel.

Fig. 6 Frontalschnitt durch eine Epithelgrube vom Schwanz des Neunauges $300: 1$

a. Sinnes-Kegel.

Fig. 7 tiefste Epithelschicht eines Epithelkegels des Seitenorganes vom Ammocoetes: Maceration in $1 / 10 \%$ Osmium. $1000: 1$.

Fig. 8 obere Epithelschicht ebendaher vom Neunauge. Methode und Vergrösserung dieselben.

Fig. 9 mittlere Zellenlage ebendaher. Kopfgrube des Ammocoetes.

Fig. 10 Isolirte Zellen aus Seitenorganen des Querders. 

a. deckende Epithelzelle
b. Sinneszelle
c. stützende Epithelzellen der tiefsten Schicht.

Fig. 11 Isolirte Hautzellen des Querders.
a. aus der tiefsten
b. aus den mittleren
c. aus der obern
d. kleine Rundzelle; ebensolche an c. in situ.

Bei den Fig. 9, 10 und 11 Methode und Vergrösserung wie bei 7.

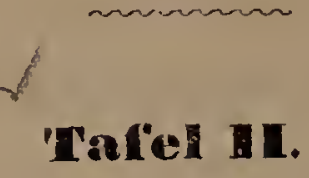

Fig. 1. Kopfgrube des Neunauges im Frontalschnitt 500: 1.

Härtung in Usmiumsäure.
a. Sinneskegel
b. corium
n. Nerv, angeschnitten
$\mathrm{n}_{1}$ derselbe, durchtretend durch das corium
1. subcutaner Lymphraum
v. Blutgefäss.

Fig. 2 Haut vom Neunauge von oben gesehen. An einigen Zellen sind die Poren der cuticula eingezeichnet; auf einigen vereinzelte Wimperhaare, frisch. $1000: 1$.

Fig. 3 einzelne Zelle mit Wimperhaaren aus der obersten Hautschicht isolirt. 1000:1. Maceration in 1/10\% Osmiumsäure.

Fig. 4 haartragende Sinneszelle von einer Mundpapille des Neunauges in situ. Frisch in 0,6\% Kochsalz. 1000:1.

Fig. 5 ebensolche Zellen ebendaher von oben gesehen $1000: 1$. Nan sieht auf den einzelnen Zellen zwischen den grossen Epidermiszellen die optischen Querschnitte der Haare. firisch wie oben.

Fig. 6 Isolirte haartragende Zellen aus der Haut der Mundpapille, nach 24stündiger Maceration in $\% 10 \%$ Osmiumsäure. 1000:1.

Fig. 7 subcutanes Gewebe vom Halse des Neunauges. 500:1. bei a grosse ovoide Zellen mit Fett b. Bindegewebskörperchen. 


\section{Trfel 111.}

Fig. 1 Papille der ersten Rückenflosse vom Neunauge nach 24stündiger Behandlung mit Essigsäure von 0,2\%. Dic Nerven gehören der dem Beobachter zugekehrten Hälfte an; die der tiefern Hälfte sind fortgelassen. $1000: 1$.

Fig. 2 Dasselbe frisch um die den Simneszellen aufsitzenden Haarbüschel zu zeigen. In Kochsalz von 0,6\%, 1000:1.

Fig. 3 bis 8 in zehnfacher Vergrösserung wach Maceration in Salpetersäure.

Fig. 3 Muskelplatte der Rumpfmuskeln; dorsal.

Fig. 4 Platte rlesselben Segmentes, ventral.

Fig. 5 ventrale Platte vom Neunauge, vorderstes Segment.

Fig. 6 Flossenmuskelplatte.

Fig. 7 Platten des vordersten Abschnittes vom Seitenrumpfmuskel.

a. des oberen Theiles

b. des kleineren unteren, dem Auge aufliegenden Theiles.

Fig. 8 Platten desselben Muskels vom Querder

a. des obern Theiles

b. des mittleren, dem Auge aufliegenden Abschnittes

c. des grossen untern Theiles.

Fig. 9 Theile von Kiemensackmuskeln vom Neunauge, 1000: 1 .

Fig. 10 Herzmuskel vom Qtierder. Kalimaceration $500: 1$.

\section{Trafel 1 v.}

Fig. 1 linke Hälfte des Schädelknorpels von Petromyzon unmittelbar hinter der Nasenkapsel frontal geschnitten. Bei a heht sich ein rundliches Knorpelstück deutlich ab, welches genau der Knorpelleiste des Querders entspricht.

Fig. 2 Knorpeliger Schädelantheil des Ammocoetes, SillpetersäureMaceration. Geringe Vergrösserung.

pr. Gehörkapsel

a. Fortsatz vor derselben

b. Basalknorpel

ch. Anfang der Chorda dorsalis.

Fig. 3 Flächenansicht des Mundsegel-Epithels vom Ammocoetes: von der medialen Fläche. Man sieht den optischen Querschnitt des Cuticularfortsatzes in der Mitte jeder Zelle. 1000 : 1. Maceration in dünner Osmiumsäure. 
Fig. 4 Dasselbe. Ansicht der Zellen im Profil. bei a solche mit niedrigem, bei $b$ mit höherem Cuticularfortsatz.

Fig. 5 Querschnitt durch den Munddarm des Ammocoetes. Osmiumhärtung. $900: 1$.
s. serosa
m. muscularis
p. Falten der Schleimhaut
e. Epithel derselben.

L'ig. 6 Querschnitt durch den Mitteldarm des Ammocoetes. Härtung in Müller'scher Flüssigkeit $300: 1$.
s. serosa
m cavernöse Schleimhaut
m. a. äussere, Quermuskulatur
m. 1. innere Längsmuskulatur
g. Ganglienzellen
M. Stamm der A. mesenterica.
A. Ast derselben
V. Vena portae.

Fig. 7 Darmgefässe des Ammocoetes von der Fläche geselıen in natürlicher Injection. $500: 1$.

A. Arterie, oberflächlicher verlaufend als

V. das Netz der capillaren Venen.

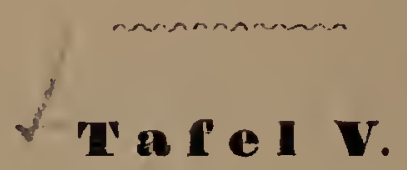

Fig. 1 Anfang des Mitteldarmes vom Ammocoetes bei schwacher Vergrösserung.

m. Munddarm

d. ch. Gallengang

p. Pancreas

d. Mitteldarm.

Fig. 2 Epithelzellen aus dem Mitteldarm vom Querder. 1000:1.

a. Flimmerzellen in Müller'scher Flüssigkeit

b. Cuticularzellen frisch in dümner Osmiumsäure.

Fig. 3 scheinbare "Becherzellen" ebendalier. $500: 1$.

Fig. 4 Gangliengeflecht vom Mitteldarm des Querders 500:1.

Fig. 5 Isolirte Ganglienzelle mit Scheide ebendaher vom Neunauge. Salpetersäure-Maceration. $1000: 1$. 
Fig. 6 Frontalschnitt durch die Leber des Ammocoetes. ca. $200: 1$.

s. serosa

v. p. Pfortader

1. ch. Gallengänge.

Fig. 7 Isolirter Leberschlauch vom Ammocoetes. Salpetersäurepräparat. $1000: 1$

Fig. 8 Dasselbe $500: 1$. Bei beiden:

a. Gallengang $a^{2}$ sich abzweigender Gallengang

b. Uebergangs- oder Schaltstiick

c. Leberschlauch

d. blinde Enden vom Leberschlanch.

e. anastomosirende Aeste eines solchen.

\section{Tafe 1 vi.}

Fig. 1 Frontalschnitt durch die Nase des Neunauges.

Fig. 2 Dasselbe vom Ammocoetes. Schwache Vergrösserung.

b. Schädelknorpel

e. Siebbein

n. Nasengaumengang

s. untere sagittale Falte

$\mathrm{s}^{1}$ obere sagittale Falte.

Fig 3 isolirtc Zellen aus der regio olfactoria des Neunauges. Maceration in ${ }^{1}{ }_{10}{ }^{\circ}{ }_{0}$ Osmiumsäure. $1000: 1$.

a. Flimmerepithelien

b. Ricchzellen.

Fig. 4 Theil eines Querschnittes durch das Auge von Petromyzon. Schwache Vergrösserung.

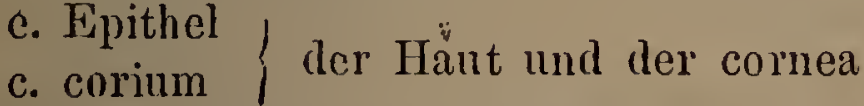

m. D. membrana Descemetii.

ch. choroidea

I. Iris

m. Muskeln

r. retina

l. Linse.

Fig. 5 Querschnitt durch das Auge des Ammocoetes. Schwache Vergrösserung.

c. Lederhaut und Bindegewebe der cornea (das Epithel ist abgefallen). 
s. c. subcutanes Gewebe unter der cornea.

o. Bindlegewebe der Orbitalwand.

ch. chorioides und retinalpigment

D. verdickte membrana Descemetii

m. Muskeln

1. Iris

r. retina

1. Linse.

Fig. 6 Vordere Theil der retina resp. Iris des Querders. 1000: 1.
a. äusseres|
i. inneres $\}$ Blatt der Augenblase
ch. chorioidea
i. ch. bindegewebiges Blatt von der choroidea zur Iris,
D. Anfang der membrana Descemetii.

\section{Tafel vil.}

Fig. 1 Schnitt durch die retina vom Petromyzon an der Eintriltsstelle des opticus. Schwache Vergrösserung, etwa 100 : 1. Härtung in Müller'scher Flüssigkeit-Tinction mit Haematoxylin.

1. membrana limitans interna

2. innere graunlirte Schicht

3. Opticusfaserschicht

4. innere Körner

5. Ganglienscliicht

6. äussere Granulosa

7. äussere Körner

8. limitans externa

9. Stäbchen und Zapfen

10. Pigmentepithel.

Fig 2 Die fünfte, Ganglienzellenschicht, bei stärkerer Vergrösserıng 600:1 Härtung in Müller'scher Flüssigkcit. Man sieht die beiden Reihen von Ganglienzellen, die höleren peripheren bei a, die kleineren inneren bei c, dazwischen die sekundäre Gehirnschicht bei b, und den Anfang der inneren Körner bei d.

Fig. 3 bis 14 nach Macerations-Präparaten in $1 / 1, \%$ Osmiumsäure.

Fig. 3 aus der granulosa interna 1000: 1.

a. Bindegewebige Zelle in Verhindung mit dem Netzwerk der granulosa.

b. Ganglienzelle hart an der limitans interna. 
Fig. 4 aus der inneren Körnerschicht $1000: 1$.

a. kleine Ganglienzelle

b. zwei Bindegewebszellen in Verbindung mit einer Verbreiterung der Radialfasern.

Fig. 5 Stäbchen $s$ und Zapfen z. Nähere Beschreibnng im Text. $1200: 1$.

Fig. 6 Stäbchenkorn, dessen kelchförmige Anschwellung nur zum Theil erhalten ist, und sich in das Maschenwerk der granulosa externa auflöst. Bei b erhebt sich aus dieser ein bindegewebiger Fortsatz in die äussere Körnerschicht. $1200: 1$.

Fig. 7 Zapfenkorn mit Kelchanschwellung, die sich zum Theil in die granulosa externa auflöst. $1200: 1$.

Fig. 8 Stïbchen, dessen Kelch mit der granulosa externa in Verbindung steht. In dieselbe geht ein Bindegewebskörperchen (a) aus der obern Ganglienzellenschicht über; aus ilnr erhebt sich ein solches (b) in die äussere Körnerschicht. $1200: 1$.

Fig. 9 Zapfenkorn in ähnlichem Verhalten, wie das Stäbchenkorn der Fig. 8. $1200: 1$.

Fig. 10 Obere Ganglienzellenreihe mit Bindegewebskörperchen, granulosa externa und Kelchen der äusseren Körner. 500:1.

Fig. 11 isolirte Ganglienzelle der peripheren Schicht. 1200:1.

Fig. 12 und 13 dasselbe mit aufsitzenden Kelchen der Körnerfasern. $1200: 1$.

Fig. 14 dasselbe, im Kelch kann man den Ganglienzellenfortsatz noch unterscheiden.

Fig. 15 retina des Ammocoetes nach Härtung in Müller'scher Flüssigkeit und Tinction. Bezeichnung wie Fig. 1. Vergrösserung ungefähr 300 .

Fig. 16 äussere Körner und limitans externa des Ammocoetes $1200: 1$. frisch in diinner Osmiumsïture.

\section{Ta e I var.}

Fig. 1 Rückenmark vom Petromyzon. Härtıng in Kali bichromicum, Tinction mit Haematoxylin. $50: 1$.

r. s. r. i. obere und untere Wurzel

a. Narbe der Primitivrinne

b. Epithel des Centralkanales.

c Reissner'scher Faden

d. centrale grosse Zelle 
e. äussere grosse Zellen

f. Zellen in den Seitensträngen

1. d. ligamentum denticulatum,

In der grauen Substanz sind die Bindegewebskerne, im Präparat gefirbt, schwarz eingezeichnet. Der seitliche Theil (laterale Zellen und Band) sind nach einem andern Präparat gezeichnet, das, nach Alcoholhärtung, carminirt war.

Fig. 2 Schnitt durch die untere Grenze der medulla oblongata 50:1.

Methode wie oben.

d. centrale grosse Zellen

e. äussere grosse Zellen

R. Raphe

c. Commissur

o. Capillaren.

Fig 3 Schnitt durch die medulla oblongata kurz vor der Eröffnung des sinus rhomboidalis. $50: 1$.

(l. centrale grosse Zellen

e. äussere grosse Zellen (Unterhörner).

c. Commissu r

v. Capillarschlingen.

Fig 4 Schnitt durch die medulla oblongata vor der hintern Vaguswurzel. $50: 1$.

a. Circularfasern von der Raplıe ausgehend.

e. äussere grosse Zellen (Unterhörner)

f. oberes laterales Ganglion

c. Commissur.

\section{$\sqrt{\mathbf{T} a \mathbf{r}} \mathbf{1} \mathbf{x}$}

Fig. 1 Schnitt durch die medulla oblongata zwischen Vagus und acusticus. $50: 1$.

a. Circularfasern

f. oberes laterales Ganglion

g. Zellen der gekreuzten Müller'schen Fasern.

Fig. 2 Schnitt durch die mednlla oblongata vor dem sinus rhomboidalis. Schwach vergrössert.

f. oberes laterales Ganglion. 
Fig. 3 Schnitt durch den vordersten Theil der medulla oblongata.

V. Quintuswurzeln

o. Zellen, von denen der tractus oculomotorius entspringt.

Fig. 4 Ganglienzelle aus dem Ganglion Gasseri. Salpetersüuremaceration. $1000: 1$

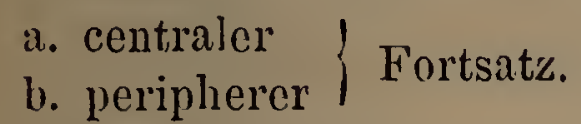

Fig. 5 Ganglienzelle aus dem Nervengeflecht der vordern Rückenflosse. Methode, Vergrösserung und Bezeichnung wie in F'ig. 4.

\section{Trafel $x$}

Fig. 1 Seitlicher Sagittalschnitt durch das Gehirn von Petromyzon Planeri.

B. Bulbus olfactorius

I. Vorderhirn. Hemisphäre

II. Zwischenhirn. Lobus ventriculi tertii.

III. Mittelhirn. Eminentia bigemina

IV. Hinterhirn. Cerebellum

V. Nachhirn. medulla oblongata

H. Hypophysis

U. N. oculomotorius

t. Richting des tractus oculomotorius

v. o. Ventrikel des bulbus olfactorius.

v. l. Seitenventrikel.

Der erste Schnitt hat nur eine laterale schmale Partie entfernt, so dass die Ventrikel eröffinet sind, und medial sind durch den zweiten dic mittleren Partien soweit entfernt, dass vom Schnabel des Zwischenhirnes nichts zu sehen ist.

Fig. 2 Querschnitt durch dic Seitenventrikel und den dritten.

Fig. 3 Chiasma Nervi optici. $250: 1$.

t. tractus opticus

o. N. opticus

a. Substanz der lobus ventriculi tertii.

Fig. 4 Müller'sche Faser mit ihrer Ganglienzelle und der peripheren Faser $500: 1$. Osmium-Glycerin-Maceration.

a. Nervenscheide.

Fig. 5 und 6 Müller'sche Faser aus dem motorischen Theil des Quintus in Theilung. Salpetersäure-Maceration. 500:1. 
Fig. 7 Durchnitt des Kopfes des Neunauges mit injicirtem Lymphraum.

c. Schädelkapsel

n. Nase

1. p. hinterer, 1. a. vorderer Labialknorpel.

Fig. 8 Gefässe der Mundpapillen. $50: 1$.

Fig. 9 Gefüsse der vordern Rückentlosse mit Papillen.

das Epithel ist abgefallen.

c. Grenzschicht der cutis

k. Knorpelstrahlen.

Fig. 10 Dasselbe ohne Papillen.

e. Epithel

k. Knorpelstrahlen

c. Grenzschicht der Haut. 


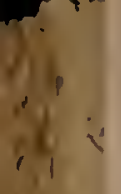



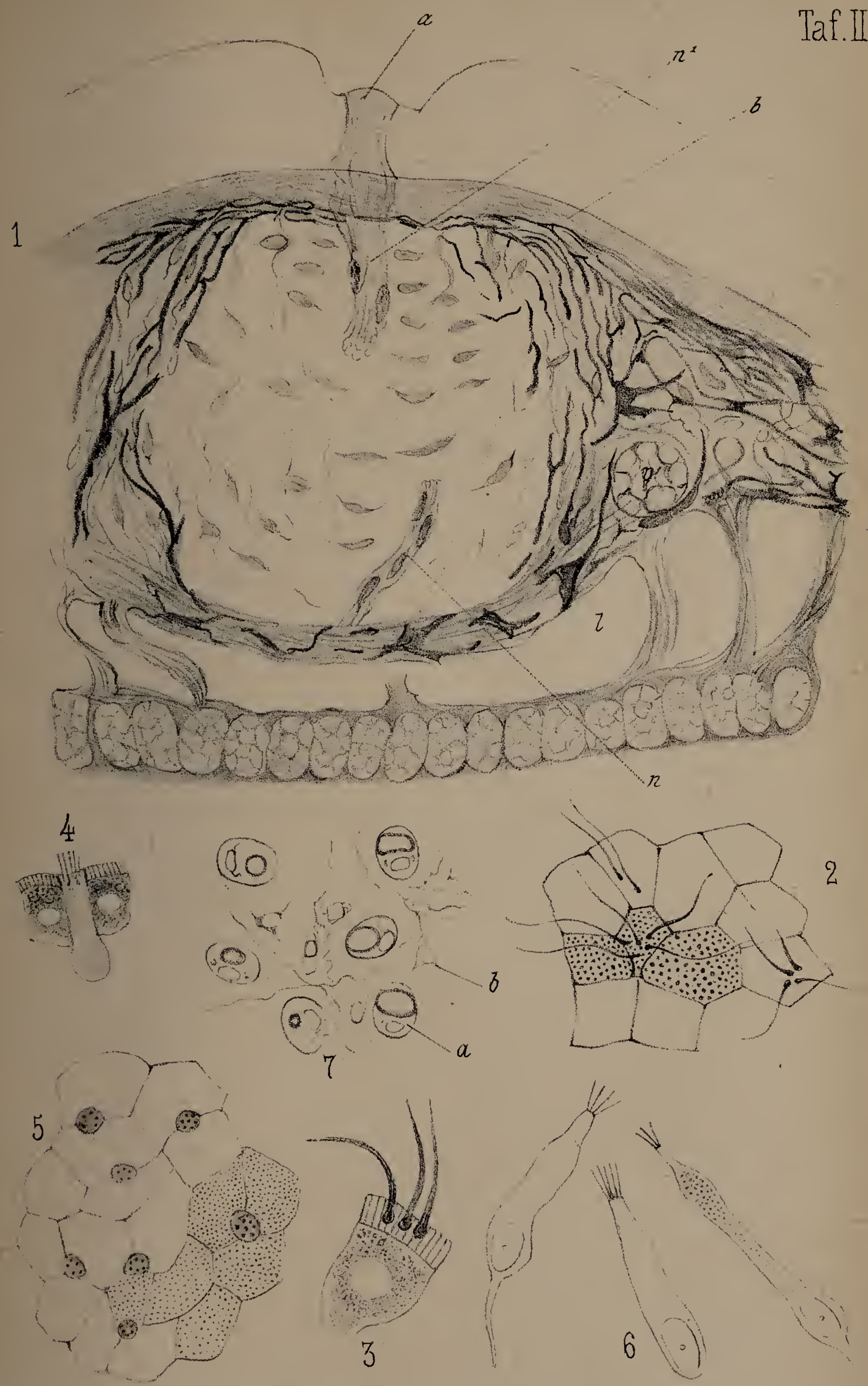



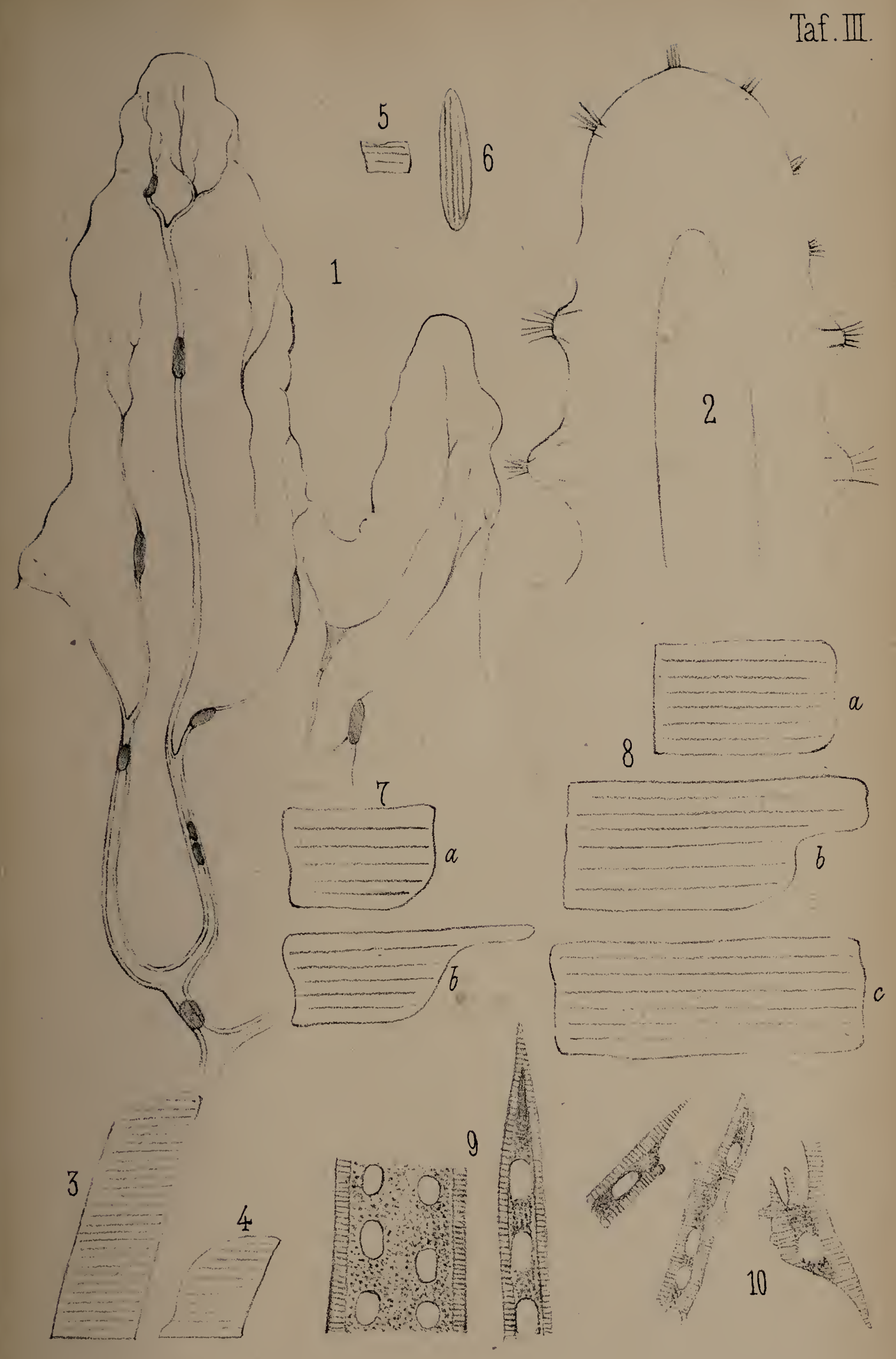




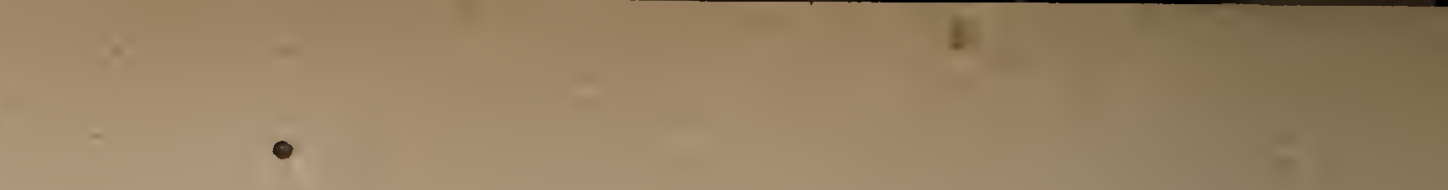




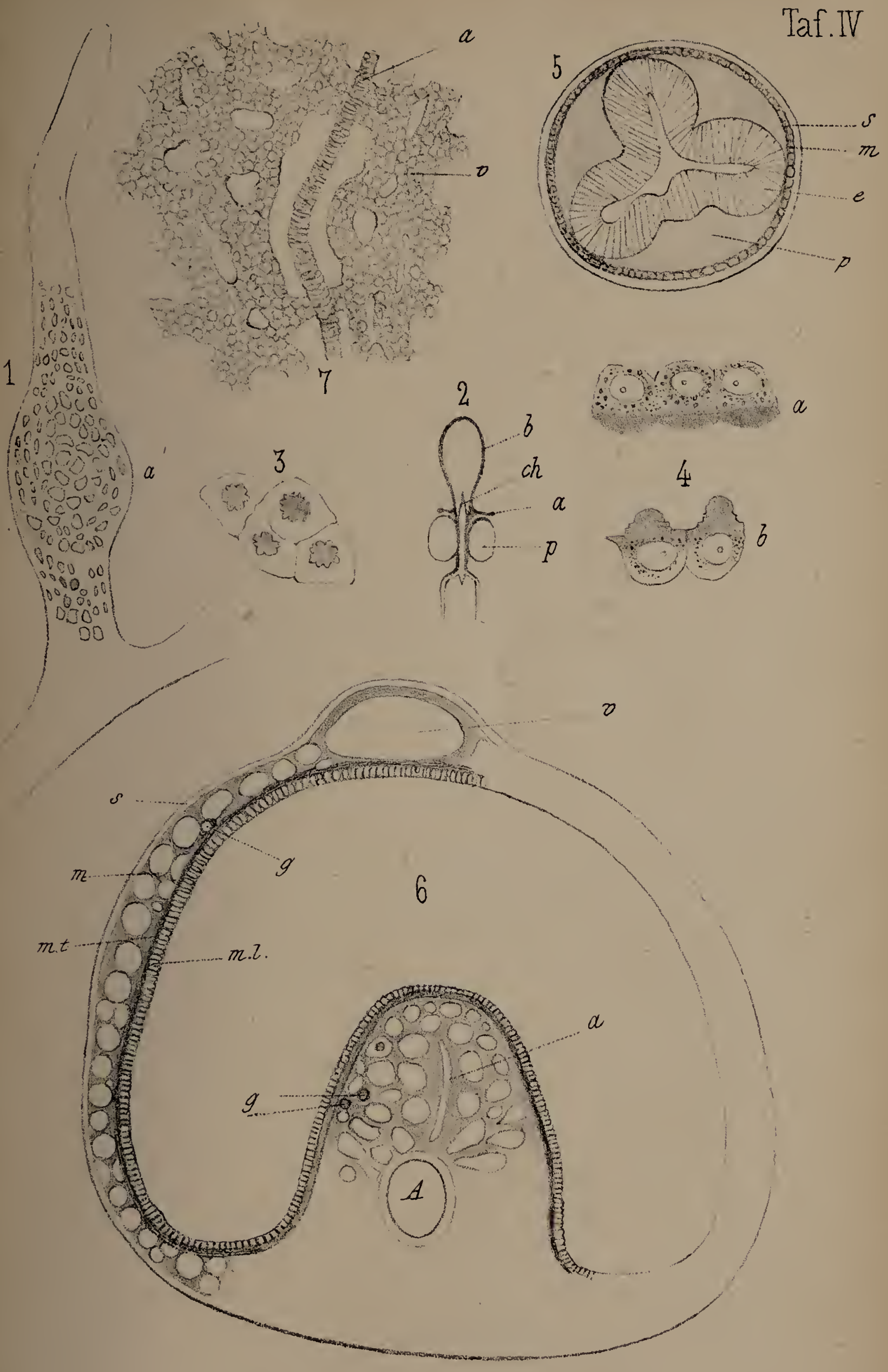

gyorharus áci.

J. Lenct Lith.

Druct o. VBaunaur Freidurg is 


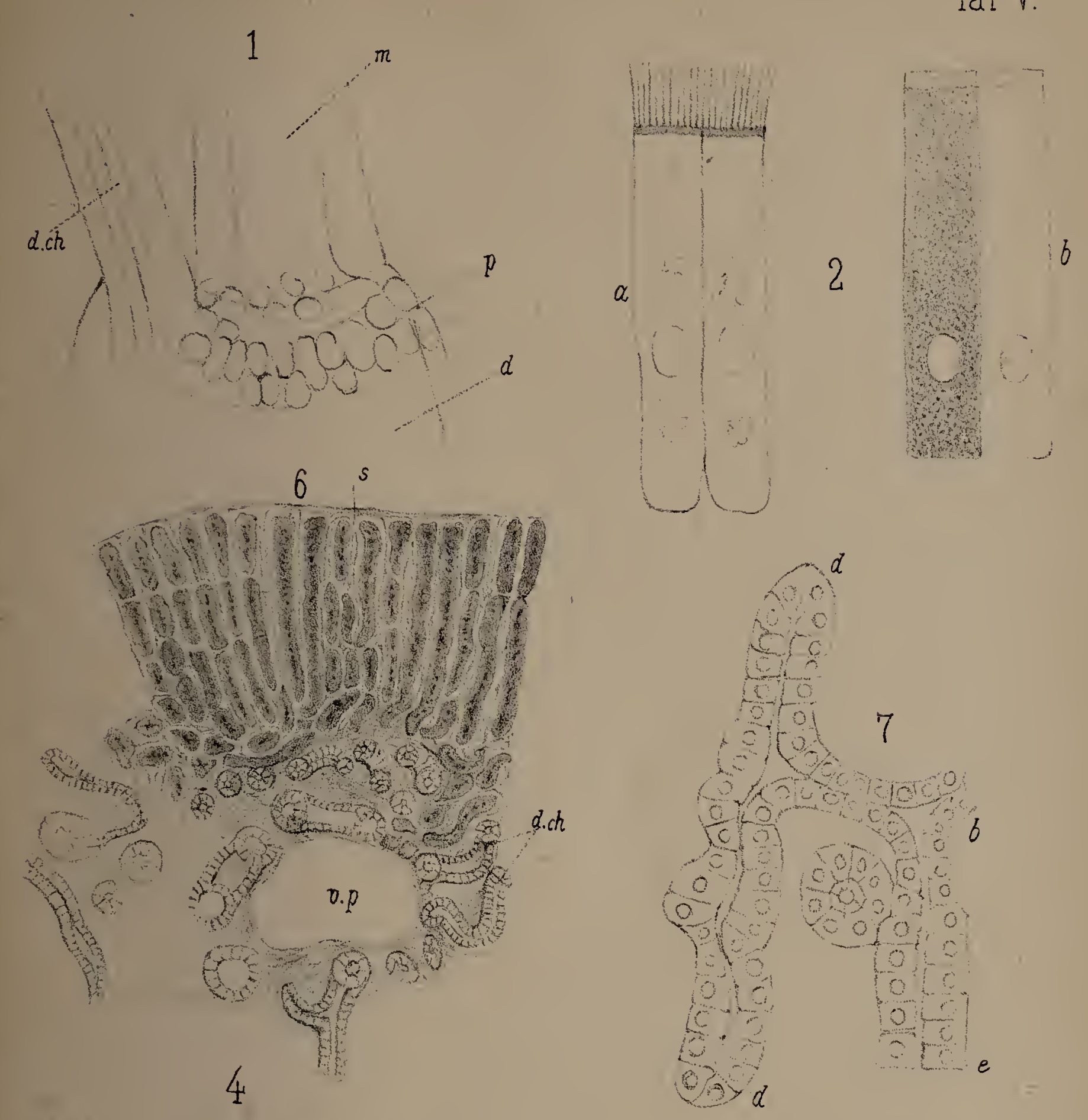

Taf V.
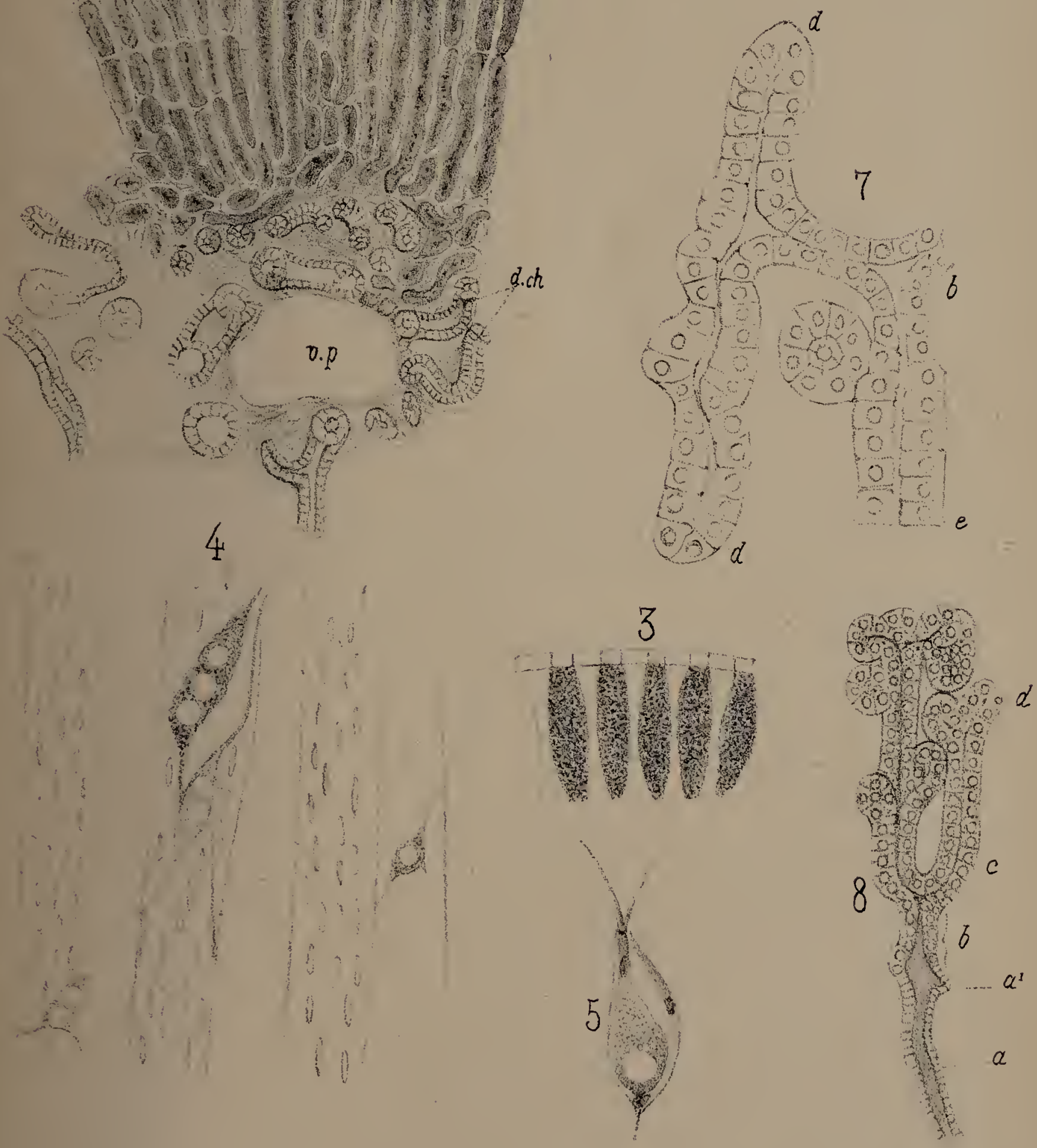



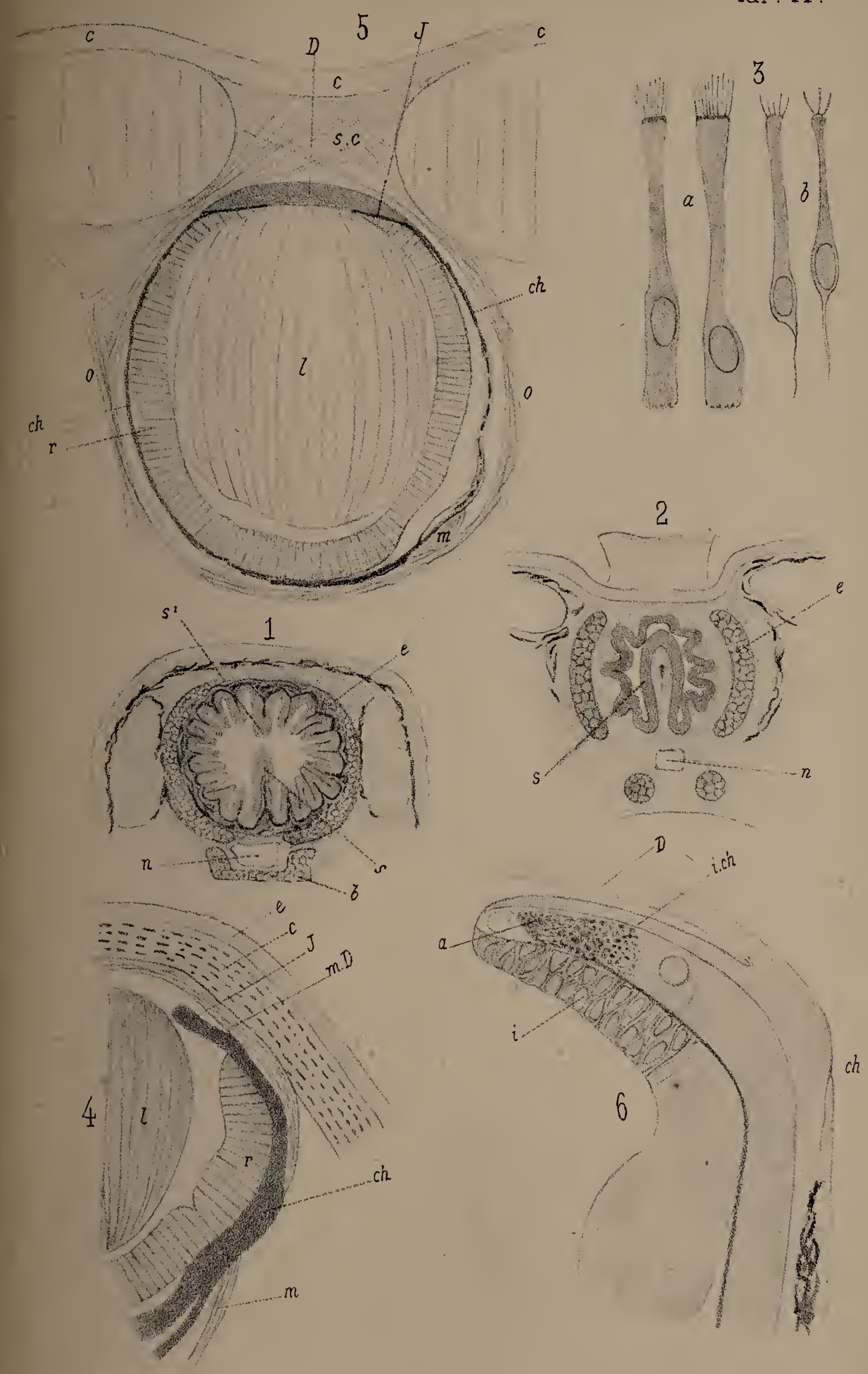



Taf VII
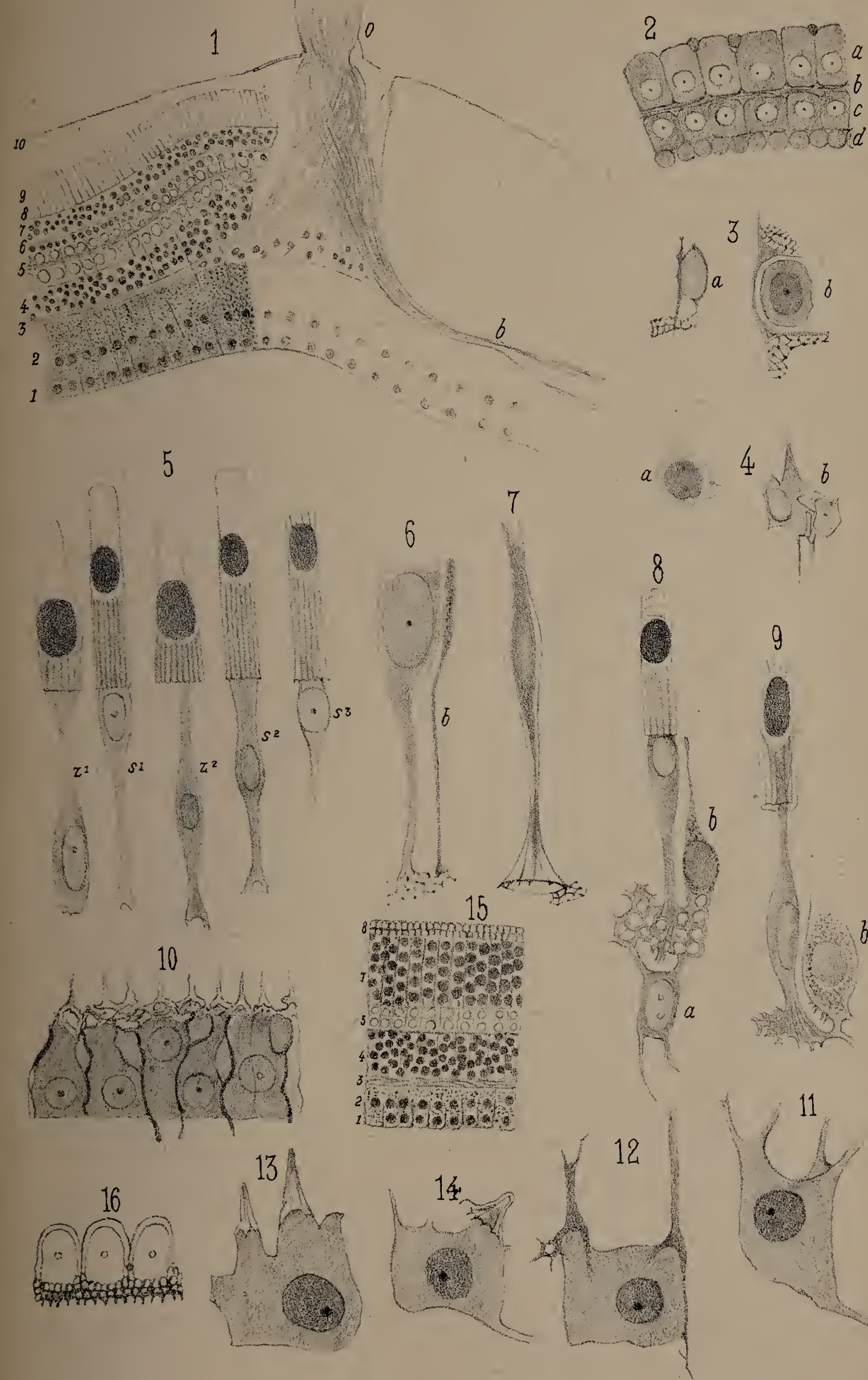

9
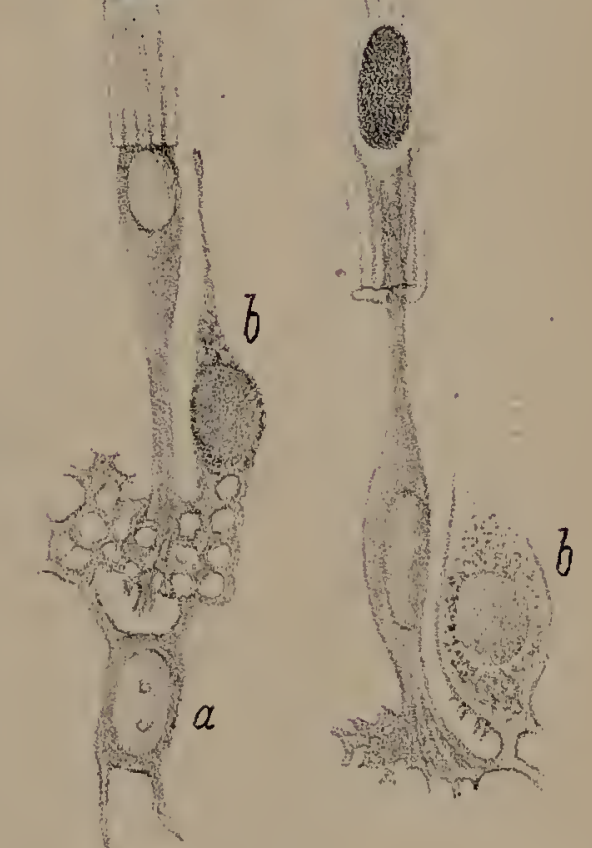


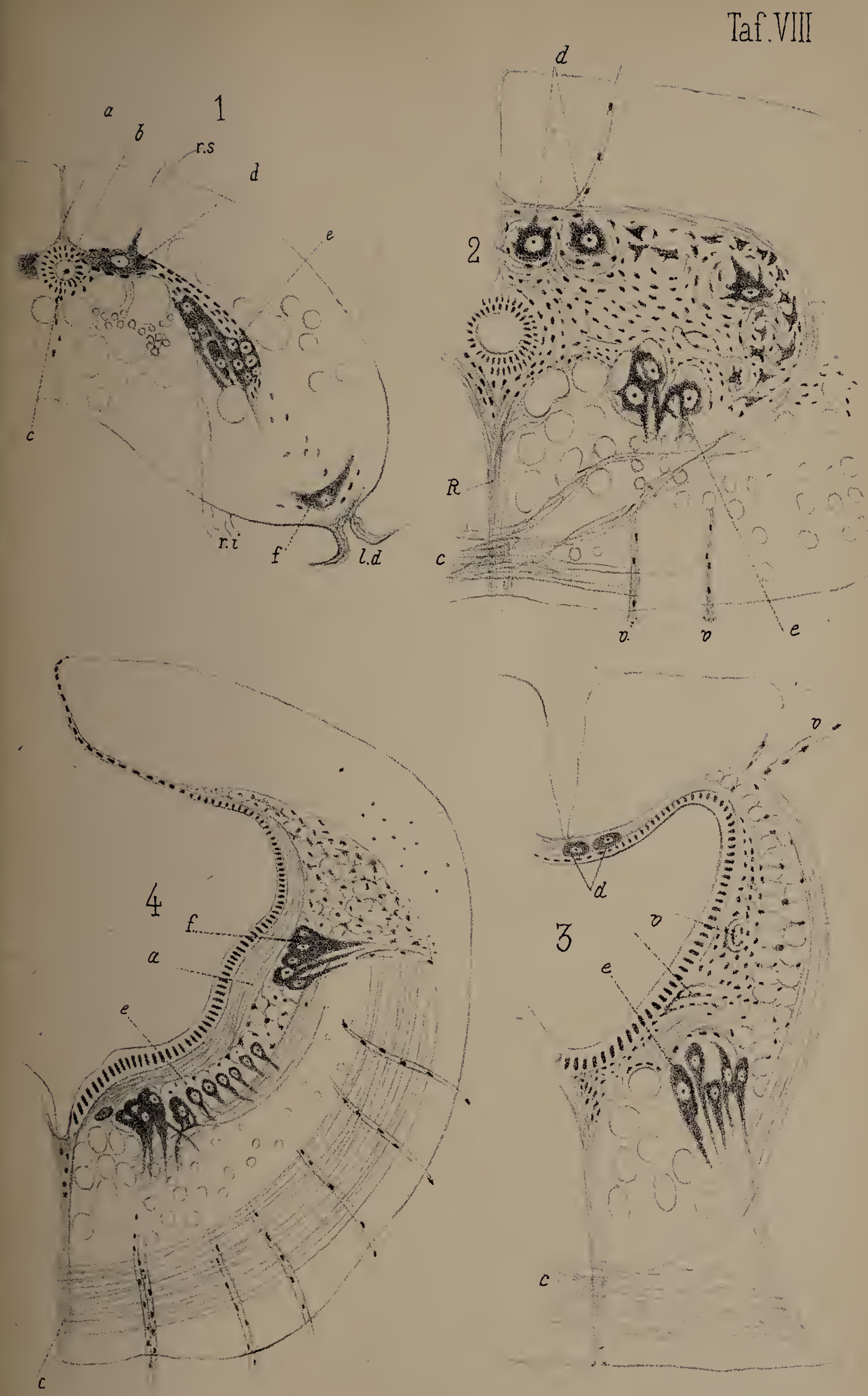

TafIX
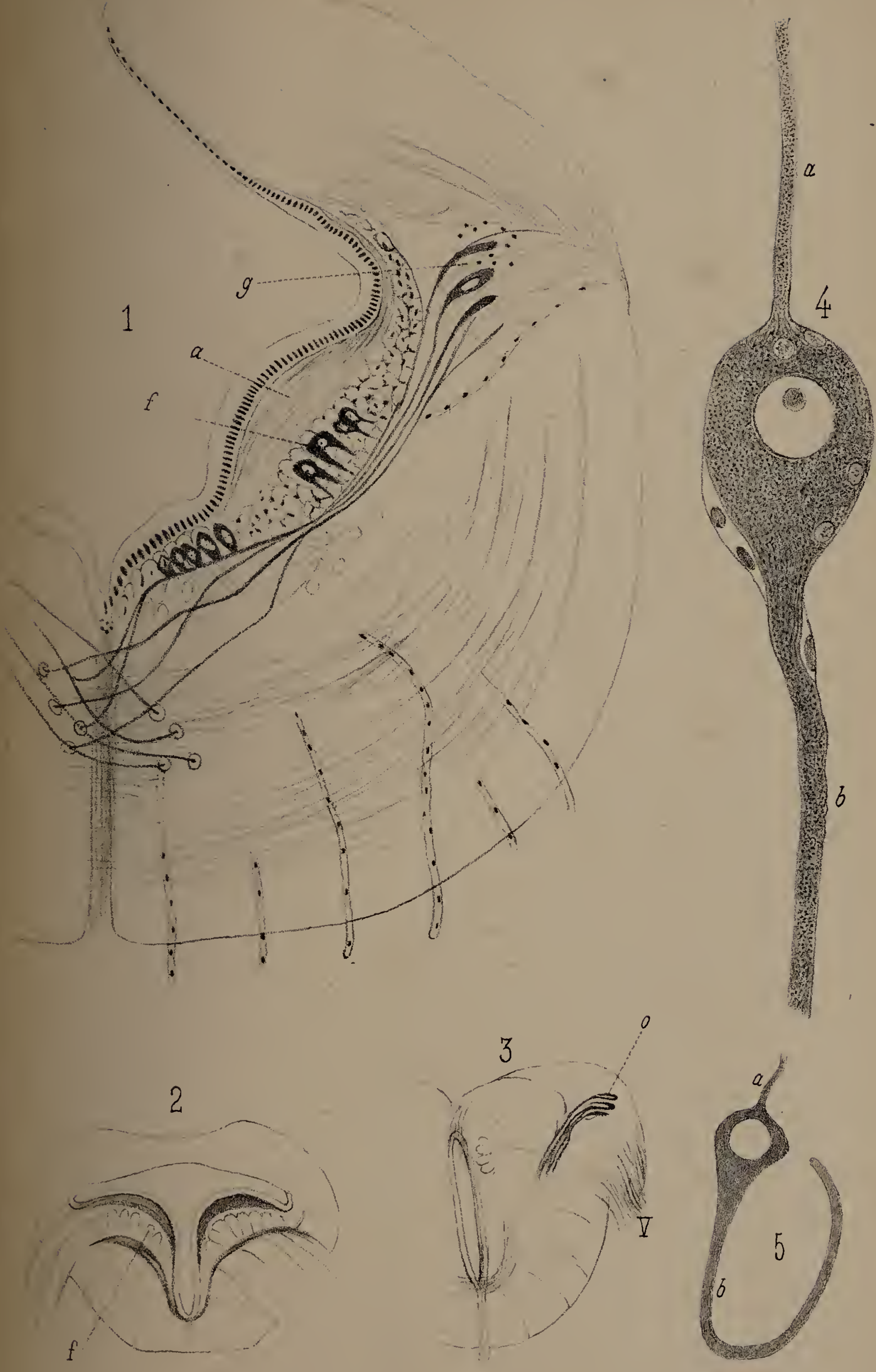



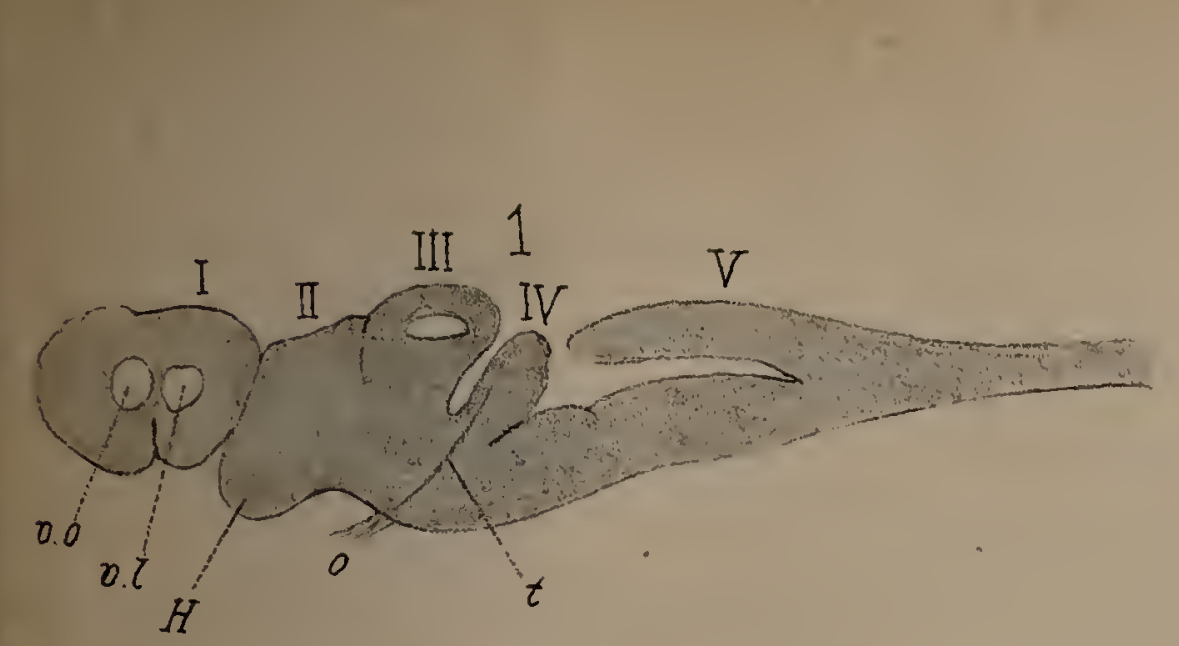

Taf.X
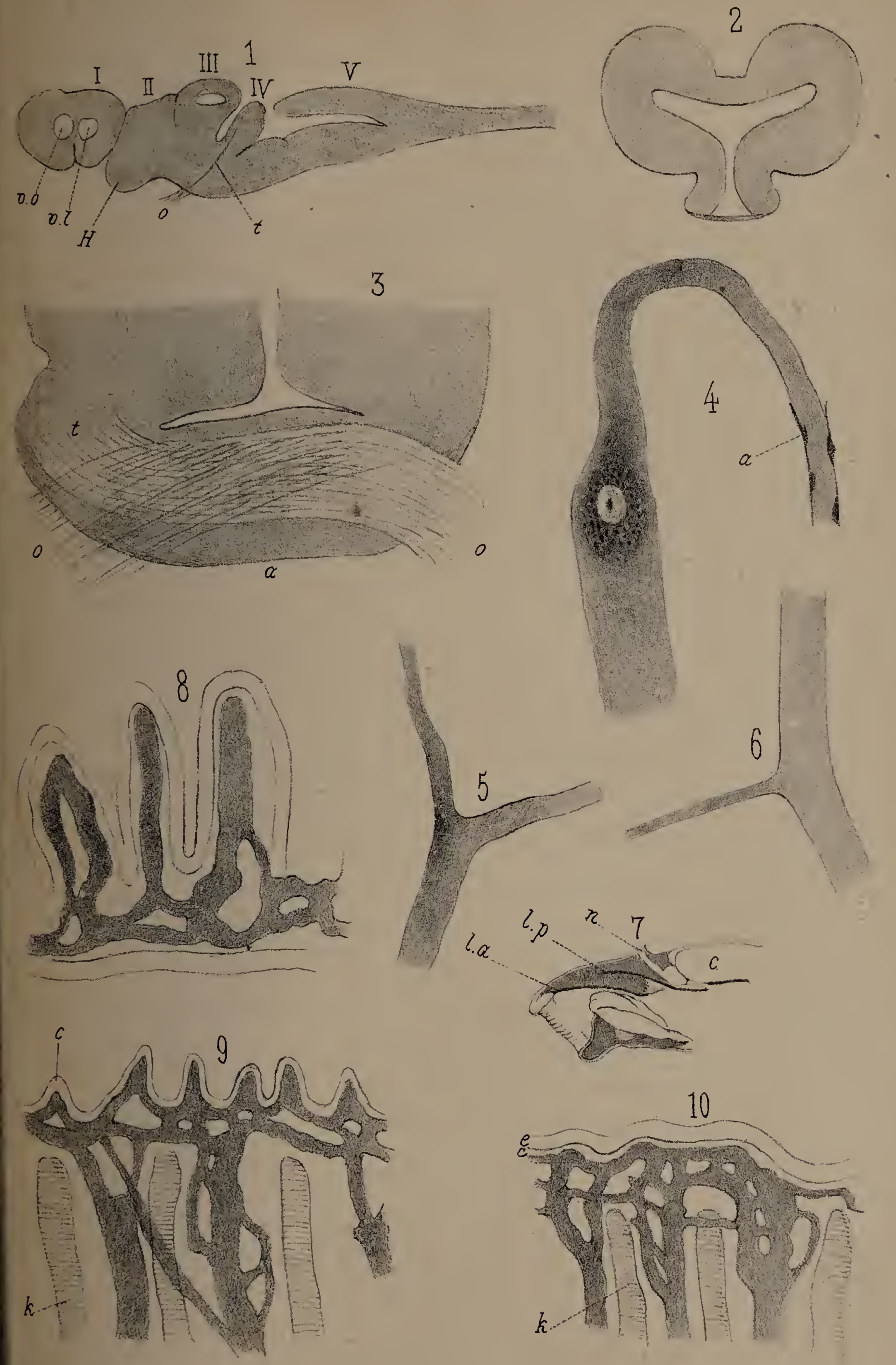


$$
8 \operatorname{mat} 13
$$




